DOC.20041008.0007

QA: QA

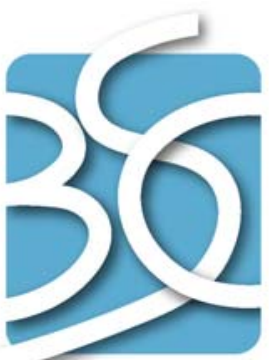

BECHTEL SAIC COMPANYLC

\title{
Saturated Zone Colloid Transport
}

Prepared for:

U.S. Department of Energy

Office of Civilian Radioactive Waste Management

Office of Repository Development

1551 Hillshire Drive

Las Vegas, Nevada 89134-6321

Prepared by:

Bechtel SAIC Company, LLC

1180 Town Center Drive

Las Vegas, Nevada 89144

Under Contract Number

DE-AC28-01RW12101 


\section{DISCLAIMER}

This report was prepared as an account of work sponsored by an agency of the United States Government. Neither the United States Government nor any agency thereof, nor any of their employees, nor any of their contractors, subcontractors or their employees, makes any warranty, express or implied, or assumes any legal liability or responsibility for the accuracy, completeness, or any third party's use or the results of such use of any information, apparatus, product, or process disclosed, or represents that its use would not infringe privately owned rights. Reference herein to any specific commercial product, process, or service by trade name, trademark, manufacturer, or otherwise, does not necessarily constitute or imply its endorsement, recommendation, or favoring by the United States Government or any agency thereof or its contractors or subcontractors. The views and opinions of authors expressed herein do not necessarily state or reflect those of the United States Government or any agency thereof. 
QA: QA

Saturated Zone Colloid Transport ANL-NBS-HS-000031 REV 02

October 2004 


\section{OCRWM}

\section{Scientific Analysis Signature Page/ Change History}

\section{Sclentific Analyabs Ttito \\ Saturated Zone Colloid Transport \\ 3. DI (including Rovision Number) \\ ANL-NBS-HS-000031 REV 02 \\ 4. Totel Appendices \\ N/A}

6. Number of Pages in Each Appendix

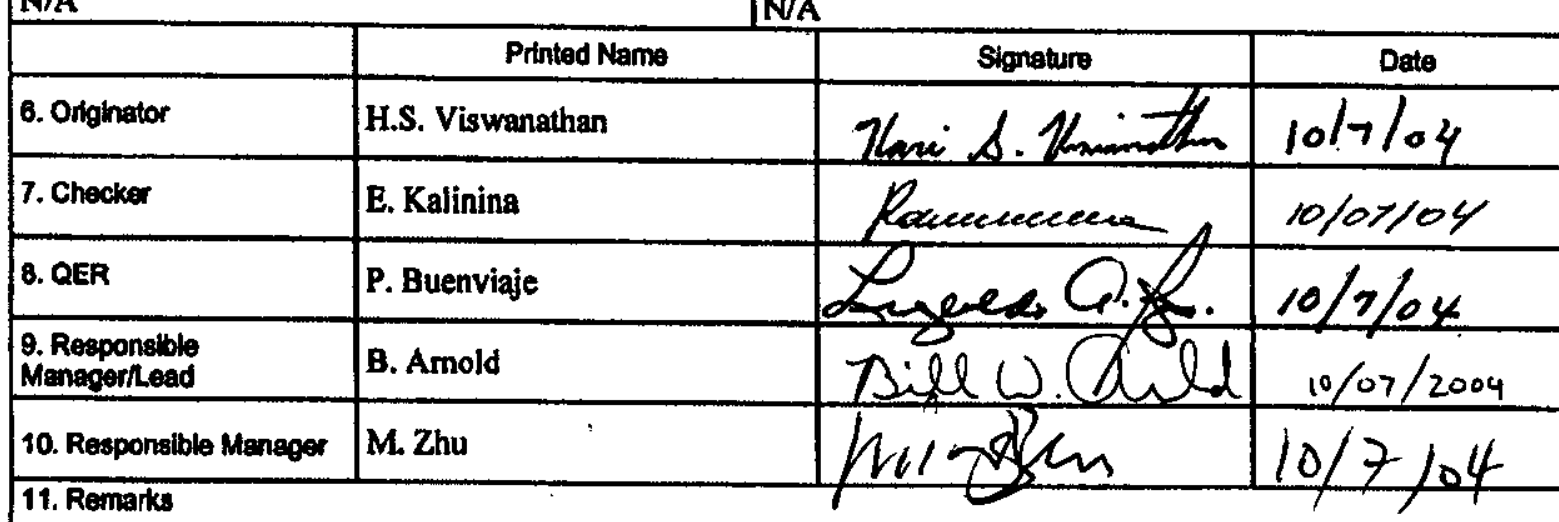

Change History

\begin{tabular}{|l|l|}
\hline \multicolumn{1}{|c|}{ 12. Revision No. } & \multicolumn{1}{|c|}{ 13. Deacription of Change } \\
\hline 00 & Initial issue \\
\hline 00 ICN 01 & $\begin{array}{l}\text { REV } 00 \text { ICN } 01 \text { of this AMR incorporated the updating of technical information and } \\
\text { editorial changes. }\end{array}$ \\
\hline 01 & $\begin{array}{l}\text { REV } 01 \text { includes additional field and laboratory analysis. Change bars were not used } \\
\text { because the changes were extensive. }\end{array}$ \\
\hline 02 & $\begin{array}{l}\text { Made changes to report in response to recommendations from Regulatory Integration } \\
\text { Team/Natural Systems Team. Entire scientific analysis documentation was revised. } \\
\text { Change bars were not used because the changes were extensive. }\end{array}$ \\
\hline
\end{tabular}




\section{INTENTIONALLY LEFT BLANK}




\section{CONTENTS}

Page

ACRONYMS AND ABBREVIATIONS ..................................................................... xi

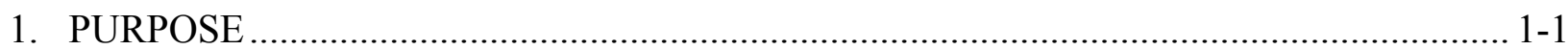

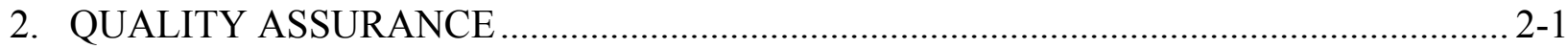

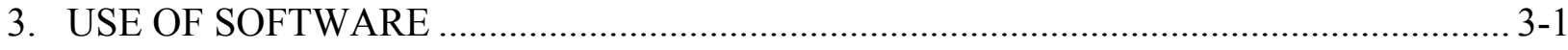

3.1 SOFTWARE TRACKED BY CONFIGURATION MANAGEMENT .................... 3-1

3.2 EXEMPT SOFTWARE .............................................................................. $3-1$

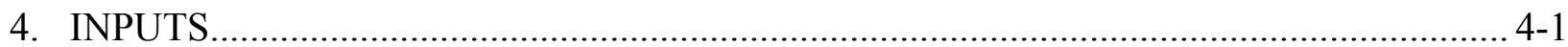

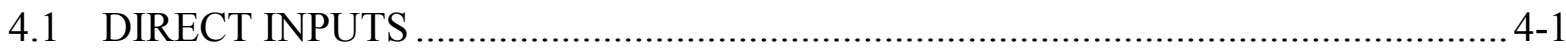

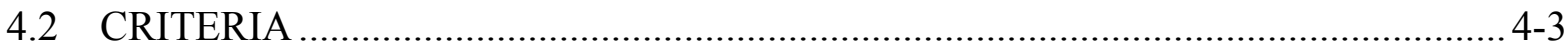

4.3 CODES, STANDARDS, AND REGULATIONS .................................................. 4-5

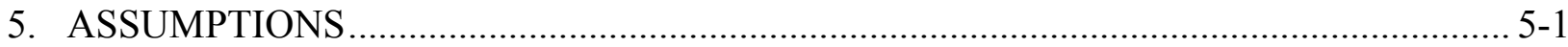

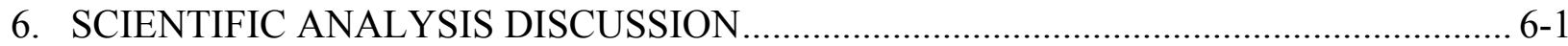

6.1 OBJECTIVES ..................................................................................... $6-1$

6.2 FEATURES, EVENTS, AND PROCESSES SUPPORTED BY THIS

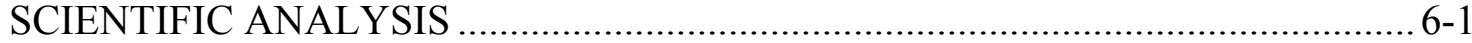

6.3 COLLOID TRANSPORT PARAMETERS NECESSARY FOR TSPA ................... 6-2

6.4 COLLOID TRANSPORT IN FRACTURED TUFF ............................................... $6-3$

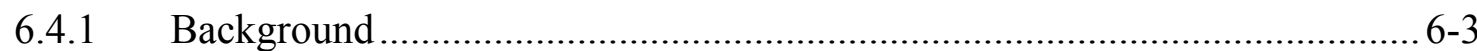

6.4.2 Colloid Filtration Rate Constants for Fractured Volcanics........................... 6-5

6.4.3 Colloid Retardation Factors for Fractured Volcanics ................................. 6-8

6.5 COLLOID TRANSPORT IN ALLUVIAL MATERIAL ....................................... 6-12

6.5.1 Background ................................................................................. 6-12

6.5.2 Colloid Filtration Rate Constants in Alluvial Material............................... 6-13

6.5.3 Colloid Retardation Factors in Alluvial Material ...................................... 6-14

6.6 FRACTION OF COLLOIDS TRANSPORTING WITH NO RETARDATION...... 6-17

6.7 VALIDITY OF THE LOCAL EQUILIBRIUM ASSUMPTION FOR COLLOIDS THAT ARE RETARDED ........................................................... 6-19

6.8 USE OF POLYSTYRENE MICROSPHERES AS TRACER SURROGATES FOR INORGANIC GROUNDWATER COLLOIDS .................................................... 6-20

6.8.1 Comparison of CML and Silica Microsphere Transport in Fractured Volcanic Rocks ................................................................................... 6-22

6.8.2 Comparison of CML Microsphere and Inorganic Colloid Transport in Saturated Alluvium ................................................................................ 6-35

6.8.3 Conclusions from CML and Silica Microsphere and Inorganic Colloid Transport Comparisons 
CONTENTS (Continued)

Page

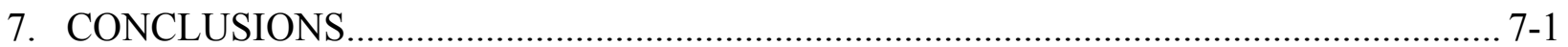

7.1 SUMMARY OF SCIENTIFIC ANALYSIS ………............................................. $7-1$

7.2 HOW THE APPLICABLE ACCEPTANCE CRITERIA ARE ADDRESSED ............ 7-2

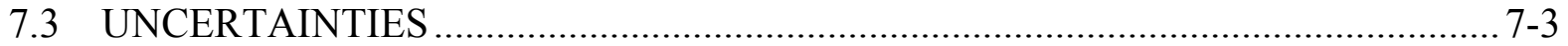

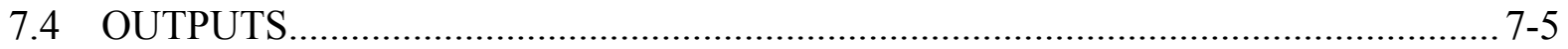

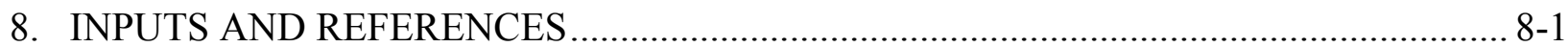

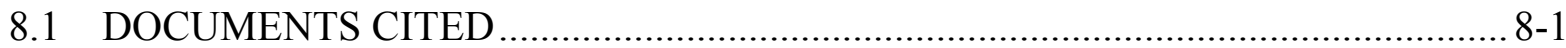

8.2 CODES, STANDARDS, REGULATIONS, AND PROCEDURES .......................... 8-3

8.3 SOURCE DATA, LISTED BY DATA TRACKING NUMBER ………………........ 8-4

8.4 OUTPUT DATA, LISTED BY DATA TRACKING NUMBER …………............... 8-5

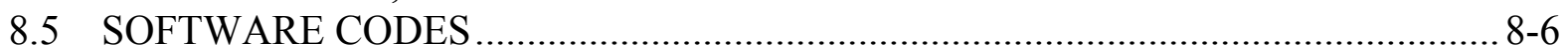




\section{FIGURES}

Page

1-1. Relationships and Flow of Key Information Among Reports Pertaining to Flow and Transport in the SZ

6-1. CML Microsphere and Inorganic Colloid Filtration Rate Constants as a Function of Time to Solute Peak Concentration in Several Field and Laboratory Tracer Tests in Saturated, Fractured Media.

6-2. Cumulative Probability Distribution of Log Colloid Filtration Rate Constants for Fractured Media

6-3 Truncated Cumulative Probability Distribution of Retardation Factors for the Fractured Volcanics

6-4. Colloid Filtration Rate Constants, $\mathrm{k}_{\mathrm{f}}$, as a Function of Mean Residence Time in Several Laboratory Experiments and a Field Study in Saturated, Alluvium Material .. 6-14

6-5. Cumulative Probability Distribution of Log Colloid Filtration Rate Constants in the Alluvium $6-15$

6-6. Truncated Cumulative Probability Distribution of Log Retardation Factors in Alluvium .....

6-7. Unretarded Fraction Cumulative Probability Distribution for the Fractured

Volcanics, Alluvium, and the Combined Distribution of the Volcanics and Alluvium

6-8. Normalized Concentrations of 330-nm Diameter CML Microspheres, 100-nm Diameter Silica Microspheres, and Iodide in Vertically Oriented Fractured Core from ER-20-6\#1 at $2406 \mathrm{ft}$

6-9. Normalized Concentrations of 330-nm Diameter CML Microspheres, 100-nm Diameter Silica Microspheres, and Iodide in Vertically Oriented Fractured Core from PM-2 at $7032 \mathrm{ft}$ at $10 \mathrm{~mL} / \mathrm{hr}$

6-10 Normalized Concentrations of 330-nm Diameter CML Microspheres, 100-nm Diameter Silica Microspheres, and Iodide in Vertically Oriented Fractured Core from PM-2 at $7032 \mathrm{ft}$ at $2.5 \mathrm{~mL} / \mathrm{hr}$

6-11. Normalized Concentrations of 330-nm Diameter CML Microspheres, 100-nm Diameter Silica Microspheres, and Iodide in Vertically Oriented

Fractured Core from PM-2 at $7032 \mathrm{ft}$ at Approximately $0.6 \mathrm{~mL} / \mathrm{hr}$

6-12. Normalized Concentrations of 330-nm Diameter CML Microspheres,

100-nm Diameter Silica Microspheres, and Iodide in Horizontally Oriented

Fractured Core from PM-2 at $7032 \mathrm{ft}$ at Approximately $0.6 \mathrm{~mL} / \mathrm{hr}$

6-13. Log Normalized Concentrations of 330-nm Diameter CML Microspheres, 100-nm Diameter Silica Microspheres, and Bromide in Alluvium-Packed Column A.

6-14. Log Normalized Concentrations of 330-nm Diameter CML Microspheres, 100-nm Diameter Silica Microspheres, and Bromide in Alluvium-Packed

Column B.

6-15. Log Normalized Concentrations of 330-nm Diameter CML Microspheres, 100-nm Diameter Silica Microspheres, and Bromide in Second Experiment in Alluvium-Packed Column A 


\section{FIGURES (Continued)}

Page

6-16. Log Normalized Concentrations of 330-nm Diameter CML Microspheres, 100-nm Diameter Silica Microspheres, and Bromide in Second Experiment in Alluvium-Packed Column B

6-17. ${ }^{3} \mathrm{HHO}$ and Colloid Breakthrough Curves and RELAP Fits in Test 1, Column C (6.01 mL/hr Flow Rate)

6-18. ${ }^{3} \mathrm{HHO}$ and Colloid Breakthrough Curves and RELAP Fits in Test 1, Column D (5.93 $\mathrm{mL} / \mathrm{hr}$ Flow Rate) $6-45$

6-19. ${ }^{3} \mathrm{HHO}$ and Colloid Breakthrough Curves and RELAP Fits in Test 2, Column C (1.19 mL/hr Flow Rate)

6-20. ${ }^{3} \mathrm{HHO}$ and Colloid Breakthrough Curves and RELAP Fits in Test 2, Column D (1.19 $\mathrm{mL} / \mathrm{hr}$ Flow Rate) $6-46$ 


\section{TABLES}

Page

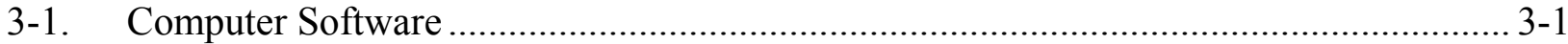

3-2. Exempt Software .............................................................................................. 3-1

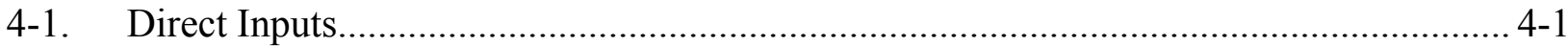

4-2. Project Requirements for This Analysis Report ......................................................... 4-4

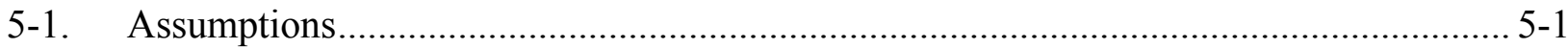

6-1. Features, Events, and Processes Included in TSPA-LA and Relevant to This Report ... 6-1

6-2. Retardation Factor, $R_{c o l}$, Cumulative Probability Distributions for Fractured Volcanics

6-3. Retardation Factor, $R_{\text {col }}$, Cumulative Probability Distributions for Alluvium................ 6-16

6-4. Unretarded Fraction Cumulative Probability Distribution for the Fractured Volcanics and the Alluvium.................................................................................. 6-18

6-5. Properties of CML and Silica Microspheres Used in Experiments ............................. 6-23

6-6. Properties of the Fractured Cores Used in the Colloid Transport Experiments: Physical Characteristics .................................................................................... 6-23

6-7. Properties of the Fractured Cores Used in the Colloid Transport Experiments: X-Ray Diffraction Results (wt \%)

6-8. Properties of the Fractured Cores Used in the Colloid Transport Experiments: Lithologic Descriptions.

6-9. Chemical Composition of U-20WW Groundwater

6-10. Summary of Experimental Conditions in the Fractured Core Tests

6-11. Model Parameters from RELAP Fits of Tracer Breakthrough Curves in Experiments in Fractured Core from Borehole PM-2.

6-12. Characteristic Diffusion and Settling Lengths $\left(L_{\mathrm{D}}\right.$ and $\left.L_{\mathrm{S}}\right)$ for the CML and Silica Microspheres in the Four Experiments in the Fractured Core from Borehole PM-2 .... 6-33

6-13. Estimates of Filtration Rate Constants and Detachment Rate Constants for CML Microspheres and Silica Colloids in Columns Packed with Alluvium.......................... 6-41

6-14. Column Parameters in the CML Microsphere and Natural Colloid Experiments ......... 6-44

6-15. Experimental Conditions in the CML Microsphere and Natural Colloid Experiments

6-16. Model Parameters from RELAP Fits of Tracer Breakthrough Curves in CML Microsphere and Natural Colloid Experiments in Saturated Alluvium. $6-47$

7-1. Output Data 


\section{INTENTIONALLY LEFT BLANK}




\section{ACRONYMS AND ABBREVIATIONS}

ATC Alluvial Testing Complex

CDF cumulative distribution function

CML carboxylate-modified latex

DIRS Document Input Reference System

DTN data tracking number

FEPs features, events, and processes

LA license application

QARD Quality Assurance and Requirements Description

SZ saturated zone

TSPA total system performance assessment

UZ unsaturated zone

YMP Yucca Mountain Project

YMRP Yucca Mountain Review Plan, Final Report 


\section{INTENTIONALLY LEFT BLANK}




\section{PURPOSE}

This scientific analysis provides retardation factors for colloids transporting in the saturated zone (SZ) and the unsaturated zone (UZ). These retardation factors represent the reversible chemical and physical filtration of colloids in the SZ. The value of the colloid retardation factor, $R_{\text {col }}$ is dependent on several factors, such as colloid size, colloid type, and geochemical conditions (e.g., $\mathrm{pH}$, Eh, and ionic strength). These factors are folded into the distributions of $R_{c o l}$ that have been developed from field and experimental data collected under varying geochemical conditions with different colloid types and sizes. Attachment rate constants, $k_{a t t}$, and detachment rate constants, $k_{\text {det }}$, of colloids to the fracture surface have been measured for the fractured volcanics, and separate $R_{c o l}$ uncertainty distributions have been developed for attachment and detachment to clastic material and mineral grains in the alluvium.

Radionuclides such as plutonium and americium sorb mostly (90 to 99 percent) irreversibly to colloids (BSC 2004 [DIRS 170025], Section 6.3.3.2). The colloid retardation factors developed in this analysis are needed to simulate the transport of radionuclides that are irreversibly sorbed onto colloids; this transport is discussed in the model report Site-Scale Saturated Zone Transport (BSC 2004 [DIRS 170036]). Although it is not exclusive to any particular radionuclide release scenario, this scientific analysis especially addresses those scenarios pertaining to evidence from waste-degradation experiments, which indicate that plutonium and americium may be irreversibly attached to colloids for the time scales of interest. A section of this report will also discuss the validity of using microspheres as analogs to colloids in some of the lab and field experiments used to obtain the colloid retardation factors.

In addition, a small fraction of colloids travels with the groundwater without any significant retardation. Radionuclides irreversibly sorbed onto this fraction of colloids also transport without retardation. The transport times for these radionuclides will be the same as those for nonsorbing radionuclides. The fraction of nonretarding colloids developed in this analysis report is used in the abstraction of SZ and UZ transport models in support of the total system performance assessment (TSPA) for the license application (LA).

This analysis report uses input from two Yucca Mountain Project (YMP) analysis reports. This analysis uses the assumption from Waste Form and In-Drift Colloids-Associated Radionuclide Concentrations: Abstraction and Summary that plutonium and americium are irreversibly sorbed to colloids generated by the waste degradation processes (BSC 2004 [DIRS 170025]). In addition, interpretations from RELAP analyses from Saturated Zone In-Situ Testing (BSC 2004 [DIRS 170010]) are used to develop the retardation factor distributions in this analysis. 
Figure 1-1 shows the relationship of this report to other model reports that also pertain to flow and transport in the SZ. Figure 1-1 also shows the flow of key information among the SZ reports. It should be noted that Figure 1-1 does not contain a complete representation of the data and parameter inputs and outputs of all SZ reports, nor does it show inputs external to this suite of SZ reports.

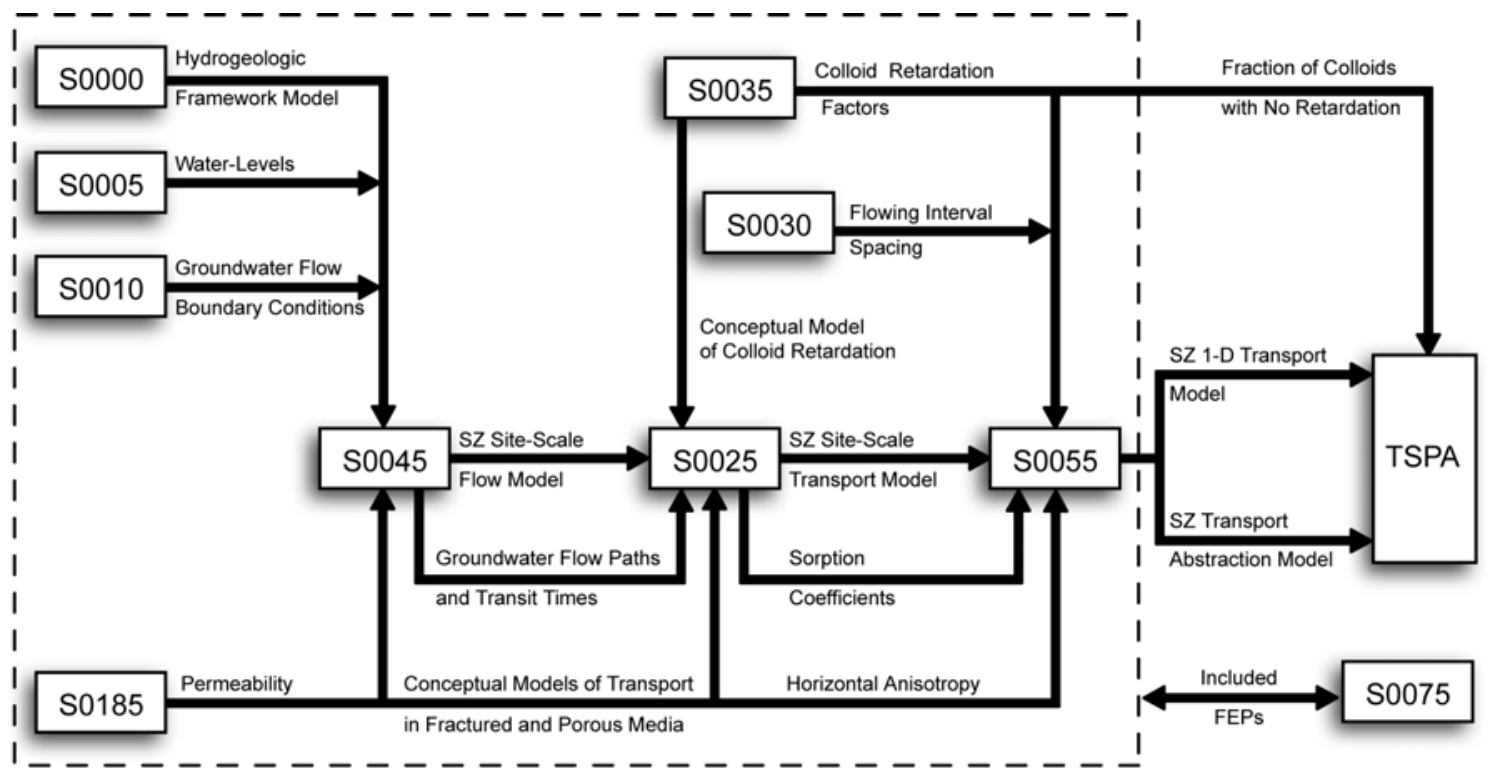

\begin{tabular}{|ll|}
\hline \multicolumn{1}{|c|}{ Legend } & \\
S0000 - Hydrogeologic Framework Model & MDL-NBS-HS-000024 \\
S0005 - Water-Level Data Analysis & ANL-NBS-HS-000034 \\
S0010 - Recharge and Lateral Groundwater Flow Boundary Conditions & ANL-NBS-MD-000010 \\
S0025 - Site-Scale Saturated Zone Transport & MDL-NBS-HS-000010 \\
S0030 - Probability Distribution for Flowing Interval Spacing & ANL-NBS-MD-000003 \\
S0035 - Saturated Zone Colloid Transport & ANL-NBS-HS-000031 \\
S0045 - Site-Scale Saturated Zone Flow Model & MDL-NBS-HS-000011 \\
S0055 - Saturated Zone Flow and Transport Model Abstraction & MDL-NBS-HS-000021 \\
S0075 - Features, Events, and Processes in SZ Flow and Transport & ANL-NBS-MD-000002 \\
S0185 - Saturated Zone In-Situ Testing & ANL-NBS-HS-000039 \\
\hline
\end{tabular}

NOTE: This figure is a simplified representation of the flow of information among SZ reports. See the DIRS of each report for a complete listing of data and parameter inputs. This figure does not show inputs external to this suite of SZ reports.

Figure 1-1. Relationships and Flow of Key Information Among Reports Pertaining to Flow and Transport in the SZ 
The primary outputs of this report are the uncertainty distributions of colloid retardation factors for use in the SZ site-scale transport model, SZ transport abstraction model, and SZ onedimensional (1-D) transport model; and the fraction of colloids with no retardation for use in the TSPA model. In addition, the distribution for retardation factor for colloids as well as the fraction of colloids that transport unretarded in the UZ are used by Particle Tracking Model and Abstraction of Transport Processes. Additional users of this document are:

- Features, Events, and Processes in SZ Flow and Transport

- Features, Events, and Processes in UZ Flow and Transport.

This report establishes the requirements and elements of the design of a methodology for calculating colloid transport in the SZ at Yucca Mountain. Field experiments in fractured tuff at Yucca Mountain and in porous media at other sites indicate that colloids experience retardation relative to the mean pore-water velocity, suggesting that contaminants associated with colloids should also experience some retardation. Therefore, this analysis incorporates experimental and field data where available for estimating plausible ranges of retardation factors in both saturated fractured tuff and saturated alluvium. The distribution of retardation factors for tuff and alluvium are developed in a form consistent with the performance assessment analysis framework for simulating colloid-facilitated radionuclide transport in the SZ.

To improve on the work performed so far for the saturated-zone flow and transport modeling, this report quantifies physical and chemical colloid filtration in both fractured tuff and alluvium. The filtration is simulated with a retardation factor that is developed from field and laboratory results. The fractured tuff analysis uses recent experimental data and interpretation from the $\mathrm{C}$-wells reactive tracer testing complex in the SZ of Yucca Mountain to develop the retardation factor distribution. For the alluvium system, recent experimental data as well as field data from the literature are used to develop the retardation-factor distribution. The parameters derived in this report are developed in a manner consistent with the performance assessment methodology and can be readily integrated into that analysis. The parameters have been developed in accordance with the Total System Performance Assessment-License Application Methods and Approach (BSC 2003 [DIRS 166296], Sections 3 to 5).The RELAP computer code (RELAP V2.0, STN: 10551-2.0-00 [DIRS 159065]) was used in this report rather than the previously developed code RTA V1.1 (STN: 10032-1.1-00). RELAP is more appropriate for fitting the experiments described in this report than RTA V1.1. RELAP was developed in this analysis with a specific goal of interpreting colloid transport parameters in fractured tuff at Yucca Mountain. Microsoft Excel 2000 was used to develop retardation-factor distributions for the alluvium since experimental and field data are now available. (Note: The six-digit numerical identifier in brackets next to each reference callout throughout this report is the YMP Document Input Reference System (DIRS) number, the purpose of which is to assist the reader in locating a specific reference in the DIRS database.)

This scientific analysis is governed by the Technical Work Plan For: Natural System - Saturated Zone Analysis Model Integration (BSC 2004 [DIRS 171421]). All activities listed in the technical work plan are documented in this report. 


\section{INTENTIONALLY LEFT BLANK}




\section{QUALITY ASSURANCE}

The scientific analysis documented in this report was evaluated in accordance with AP-2.27Q, Planning for Science Activities, and AP-SIII.9Q, Scientific Analyses, and was determined to be quality-affecting and subject to the Yucca Mountain Project's quality assurance program as indicated in the Technical Work Plan For: Natural System - Saturated Zone Analysis and Model Report Integration (BSC 2004 [DIRS 171421]). The technical work plan also identifies the methods used to control the electronic management of data (BSC 2004 [DIRS 171421], Section 8).

This analysis report provides a transport property of a natural barrier that is important to the demonstration of compliance with the postclosure performance objectives prescribed in 10 CFR 63.113. Therefore, it is classified in the Q-List (BSC 2004 [DIRS 168361]) as "SC" (Safety Category), reflecting its importance to waste isolation, as defined in AP-2.22Q, Classification Criteria and Maintenance of the Monitored Geologic Repository Q-List. The report contributes to the analysis data used to support postclosure performance assessment; the conclusions do not directly impact preclosure engineered features important to safety, as defined in AP-2.22Q. 


\section{INTENTIONALLY LEFT BLANK}




\section{USE OF SOFTWARE}

\subsection{SOFTWARE TRACKED BY CONFIGURATION MANAGEMENT}

The computer code used directly in this scientific analysis is listed in Table 3-1. This software was obtained from Software Configuration Management and is appropriate for the application. This qualified code was used only within the range of validation as required by LP-SI.11Q-BSC, Software Management.

Table 3-1. Computer Software

\begin{tabular}{|c|c|c|c|c|}
\hline $\begin{array}{c}\text { Software } \\
\text { Title/Version }\end{array}$ & $\begin{array}{l}\text { Software } \\
\text { Tracking } \\
\text { Number }\end{array}$ & Code Usage & $\begin{array}{c}\text { Computer, } \\
\text { Type, } \\
\text { Platform, and } \\
\text { Location }\end{array}$ & $\begin{array}{c}\text { Date } \\
\text { Baselined }\end{array}$ \\
\hline $\begin{array}{l}\text { RELAP V2.0 } \\
\text { [DIRS 159065] }\end{array}$ & $10551-2.0-00$ & $\begin{array}{l}\text { This software models tracer transport by } \\
\text { convoluting a Laplace-domain transfer } \\
\text { function for transport through dual-porosity } \\
\text { media with transfer functions that describe } \\
\text { tracer injection, mixing in the injection and } \\
\text { production wellbores (or flow manifolds in } \\
\text { laboratory experiments), and recirculation } \\
\text { of the product fluid (in field experiments } \\
\text { only). It also performs curve fits to field or } \\
\text { laboratory tracer test data to obtain the } \\
\text { best-fitting transport parameter values. }\end{array}$ & $\begin{array}{l}\text { PC, Windows } \\
\text { 2000/NT } \\
\text { Location: Los } \\
\text { Alamos } \\
\text { National } \\
\text { Laboratory }\end{array}$ & 05/21/2002 \\
\hline
\end{tabular}

NOTE: The input and output RELAP 2.0 files are documented in the Technical Data Management System and identified by the following data tracking numbers: LA0303PR831231.003 [DIRS 163756], LA0303PR831352.002 [DIRS 163136], LA0403PR831352.001 [DIRS 171416], LA0303PR831361.001 [DIRS 163135].

$\mathrm{PC}=$ personal computer

\subsection{EXEMPT SOFTWARE}

Commercial off-the-shelf software used in support of this scientific analysis report is listed in Table 3-2. This software is exempt from the requirements of LP-SI.11Q-BSC.

Table 3-2. Exempt Software

\begin{tabular}{|l|l|l|}
\hline $\begin{array}{c}\text { Software } \\
\text { Name and } \\
\text { Version (V) }\end{array}$ & \multicolumn{1}{|c|}{ Description } & $\begin{array}{c}\text { Computer and } \\
\text { Platform } \\
\text { Identification }\end{array}$ \\
\hline $\begin{array}{l}\text { Microsoft } \\
\text { Excel 2000 }\end{array}$ & $\begin{array}{l}\text { The commercial software, Microsoft Excel 2000, was used for statistical } \\
\text { analysis of data and plotting graphs. Only built-in standard functions in this } \\
\text { software were used. No software routines or macros were used with this } \\
\text { software to prepare this report. The output was visually checked for } \\
\text { correctness, and the results of all calculations were hand-checked. }\end{array}$ & $\begin{array}{l}\text { PC, Microsoft } \\
\text { Windows 2000/NT }\end{array}$ \\
\hline
\end{tabular}

NOTE: The formula and calculations performed in Microsoft Excel 2000 are too detailed to be included in this report but are documented in Notebook SN-LANL-SCI-297-V1 (Viswanathan 2003 [DIRS 163757]). Section 6 presents the formulae used to calculate the retardation factors. Built-in Microsoft Excel functions were used in this analysis.

$\mathrm{PC}=$ personal computer 


\section{INTENTIONALLY LEFT BLANK}




\section{INPUTS}

\subsection{DIRECT INPUTS}

Input information used in this analysis comes from several sources, summarized in Table 4-1 along with their data tracking numbers (DTNs). Note that all input in Table 4-1 is direct input. The data are fully appropriate for the discussion of colloid transport in the fractured volcanics and alluvium in this scientific analysis report. The qualification status of the input sources is provided in the Technical Data Management System. Uncertainty of the input parameters is discussed in Section 7.3.

Table 4-1. Direct Inputs

\begin{tabular}{|c|c|c|}
\hline Data Description & Data Tracking Number & Data Used \\
\hline $\begin{array}{l}\text { Solute and microsphere responses from the Bullfrog } \\
\text { Tuff tracer test at the C-wells }\end{array}$ & $\begin{array}{l}\text { LA0007PR831231.001 } \\
\text { [DIRS 156043] }\end{array}$ & S00349_001-004 \\
\hline $\begin{array}{l}\text { Solute and microsphere responses from the Prow } \\
\text { Pass Tuff tracer test at the C-wells }\end{array}$ & $\begin{array}{l}\text { LAPR831231AQ99.001 } \\
\text { [DIRS 140134] }\end{array}$ & S99126_001-004 \\
\hline $\begin{array}{l}\text { Microsphere responses in ER-20-6 \#3 in the } \\
\text { BULLION forced-gradient experiment on Pahute } \\
\text { Mesa, NTS }\end{array}$ & $\begin{array}{l}\text { LA0302PR831352.002 } \\
\text { [DIRS 162440] } \\
\text { See Note } 1 \text { below for the } \\
\text { justification of the use of } \\
\text { UGTA/NTS data }\end{array}$ & S03120_001 \\
\hline $\begin{array}{l}\text { Microsphere responses in ER-20-6 \#2 in the } \\
\text { BULLION forced-gradient experiment on Pahute } \\
\text { Mesa, NTS }\end{array}$ & $\begin{array}{l}\text { LA0302PR831352.001 } \\
\text { [DIRS 162439] } \\
\text { See Note } 1 \text { below for the } \\
\text { justification of the use of } \\
\text { UGTA/NTS data }\end{array}$ & S03119_001 \\
\hline $\begin{array}{l}\text { Solute responses in ER-20-6 \#3 in the BULLION } \\
\text { forced-gradient experiment on Pahute Mesa, NTS }\end{array}$ & $\begin{array}{l}\text { LA0302PR831231.003 } \\
\text { [DIRS 162438] } \\
\text { See Note } 1 \text { below for the } \\
\text { justification of the use of } \\
\text { UGTA/NTS data }\end{array}$ & S03063_001 \\
\hline $\begin{array}{l}\text { Solute responses in ER-20-6 \#2 in the BULLION } \\
\text { forced-gradient experiment on Pahute Mesa, NTS }\end{array}$ & $\begin{array}{l}\text { LA0302PR831231.002 } \\
\text { [DIRS 162437] } \\
\text { See Note } 1 \text { below for the } \\
\text { justification of the use of } \\
\text { UGTA/NTS data }\end{array}$ & S03064_001 \\
\hline $\begin{array}{l}\text { Breakthrough curves of CML microspheres, silica } \\
\text { colloids, and iodide in fractured cores from the NTS }\end{array}$ & $\begin{array}{l}\text { LA0301PR831352.001 } \\
\text { [DIRS 162434] }\end{array}$ & S03034_001 \\
\hline $\begin{array}{l}\text { Breakthrough curves of tritium, plutonium, and } \\
\text { various colloids in fractured cores from Borehole } \\
\text { UE20c at the NTS }\end{array}$ & $\begin{array}{l}\text { LA0301PR831361.003 } \\
\text { [DIRS 162435] }\end{array}$ & S03026_001 \\
\hline $\begin{array}{l}\text { Breakthrough curves of tritium, plutonium, and } \\
\text { various colloids in fractured cores from Boreholes } \\
\text { PM-1 and PM-2 at the NTS }\end{array}$ & $\begin{array}{l}\text { LA0301PR831361.004 } \\
\text { [DIRS 162436] }\end{array}$ & S03027_001 \\
\hline $\begin{array}{l}\text { RELAP computer code interpretations of solute and } \\
\text { microsphere responses in the Bullfrog Tuff and Prow } \\
\text { Pass Tuff tracer tests at the C-wells }\end{array}$ & $\begin{array}{l}\text { LA0303PR831231.003 } \\
\text { [DIRS 163756] }\end{array}$ & C-Wells_Field_Test_Calcs \\
\hline
\end{tabular}


Table 4-1. Direct Inputs (Continued)

\begin{tabular}{|c|c|c|}
\hline Data Description & Data Tracking Number & Data Used \\
\hline $\begin{array}{l}\text { Calculations to determine detachment rate constant } \\
\text { of microspheres in a singe-well tracer test in } \\
\text { saturated alluvium }\end{array}$ & $\begin{array}{l}\text { LA0303PR831352.001 } \\
\text { [DIRS 163138] }\end{array}$ & $\begin{array}{l}\text { Calculations to Determine } \\
\text { detachment rate constant } \\
\text { of microspheres in a single- } \\
\text { well tracer test in saturated } \\
\text { alluvium }\end{array}$ \\
\hline $\begin{array}{l}\text { Model interpretations of ER-20-6 field tracer transport } \\
\text { experiment }\end{array}$ & $\begin{array}{l}\text { LA0303PR831352.002 } \\
\text { [DIRS 163136] } \\
\text { See Note } 1 \text { below for the } \\
\text { justification of the use of } \\
\text { UGTA/NTS data }\end{array}$ & $\begin{array}{l}\text { Model Interpretations of } \\
\text { ER-20-6 field tracer } \\
\text { transport experiment }\end{array}$ \\
\hline $\begin{array}{l}\text { Model interpretations of NTS fractured core colloid } \\
\text { and colloid-facilitated transport experiments }\end{array}$ & $\begin{array}{l}\text { LA0403PR831352.001 } \\
\text { [DIRS 171416] } \\
\text { See Note } 1 \text { below for the } \\
\text { justification of the use of } \\
\text { UGTA/NTS data }\end{array}$ & $\begin{array}{l}\text { Model interpretations of } \\
\text { NTS fractured core colloid } \\
\text { and colloid-facilitated } \\
\text { transport experiments }\end{array}$ \\
\hline $\begin{array}{l}\text { RELAP computer code interpretations of laboratory } \\
\text { rate constants in alluvium }\end{array}$ & $\begin{array}{l}\text { LA0303PR831361.001 } \\
\text { [DIRS 163135] }\end{array}$ & $\begin{array}{l}\text { RELAP V2.0 Model } \\
\text { Interpretations of solute } \\
\text { and colloid transport in } \\
\text { alluvium-packed column } \\
\text { transport experiments }\end{array}$ \\
\hline $\begin{array}{l}\text { Breakthrough curves of CML microspheres, silica } \\
\text { colloids, and bromide in alluvium-packed Column A, } \\
\text { Run } 1\end{array}$ & $\begin{array}{l}\text { LA0206MH831361.001 } \\
\text { [DIRS 162426] }\end{array}$ & S02152_001 \\
\hline $\begin{array}{l}\text { Breakthrough curves of CML microspheres, silica } \\
\text { colloids, and bromide in alluvium-packed Column B, } \\
\text { Run } 1\end{array}$ & $\begin{array}{l}\text { LA0206MH831361.002 } \\
\text { [DIRS 162427] }\end{array}$ & S02153_001 \\
\hline $\begin{array}{l}\text { Breakthrough curves of CML microspheres, silica } \\
\text { colloids, and bromide in alluvium-packed Column A, } \\
\text { Run } 2\end{array}$ & $\begin{array}{l}\text { LA0206MH831361.003 } \\
\text { [DIRS 162428] }\end{array}$ & S02154_001 \\
\hline $\begin{array}{l}\text { Breakthrough curves of CML microspheres, silica } \\
\text { colloids, and bromide in alluvium-packed Column B, } \\
\text { Run } 2\end{array}$ & $\begin{array}{l}\text { LA0206MH831361.004 } \\
\text { [DIRS 162430] }\end{array}$ & S02155_001 \\
\hline $\begin{array}{l}\text { Breakthrough curves of tritium, } \mathrm{Pu} \text {, and natural } \\
\text { colloids in two alluvium-packed columns }\end{array}$ & $\begin{array}{l}\text { LA0301AA831352.001 } \\
\text { [DIRS 162433] }\end{array}$ & S03043_001 \\
\hline $\begin{array}{l}\text { Field-scale attachment/detachment rates and } \\
\text { retardation factors for colloids in alluvial material }\end{array}$ & $\begin{array}{l}\text { Schijven et al. } 1999 \text { [DIRS } \\
\text { 162423] } \\
\text { See Note } 2 \text { below for the } \\
\text { justification of the use of } \\
\text { literature data }\end{array}$ & $\begin{array}{l}\text { Rate constants and } \\
\text { retardation factors obtained } \\
\text { from model interpretations } \\
\text { of colloid breakthrough } \\
\text { curves. }\end{array}$ \\
\hline
\end{tabular}

NOTE 1: Justification for use of data obtained from outside sources (AP-SIII.9Q, Scientific Analyses): The UGTA/NTS data used in this report were obtained from outside sources. These data were obtained from the U.S. Department of Energy UGTA program, which has a quality assurance program in place. In addition, the researchers collecting the data are the same researchers conducting the Yucca Mountain colloid research (e.g., Paul Reimus, coauthor of this report). The data were collected at the same laboratory facilities as the Yucca Mountain data. Therefore, the reliability of the data source and the qualifications of personnel or organizations generating the data is sufficient. The data apply to this analysis because the UGTA program operates in close proximity to Yucca Mountain, making it a good analog due to similarities in geology, mineralogy, and hydrology. Specifically, NTS shares many of the same geologic units as Yucca Mountain. The mineralogy consists of fractured volcanic tuffs and alluvium which is the same mineralogy found at the Yucca Mountain site. Therefore, colloid transport parameters measured at NTS are applicable to Yucca Mountain (DTNs: LA0302PR831352.002 [DIRS 162440]; 
Table 4-1. Direct Inputs (Continued)

LA0302PR831352.001 [DIRS 162439]; LA0302PR831231.003 [DIRS 162438]; LA0302PR831231.002

[DIRS 162437]; LA0303PR831352.002 [DIRS 163136]; LA0403PR831352.001

[DIRS 171416]).

NOTE 2: The field-scale attachment/detachment rates and retardation factors for colloids in alluvial material data are obtained from outside sources. These data appeared in a scientific journal, Water Resources Research, in an article entitled "Modeling Removal of Bacteriophages MS2 and PRD1 by Dune Recharge at Castricum, Netherlands" (Schijven et al. 1999 [DIRS 162423]). Articles appearing in Water Resources Research undergo a peer review process, which enhances confidence that the data source is reliable. J. Schijven is from the Microbiological Laboratory for Health Protection, National Institute of Public Health and the Environment, Bilthoven, Netherlands; W. Hoogenboezem is from PWN Water Supply Company NorthHolland, Bloemendaal, Netherlands; S. Hassanizadeh is from Faculty of Civil Engineering and

Geosciences, Delft University of Technology, Delft, Netherlands; and J. Peters is from Kiwa Research and Consultancy, Nieuwegein, Netherlands. The fact that the authors of the journal article are associated with these institutions enhances confidence in the qualifications of personnel and the organizations generating the data. The data were used to estimate colloid-transport parameters in the saturated alluvium south of Yucca Mountain (with the exception of a detachment rate constant obtained in a single-well test at the Alluvial Testing Complex). Schijven et al. measured filtration and detachment rates for bacteriophages in alluvium material under natural gradient conditions (Schijven et al. 1999 [DIRS 162423], Table 3, p. 1107). They used bacteriophages denoted as MS-2 and PRD-1 that are in the same size range as colloids. These bacteriophages were chosen because they attach less than most pathogenic viruses and are relatively persistent during transport through the subsurface (Schijven et al. 1999 [DIRS 162423], p. 1101). Schijven et al. used a modeling approach very similar to RELAP to obtain colloid filtration and detachment rate constants from their field breakthrough curves. The model development and implementation is documented in detail. The groundwater at the site studied by Schijven et al. had somewhat higher divalent cation concentrations than most saturated zone waters in the vicinity of Yucca Mountain (90 to $100 \mathrm{mg} / \mathrm{L}$ $\mathrm{Ca}^{2+}$ and 10 to15 mg/ $\mathrm{Lg}^{2+}$ compared to 2 to $20 \mathrm{mg} / \mathrm{L} \mathrm{Ca}^{2+}$ and 0 to $5 \mathrm{mg} / \mathrm{L} \mathrm{Mg}^{2+}$ at Yucca Mountain), so colloids would be expected to be less stable at their site (Schijven et al. 1999 [DIRS 162423], Table 2, p. 1105). However, the alluvium material at their study site was also coarser (hydraulic conductivity of 12 $\mathrm{m} /$ day compared to $7.7 \mathrm{~m} /$ day for core permeability estimates at Yucca Mountain), with more sand, less clay, and more organic carbon than the alluvium material south of Yucca Mountain, all of which would tend to result in enhanced colloid transport relative to Yucca Mountain conditions. Thus, the combination of colloid selection, interpretive method, documentation quality, groundwater chemistry, and alluvium characteristics in the study of Schijven et al. make it possible to use their reported colloid filtration and detachment rate constants in the development of colloid-transport parameter distributions for Yucca Mountain alluvium. (AP-SIII.9Q, Scientific Analyses, first three bullets of Item L, Section 5.2.1.)

NTS=Nevada Test Site; UGTA=underground test area

\subsection{CRITERIA}

The general requirements to be satisfied by the TSPA-LA are stated in 10 CFR 63.114 [DIRS 156605]. Technical requirements to be satisfied by the TSPA-LA are identified in the Yucca Mountain Project Requirements Document (Canori and Leitner 2003 [DIRS 166275], Table B-9). The acceptance criteria that will be used by the U.S. Nuclear Regulatory Commission to determine whether the technical requirements have been met are identified in the Yucca Mountain Review Plan, Final Report (YMRP) (NRC 2003 [DIRS 163274]). The pertinent requirements and criteria for this report are summarized in Table 4-2. An evaluation of acceptance criteria against the information in this analysis report determined that criterion 2.2.1.3.9.3 AC3 (1) should be addressed. 
Table 4-2. Project Requirements for This Analysis Report

\begin{tabular}{|c|c|c|c|}
\hline $\begin{array}{c}\text { Requirement } \\
\text { Number }^{\mathrm{a}}\end{array}$ & Requirement Title ${ }^{\mathrm{a}}$ & 10 CFR 63 Link & $\begin{array}{l}\text { YMRP Acceptance } \\
\text { Criteria }^{\mathbf{b}}\end{array}$ \\
\hline PRD -002/T-015 & Requirements for Performance Assessment & $\begin{array}{l}10 \text { CFR } 63.114 \\
\text { [DIRS 156605] }\end{array}$ & $\begin{array}{l}\text { 2.2.1.3.9.3, criteria } \\
1 \text { to } 3\end{array}$ \\
\hline
\end{tabular}

${ }^{a}$ Canori and Leitner 2003 [DIRS 166275].

${ }^{\mathrm{b}} \mathrm{NRC} 2003$ [DIRS 163274].

The acceptance criteria identified in Section 2.2.1.3.9.3 of the YMRP (NRC 2003 [DIRS 163274]) are given below. In cases where subsidiary criteria are listed in the YMRP for a given criterion, only the subsidiary criteria addressed by this analysis report are listed below. Where a subcriterion includes several components, only some of those components may be addressed. How these components are addressed is summarized in Section 7.2 of this report (NRC 2003 [DIRS 163274]).

\subsection{Radionuclide Transport in the Saturated Zone}

\subsection{Acceptance Criteria}

Acceptance Criterion 1 System Description and Model Integration Are Adequate.

(1) Total system performance assessment adequately incorporates important design features, physical phenomena, and couplings, and uses consistent and appropriate assumptions throughout the radionuclide transport in the saturated zone abstraction process;

(2) The description of the aspects of hydrology, geology, geochemistry, design features, physical phenomena, and couplings, that may affect radionuclide transport in the saturated zone, is adequate. For example, the description includes changes in transport properties in the saturated zone, from water-rock interaction. Conditions and assumptions in the abstraction of radionuclide transport in the saturated zone are readily identified, and consistent with the body of data presented in the description;

(6) Guidance in NUREG-1297 and NUREG-1298 (Altman, et. al 1988a,b) or other acceptable approaches for peer review and data qualification is followed.

\section{Acceptance Criterion 2 Data Are sufficient for Model Justification.}

(1) Geological, hydrological, and geochemical values used in the license application are adequately justified (e.g., flow path lengths, sorption coefficients, retardation factors, colloid concentrations, etc.). Adequate 
descriptions of how the data were used, interpreted, and appropriately synthesized into the parameters are provided;

(3) Data on the geology, hydrology, and geochemistry of the saturated zone, including the influence of structural features, fracture distributions, fracture properties, and stratigraphy, used in the total system performance assessment abstraction, are based on appropriate techniques. These techniques may include laboratory experiments, site-specific field measurements, natural analog research, and process-level modeling studies. As appropriate, sensitivity or uncertainty analyses used to support the U.S. Department of Energy total system performance assessment abstraction are adequate to determine the possible need for additional data.

Acceptance Criterion 3: $\quad$ Data Uncertainty is Characterized and Propagated Through the Model Abstraction.

(1) Models use parameter values, assumed ranges, probability distributions, and bounding assumptions that are technically defensible, reasonably account for uncertainties and variabilities, and do not result in an underrepresentation of the risk estimate.

\subsection{CODES, STANDARDS, AND REGULATIONS}

No codes, standards, or regulations other than those identified in the Project Requirements Document (Canori and Leitner 2003 [DIRS 166275], Table 2-3) and determined to be applicable (Table 4-2) were used in this analysis. 


\section{INTENTIONALLY LEFT BLANK}




\section{ASSUMPTIONS}

The underlying assumptions of the colloid transport model are outlined in Table 5-1 as the first step toward developing the conceptual, mathematical, and computational models needed in performance assessment calculations.

Table 5-1. Assumptions

\begin{tabular}{|c|c|c|c|}
\hline No. & $\begin{array}{l}\text { Location } \\
\text { in this } \\
\text { Report }\end{array}$ & Assumption & Rationale \\
\hline 1 & $\begin{array}{l}\text { Section } \\
6.4 .3\end{array}$ & $\begin{array}{l}\text { The cumulative distribution of } \\
\text { retardation factors in the volcanics } \\
\text { has a lower limit of } R=6 \text { (there is } \\
\text { zero probability of having a } \\
\text { retardation factor less than } 6 \text { ). }\end{array}$ & $\begin{array}{l}\text { This is believed to be a reasonable lower bound for } \\
\text { retardation factors experienced by colloids that are } \\
\text { reversibly filtered in the volcanics. This lower bound is } \\
\text { chosen to create realistic distributions for use in the TSPA } \\
\text { simulations. Without this lower bound, a realization in } \\
\text { TSPA could choose a very low retardation factor resulting } \\
\text { in unrealistic breakthroughs of radionuclides through the } \\
\text { UZ and SZ in a given realization. The fact that smaller } \\
\text { retardation factors have been observed in tests is } \\
\text { accounted for by estimating a small fraction (see Section } \\
6.6 \text { ) of colloids moving unretarded through the SZ based } \\
\text { on a distribution of observed filtration rate constants. This } \\
\text { value is calculated based on existing data (Table 4-1), so } \\
\text { no additional confirmation is necessary. }\end{array}$ \\
\hline 2 & $\begin{array}{l}\text { Section } \\
6.5 .3\end{array}$ & $\begin{array}{l}\text { The cumulative distribution of } \\
\text { retardation factors in the alluvium } \\
\text { has a lower limit of } R=8 \text { (there is } \\
\text { zero probability of having a } \\
\text { retardation factor less than } 8 \text { ). }\end{array}$ & $\begin{array}{l}\text { This is believed to be a reasonable lower bound for } \\
\text { retardation factors experienced by colloids that are } \\
\text { reversibly filtered in the alluvium. This lower bound is } \\
\text { chosen to create realistic distributions for use in the TSPA } \\
\text { simulations. Without this lower bound, a realization in } \\
\text { TSPA could choose a very low retardation factor resulting } \\
\text { in unrealistic breakthroughs of radionuclides through the } \\
\text { UZ and SZ in a given realization. The fact that smaller } \\
\text { retardation factors have been observed in tests is } \\
\text { accounted for by estimating a small fraction (see Section } \\
6.6 \text { ) of colloids moving unretarded through the SZ based } \\
\text { on a distribution of observed filtration rate constants. This } \\
\text { value is calculated based on existing data (Table 4-1), so } \\
\text { no additional confirmation is necessary. }\end{array}$ \\
\hline
\end{tabular}




\section{INTENTIONALLY LEFT BLANK}




\section{SCIENTIFIC ANALYSIS DISCUSSION}

\subsection{OBJECTIVES}

Colloid retardation is influenced by the attachment and detachment of colloids from immobile surfaces. These retardation factors represent the reversible chemical and physical filtration of colloids. Measured laboratory and field filtration rate constants (attachment and detachment rate constants) are used to determine the retardation factor distribution. This analysis describes the development of parameters necessary to estimate attachment and detachment of colloids and, hence, retardation in both fractured tuff and porous alluvium. Field and experimental data specific to fractured tuff are used for the analysis of colloid retardation in fractured tuff. Experimental data specific to colloid transport in alluvial material from Yucca Mountain as well as bacteriophage field studies in alluvial material, which are good analogs for colloid transport, are used to estimate attachment and detachment of colloids in the alluvial material. There are no alternative scientific approaches or technical methods for calculating these retardation factors.

\subsection{FEATURES, EVENTS, AND PROCESSES SUPPORTED BY THIS SCIENTIFIC ANALYSIS}

As stipulated in Technical Work Plan For: Natural System - Saturated Zone Analysis and Model Report Integration (BSC 2004 [DIRS 171421] this report addresses the SZ features, events, and processes (FEPs) pertaining to colloid transport in the SZ that are included for TSPA-LA (Table 6-1). Table 6-1 provides a list of FEPs that are relevant to this model analysis in accordance with their assignment in the LA FEP list (DTN: MO0407SEPFEPLA.000 [DIRS 170760]). Specific reference to the various sections within this document where issues related to each FEP are addressed is provided in Table 6-1. The detailed discussion of these FEPs and their implementation in TSPA-LA, as well as SZ FEPs that were excluded for TSPALA, are documented in Features, Events, and Processes in SZ Flow and Transport (BSC 2004 [DIRS 170013]).

Table 6-1. Features, Events, and Processes Included in TSPA-LA and Relevant to This Report

\begin{tabular}{|c|l|c|l|}
\hline FEP No. & \multicolumn{1}{|c|}{ FEP Name } & $\begin{array}{c}\text { Sections Where } \\
\text { Disposition is } \\
\text { Supported }\end{array}$ & $\begin{array}{l}\text { FEP Topic Addressed in Other } \\
\text { SZ Analysis or Model Reports }\end{array}$ \\
\hline $2.2 .07 .17 .0 \mathrm{~A}$ & Diffusion in the SZ & 6.8 .1 & $\begin{array}{l}\text { Upstream Feeds }{ }^{\mathrm{a}}-\mathrm{N} / \mathrm{A} \\
\text { Corroborating }^{\mathrm{b}}\end{array}$ \\
\hline $2.2 .08 .08 .0 \mathrm{~A}$ & Matrix Diffusion in the SZ & 6.8 .1 & $\begin{array}{l}\text { Upstream Feeds }^{\mathrm{a}}-\mathrm{N} / \mathrm{A} \\
\text { Corroborating }^{\mathrm{b}}\end{array}$ \\
\hline $2.2 .08 .09 .0 \mathrm{~A}$ & Sorption in the SZ & 6.3 to 6.7 & $\begin{array}{l}\text { Upstream Feeds }^{\mathrm{a}}-\mathrm{N} / \mathrm{A} \\
\text { Corroborating }^{\mathrm{b}}\end{array}$ \\
\hline $2.2 .08 .10 .0 \mathrm{~A}$ & Colloidal transport in the SZ & 6 and 7 & $\begin{array}{l}\text { Upstream Feeds }^{\mathrm{a}}-\mathrm{N} / \mathrm{A} \\
\text { Corroborating }^{\mathrm{b}}\end{array}$ \\
\hline
\end{tabular}

${ }^{\mathrm{a}}$ Upstream Feeds-Aspects of the SZ FEP screening position adopted in this report are a result of SZ analyses performed in a directly upstream SZ model or analyses.

${ }^{\mathrm{b}}$ Corroborating-Corroborative aspect(s) of the FEP topic is (are) discussed in a relevant SZ analysis or model report: Saturated Zone In-Situ Testing (BSC 2004 [DIRS 170010]) 


\subsection{COLLOID TRANSPORT PARAMETERS NECESSARY FOR TSPA}

Most radionuclides are assumed to sorb onto colloids reversibly (that is, they have measurable desorption rates and can be entirely desorbed from colloids) (BSC 2004 [DIRS 170025], Section 6.3.3.1). However, $\mathrm{Pu}$ and Am can sorb either reversibly or irreversibly onto colloids with the relative percentages of these obtained from an analysis of waste-form degradation and waste-package corrosion processes occurring in the repository near-field environment (BSC 2004 [DIRS 170025], Section 6.3.3.1). In general, the majority of the Pu and Am sorbed to colloids is irreversibly sorbed, with a typical percentage being 90 to 99 percent irreversible and 1 to 10 percent reversible (BSC 2004 [DIRS 170025], Section 6.3.3.2). Irreversibly sorbed $\mathrm{Pu}$ and $\mathrm{Am}$ are either embedded in waste-form colloids (e.g., smectite colloids formed by degradation of high-level waste glass) or are so strongly sorbed onto colloids (e.g., iron oxyhydroxide colloids formed by corrosion of waste packages) that there is no possibility of detachment for typical transport time scales (thousands of years) through the SZ. Note that Appendix B of the EBS Radionuclide Transport Abstraction discusses the mathematical implementation for irreversible sorption of $\mathrm{Pu}$ and $\mathrm{Am}$ onto iron oxyhydroxide colloids in the engineered barrier system (BSC 2004 [DIRS 169868]).

Since the dissolved species of $\mathrm{Pu}$ and Am are considerably smaller than colloids, the irreversibly sorbed $\mathrm{Pu}$ and $\mathrm{Am}$ transport in a manner identical to the colloids onto which they are sorbed. Therefore, the colloid retardation factor uncertainty distributions developed in this analysis are necessary to describe the transport of the irreversibly sorbed radionuclides. These colloid retardation factors represent the reversible chemical and physical filtration of colloids in the SZ. Chemical filtration describes the interactions of colloids with fractures and porous media due to chemical reactions. Physical filtration describes the interactions of colloids with fractures and porous media due to physical processes (e.g., size restriction, settling). Measured laboratory and field filtration rate constants (attachment and detachment rate constants) are used to determine the retardation factor distribution. Several field observations have suggested that a small percentage of colloids transport with essentially no retardation in groundwater (Kersting et al. 1999 [DIRS 103282], p. 56; Penrose et al. 1990 [DIRS 100811], p. 228), whereas the majority undergoes either reversible filtration, which can be described by a retardation factor, $R_{c o l}$, or irreversible filtration. The value of $R_{c o l}$ is dependent on several factors such as colloid size, colloid type, geochemical conditions (e.g., $\mathrm{pH}$, Eh, and ionic strength), and the geologic medium. These factors are folded into the distribution of $R_{c o l}$ that has been developed from field and experimental data collected under varying geochemical conditions with different colloid types and sizes for volcanics and alluvium. The varying conditions (e.g. geochemical conditions, colloid type, colloid size, etc.) provide confidence that the range of retardation factors that make up the distributions is adequate to describe colloid transport in the SZ. Attachment rate constants, $k_{\text {att }}$, and detachment rate constants, $k_{\text {det }}$, of colloids to the fracture surface have been measured for the fractured volcanics. Separate $R_{c o l}$ uncertainty distributions have been developed for the attachment and detachment rate constants of colloids to the rock matrix in the alluvium. 
Note that it is also possible that a fraction of colloids permanently filter rather than filtering reversibly as is assumed in this analysis report. However, the case of permanent filtration is not explored since ignoring it is a conservative assumption.

The attachment rate constant $\left[\mathrm{T}^{-1}\right]$ is also used to determine the fraction, colfrac, of the colloids that transport with no retardation. Specifically, the inverse of the attachment rate constant provides a measure of the reaction timescale. Colloids for which this reaction timescale is smaller than the transport time through the system will transport with no retardation. A fraction of colloids that transport with no retardation mimic the field observations since a small percentage of colloids do not undergo filtration in groundwater (Kersting et al. 1999 [DIRS 103282], p. 56; Penrose et al. 1990 [DIRS 100811], p. 228). The following sections document the development of $R_{c o l}$ uncertainty distributions for the volcanics and the alluvium as well as the fraction of colloids that transport unretarded, called colfrac.

As with all the species transporting in the SZ, the source term for radionuclides irreversibly sorbed to colloids entering the SZ is obtained directly from the UZ. The source terms are discussed in Saturated Zone Flow and Transport Model Abstraction (BSC 2004 [DIRS 170042], Section 6.3.3).

\subsection{COLLOID TRANSPORT IN FRACTURED TUFF}

\subsubsection{Background}

Colloid filtration rate constants and retardation factors for the fractured volcanics have been estimated in a number of laboratory and field experiments conducted for the YMP and the Underground Test Area Project. These retardation factors represent the chemical and physical filtration of colloids in the SZ. All of the field measurements have involved fluorescent polystyrene carboxylate modified latex (CML) microspheres ranging in diameter from 280-nm to 830-nm. Laboratory fracture experiments have been conducted using silica, montmorillonite, and clinoptilolite colloids in addition to CML microspheres. In one study, silica colloid transport (approximately 100-nm diameter) was compared directly with CML microsphere transport (330-nm diameter), and it was found that the microspheres transported conservatively (with no retardation) relative to the silica colloids (Anghel 2001 [DIRS 158639], Chapter 6). This result suggests that colloid filtration and retardation parameters derived from CML microsphere responses in field tracer tests should be conservative if used to predict natural inorganic colloid transport in fractured systems.

Colloid filtration (attachment) and detachment rate constants have been derived from colloid responses in tracer tests by using the advection-dispersion equation (Freeze and Cherry 1979 [DIRS 101173], p. 389, Equation 9.3) with appropriate terms for a single reversible first-order reaction to account for mass transfer between mobile water and immobile surfaces (filtration and detachment) to fit the data:

$$
\frac{\partial C}{\partial t}+V \frac{\partial C}{\partial x}-D \frac{\partial^{2} C}{\partial x^{2}}+k_{f i l t} C-k_{\operatorname{det}} S=0
$$




$$
\frac{\partial S}{\partial t}-k_{f i l t} C+k_{\mathrm{det}} S=0
$$

where

$C=$ colloid concentration in solution, no. $/ \mathrm{cm}^{3}$

$S=$ no. of colloids attached to fracture surfaces per unit volume of solution, no. $/ \mathrm{cm}^{3}$

$V=$ flow velocity in fractures, $\mathrm{cm} / \mathrm{sec}$

$D=$ dispersion coefficient, $\mathrm{cm}^{2} / \mathrm{sec}$

$k_{\text {filt }}=$ filtration rate constant $(1 / \mathrm{sec})=\lambda \mathrm{V}$, where $\lambda=$ filtration coefficient $(1 / \mathrm{cm})$. (Note that $k_{\text {filt }}=k_{\text {att }}$ for the remainder of this document.)

$k_{\text {det }}=$ detachment rate constant, $1 / \mathrm{sec}$

$x, t=$ independent variables for distance $(\mathrm{cm})$ and time (sec) respectively.

Equations 6-1 and 6-2 can be solved semi-analytically using the RELAP computer code, which has been used extensively on the YMP to interpret laboratory and field-scale tracer tests in single- or dual-porosity media (e.g., model report Saturated Zone In-Situ Testing (BSC 2004 [DIRS 170010]). The term "dual-porosity" refers to a system in which flow occurs predominantly within a "primary" porosity (e.g., fractures in the volcanic tuffs) but there is a significant "secondary" porosity that contains stagnant or near-stagnant water into which solutes can diffuse from the primary porosity (e.g., the matrix in the volcanic tuffs). In contrast, a "single-porosity" system is a system that contains only primary porosity; that is, flow occurs through all of the system porosity, and there is little or no stagnant water. The procedure for determining colloid filtration and detachment rate constants $k_{\text {filt }}$ and $k_{\text {det }}$ from laboratory or field transport experiments is:

1. Nonsorbing solute tracers were always injected simultaneously with the colloid tracer(s). The mean residence time $(L / V$, where $L=$ travel distance), dispersivity $(D / V)$, and diffusive mass-transfer coefficients were determined for the solutes in the flow system using RELAP to fit the solute breakthrough curves. Diffusive mass-transfer parameters were determined by simultaneously fitting the responses of two nonsorbing tracers with different diffusion coefficients or of the same nonsorbing tracer at different flow rates through the system(s). In field tests, because of the low tracer recovery in many cases, the fraction of tracer mass participating in the test was allowed to be an additional adjustable parameter for fitting the solute breakthrough curves. The best-fitting fraction for solutes was then applied to the colloids with the rationale that the flow pathways resulting in incomplete recovery of solutes would affect the simultaneously injected colloids similarly.

2. The mean residence time, dispersivity, and mass fraction (in the case of field tests) obtained from fitting the solute breakthrough curves were assumed to apply to the 
colloids in each experiment. The matrix diffusion mass transfer coefficient for the colloids was set equal to zero because colloids were assumed to be too large to diffuse significantly into the matrix. However, on rare occasions, it was necessary to adjust the dispersivity slightly in laboratory experiments to account for a greater apparent dispersion of the colloids (generally because of an earlier first arrival time of the colloids).

3. RELAP was used to fit the colloid breakthrough curves by adjusting $k_{\text {filt }}$ and $k_{\text {det }}$ (and fixing the mean residence time, dispersivity, and mass fraction to be that of the solutes). When using RELAP to estimate these parameters, the rate-limited sorption option must be specified and colloid breakthrough curves are fitted by adjusting a retardation factor, $R_{c o l}$, and the filtration rate constant, $k_{\text {filt }}$. For any given values of $R_{c o l}$ and $k_{f i l t}$, RELAP internally calculates a detachment rate constant, $k_{\text {det }}$, for use in equations 1 and 2 by rearrangement of the relationship (Freeze and Cherry [DIRS 101173], p. 404, Equation 9.14). Note that equation 6-3 assumes local equilibrium. The validity of the local equilibrium assumption is discussed in section 6.7 .

$$
R_{c o l}=1+\frac{k_{f i l t}}{k_{\mathrm{det}}}
$$

4. $R_{c o l}$ (and, hence, $k_{d e t}$ ) was constrained primarily by fitting the tails of the colloid breakthrough curves; $k_{\text {filt }}$ was constrained primarily by fitting the early (unretarded) colloid response (i.e., the peak arriving at about the same time as nonsorbing solutes). Essentially, $k_{\text {filt }}$ was adjusted until it was small enough that the fraction of colloids NOT filtered within the system matched the early arriving peak. Thus, the early colloid response was implicitly interpreted as being a fraction of colloids that moved through the system without ever becoming filtered. Similarly, $R_{c o l}$ was adjusted until an appropriate fraction of filtered colloids was predicted to detach and appear as the tails of the colloid breakthrough curves.

5. In tests in which there was an inadvertent flow transient that resulted in a "spike" in colloid concentrations in the tail of the breakthrough curve (presumably because of enhanced detachment caused by the flow transient), the value obtained for $R_{c o l}$ (and $k_{d e t}$ ) was not considered to be representative of steady-flow conditions. Steady-flow conditions are necessary to accurately determine the parameters. However, the value obtained for $k_{\text {filt }}$, which was constrained primarily by the colloid response occurring before the flow transient, was assumed to be representative of steady-flow conditions. Thus, $k_{\text {filt }}$ values obtained from such tests were used in the development of cumulative distribution functions (CDFs) for filtration rate constants, but $R_{c o l}$ values from these tests were not used in the development of CDFs for retardation factors.

\subsubsection{Colloid Filtration Rate Constants for Fractured Volcanics}

Figure 6-1 shows a plot of filtration rate constants obtained from interpretations of several field and laboratory tracer tests conducted in saturated fractured rocks as a function of the time to reach peak nonsorbing solute concentrations in the tests. The filtration rate constants reflect the fraction of colloids that were not filtered during the tests (i.e., the rate constant was constrained 
primarily by the magnitude of the early arrival of colloids). Figure 6-1 also shows that, even though different sizes and types of colloids were used in the different tests, there is an apparent trend of decreasing filtration rate constant with residence time. The line drawn through the data (not a fit) has a slope of -1 in log space, which implies an inverse time dependence of the filtration rate constant. Schijven et al. (1999 [DIRS 162423], Table 3, p. 1107) observed a similar decrease in filtration rate constants as a function of distance (proportional to time in their system) for bacteriophage transport in a sandy alluvial aquifer.

The trend shown in Figure 6-1 suggests that some fraction of colloids may always transport through a fracture flow system regardless of the time or length scale of the observations. It is tempting to draw the conclusion that filtration rate constants will continually decrease with increasing time scales. However, it may be more appropriate to consider the possibility that, while the majority of colloids might be filtered quite quickly, a small fraction will be resistant to filtration and, therefore, capable of traveling large distances over long time periods. This statement implies that there may be a distribution of colloid filtration rate constants rather than a fixed rate constant that applies to all colloids. The appearance of a small fraction of colloids at about the same time as nonsorbing solutes in tracer tests, regardless of the overall time scale of the test, forces filtration rate constants to decrease with time when single rate constants are assumed to apply to all colloids.

Ignoring the possible scale effect for the moment, it is possible to construct a CDF for the filtration rate constants derived from all of the experiments represented in Figure 6-1. In doing so, filtration rate constants derived from field tests were weighted to be twice that of rate constants from laboratory tests, as tests at field scales are considered more relevant to TSPA modeling. Also, one data point was added that does not come from a tracer test but rather from the observation(s) of colloid-facilitated Pu transport in the ER-20-5 wells that originated from the BENHAM nuclear test cavity (Kersting et al. 1999 [DIRS 103282], pp. 56 to 59). To estimate a filtration rate constant for this observation, the following several assumptions were made:

- The Pu in the ER-20-5 wells was irreversibly sorbed to colloids, which means that Pu concentrations in the wells reflect the colloid transport parameters.

- The concentrations measured in ER-20-5 \#1 (on the order of $10^{-13} \mathrm{M} \mathrm{Pu}$ ) represent a five order-of-magnitude decrease from concentrations at the source. Thus, colloid filtration is assumed to result in a five order-of-magnitude decrease in colloid concentrations.

- Any colloids that were filtered would never make it to the observation wells (i.e., they were effectively irreversibly filtered).

- The transport time from the source to the ER-20-5 wells was approximately 30 years, which represents an upper-bound estimate. Note that we define transport time as the 50 percentile concentration breakthrough. 


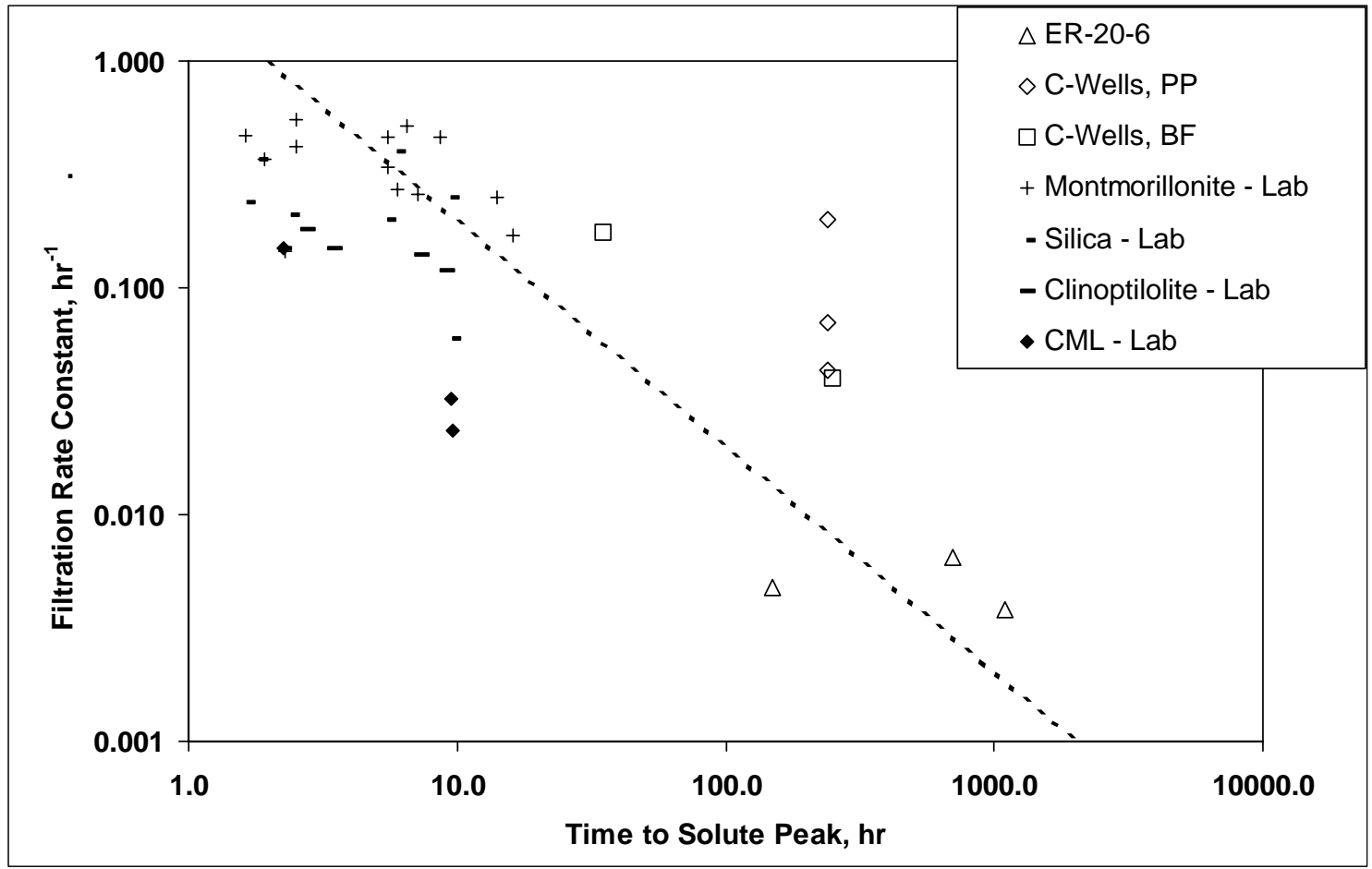

DTNs: LA0007PR831231.001 [DIRS 156043] (C-Wells BF data); LAPR831231AQ99.001 [DIRS 140134] (C-Wells PP data); LA0302PR831352.002 [DIRS 162440] (ER-20-6 well 3 data); LA0302PR831352.001 [DIRS 162439] (ER-20-6 well 2 data; silica and CML data); LA0302PR831231.003 [DIRS 162438] (ER-206 well 3 solute data); LA0302PR831231.002 [DIRS 162437] (ER-20-6 well 2 solute data); LA0301PR831361.003 [DIRS 162435] (silica and montmorillonite data); LA0301PR831361.004 [DIRS 162436] (montmorillonite and clinoptilolite data); LA0303PR831231.003 [DIRS 163756] (analysis of C-wells rate constants); LA0303PR831352.002 [DIRS 163136] (analysis of ER-20-6 rate constants); LA0403PR831352.001 [DIRS 171416] (analysis of laboratory rate constants).

NOTE: "ER-20-6" refers to the BULLION forced-gradient experiment (Reimus and Haga 1999 [DIRS 154705], p. 1). "C-wells BF" and "C-wells PP" refer to tests in the Bullfrog Tuff and Prow Pass Tuff (both members of the Crater Flat Group), respectively, at the UE-25 C-wells (BSC 2004 [DIRS 170010], Section 6). The experiments were conducted in the laboratory using fractured cores from Pahute Mesa at the Nevada Test Site. It is important to emphasize that different CML microspheres were used in the different field tests and, also, the groundwater chemistry varied from site-to-site or test-to-test. The dashed line on the figure has a slope of -1in log space.

BF=Bullfrog Tuff; PP=Prow Pass Tuff

Figure 6-1. CML Microsphere and Inorganic Colloid Filtration Rate Constants as a Function of Time to Solute Peak Concentration in Several Field and Laboratory Tracer Tests in Saturated, Fractured Media 
No assumptions were required about the travel distance. Although these assumptions cannot be verified directly, they allow us to estimate a filtration rate constant using the following expression:

$$
1 \times 10^{-5}=\operatorname{Exp}\left[-(30)(365.25)(24) k_{\text {fil }}\right]
$$

where

$1 \times 10^{-5}=$ fraction of colloids traveling from the source to the ER-20-5 wells $(30)(365.25)(24)=262,980=$ transport time in hours.

Note that Equation 6-4 assumes that the colloid concentration as a function of time in the water flowing from the source location is given by $\mathrm{dC} / \mathrm{dt}=-k_{\text {filt }} \mathrm{C}$ (i.e., the concentration decreases according to a first order filtration reaction irrespective of advection and dispersion and ignoring detachment). Solution of this equation with the initial condition $\mathrm{C}=\mathrm{Co}$ at $\mathrm{t}=0$ yields $\mathrm{C} / \mathrm{Co}=\exp \left(-k_{\text {filt }} \mathrm{t}\right)$. Equation $6-4$ is obtained by inserting $1 \times 10^{-5}$ for $\mathrm{C} / \mathrm{Co}$ and 30 years (converted to hours) for $t$.

Solving Equation 6-4 for $k_{\text {filt }}$ yields a filtration rate constant of $4.4 \times 10^{-5} \mathrm{hr}^{-1}$. This estimate is not very sensitive to the fraction of colloids assumed on the left-hand side of Equation 6-4. If the fraction is changed to $1 \times 10^{-8}$, the filtration rate constant becomes $7 \times 10^{-5} \mathrm{hr}^{-1}$. The filtration rate constant is inversely proportional to the assumed transport time; consequently, if the transport time is decreased by a factor of 3 to 10 years, the filtration rate constant increases by a factor of 3 to $1.3 \times 10^{-4} \mathrm{hr}^{-1}$.

Figure 6-2 shows the resulting cumulative probability distribution of filtration rate constants that includes the data point corresponding to the ER-20-5 observations (which was weighted the same as the field tracer test results). Both axes in Figure 6-2 are logarithmic. Note that data points associated with the two alternative scenarios discussed above for the ER-20-5 observations are also shown in Figure 6-2 (as squares) to illustrate the insensitivity of the overall cumulative distribution to these assumptions. However, these points are not used in the fit.

\subsubsection{Colloid Retardation Factors for Fractured Volcanics}

Using the interpretive results from all the tests represented in Figure 6-2, with the exception of the ER-20-5 observations and two of the three CML microsphere responses from the BULLION forced-gradient experiment (Reimus and Haga 1999 [DIRS 154705], pp. 29 to 31, Figures 13-15), a cumulative probability distribution for $R_{c o l}$ can be generated. This distribution is shown in Table 6-2 and Figure 6-3 (log scale on $x$ axis), which again has the field test results weighted a factor of two greater than the laboratory test results. Table 6-2 contains three cumulative probability distributions. The first distribution consists of the best-fitting $R_{c o l}$ values obtained from RELAP (taken from the input DTNs listed in Figure 6-1). The second distribution is a truncated version of this CDF in which all retardation factors less than 6 are set equal to 6. The final distribution is the CDF for use by TSPA, which captures the same trends as the truncated CDF while using fewer points. 


\section{Log Prob. vs. Log Rate Constant}

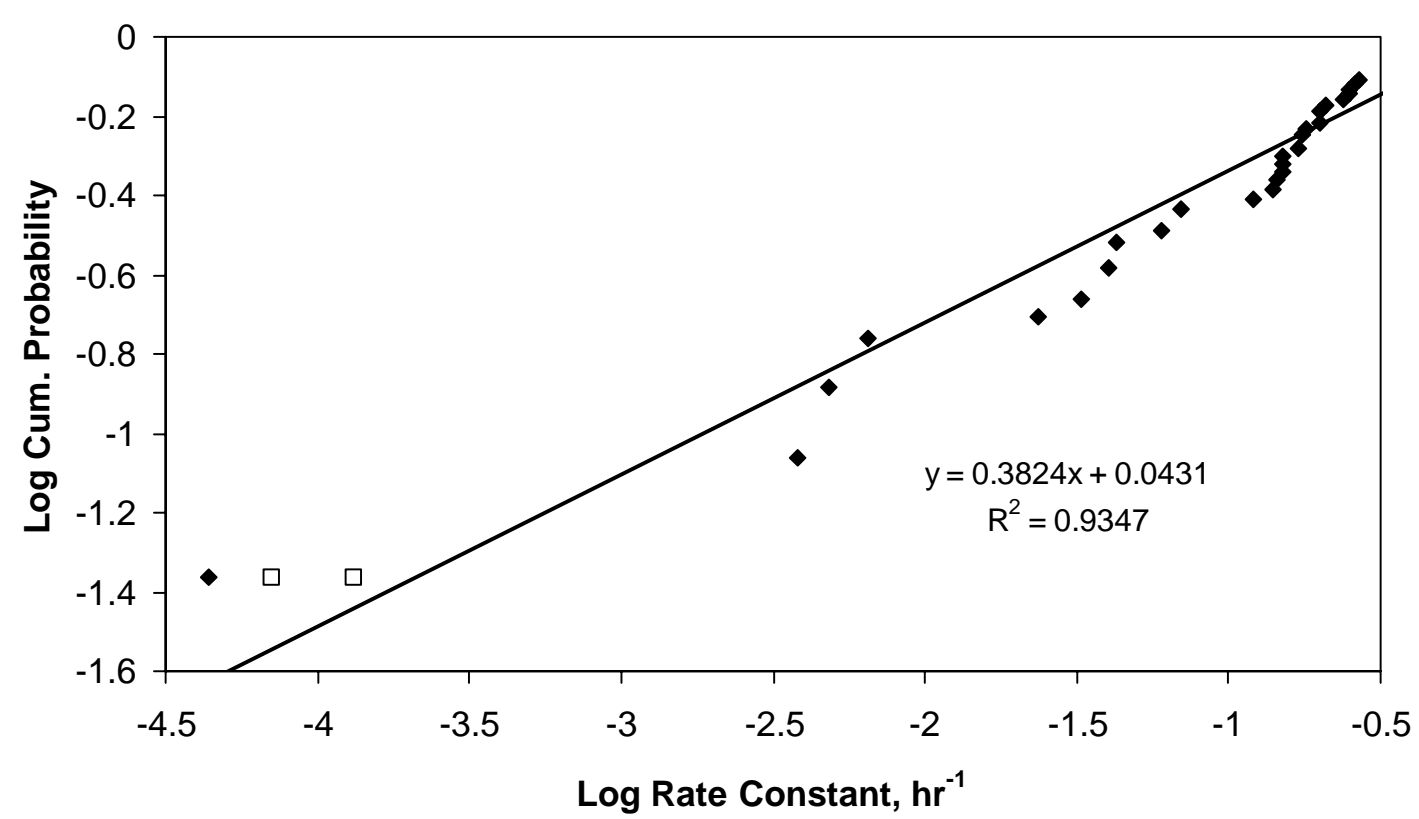

Source: Notebook SN-LANL-SCI-297-V1 (Viswanathan 2003 [DIRS 163757], p 11).

NOTE: The two squares show the effect of changing the assumptions associated with the filtration rate constant estimates for the ER-20-5 observations (see text).

Figure 6-2. Cumulative Probability Distribution of Log Colloid Filtration Rate Constants for Fractured Media

The CDF for TSPA represents the uncertainty in the retardation factor for colloids in the volcanic units. These values of retardation factors in the CDF can be applied on a log scale for the purposes of TSPA. The rationale for truncating the original CDF at $R_{c o l}=6$ is that 6 is the smallest value of $R_{c o l}$ that is reasonably well constrained by fitting the tails of colloid breakthrough curves. $R_{c o l}$ values less than 6 were poorly constrained because the breakthrough curves had relatively high recoveries and tails with low concentrations that could be fitted quite well over a wide range of $R_{c o l}$ values (the fits were much more sensitive to $k_{f i l t}$ than $R_{c o l}$ ). In the extreme case of tests with nearly complete colloid recoveries and low tail concentrations, the breakthrough curves could be fit equally well with $R_{c o l}=1$ and $k_{f i l t}=$ anything or with $R_{c o l}=\mathrm{a}$ very large number and $k_{\text {filt }}=$ a very small number. In either case, the implication is that there is no filtration, and the test data, in effect, provide no constraint whatsoever on $R_{c o l}$ or $k_{\text {filt }}$. In these situations, RELAP would default to a best fit with $R_{c o l}=\sim 1 . R_{c o l}$ values greater than 1 but less than 6 were poorly constrained because they were associated with fits that were relatively insensitive to values of $R_{c o l}$ and $k_{f i l t}$, although some combination of a low value of $R_{c o l}$ and an intermediate value of $k_{f i l t}$ offered the best least-squares fit. 
Table 6-2. Retardation Factor, $R_{c o l}$, Cumulative Probability Distributions for Fractured Volcanics

\begin{tabular}{|c|c|c|c|c|c|}
\hline \multicolumn{2}{|c|}{ Raw Data CDF } & \multicolumn{2}{|c|}{ Truncated CDF } & \multicolumn{2}{|c|}{ CDF for TSPA } \\
\hline $\begin{array}{c}\text { Retardation } \\
\text { Factor }\end{array}$ & Cumulative Probability & $\begin{array}{l}\text { Retardation } \\
\text { Factor }\end{array}$ & $\begin{array}{l}\text { Cumulative } \\
\text { Probability }\end{array}$ & $\begin{array}{l}\text { Retardation } \\
\text { Factor }\end{array}$ & $\begin{array}{l}\text { Cumulative } \\
\text { Probability }\end{array}$ \\
\hline 1 & 1.00E-05 & 6 & 1.00E-05 & 6.00 & 0 \\
\hline 1.162 & $1.94 \mathrm{E}-03$ & 6 & $1.94 \mathrm{E}-03$ & 6.00 & 0.15 \\
\hline 1.19 & 8.42E-03 & 6 & 8.42E-03 & 10.23 & 0.25 \\
\hline 2 & 3.62E-02 & 6 & 3.62E-02 & 26.00 & 0.5 \\
\hline 2.5 & $6.40 \mathrm{E}-02$ & 6 & $6.40 \mathrm{E}-02$ & 59.98 & 0.8 \\
\hline 2.5 & $9.18 \mathrm{E}-02$ & 6 & $9.18 \mathrm{E}-02$ & 800. & 1 \\
\hline 3.25 & $1.20 \mathrm{E}-01$ & 6 & $1.20 \mathrm{E}-01$ & & \\
\hline 3.5 & 1.47E-01 & 6 & $1.30 \mathrm{E}-01$ & & \\
\hline 6.3 & $1.57 \mathrm{E}-01$ & 6.3 & $1.57 \mathrm{E}-01$ & & \\
\hline 7 & 1.85E-01 & 7 & 1.85E-01 & & \\
\hline 9 & 2.13E-01 & 9 & 2.13E-01 & & \\
\hline 10 & 2.41E-01 & 10 & 2.41E-01 & & \\
\hline 12 & 2.69E-01 & 12 & 2.69E-01 & & \\
\hline 14 & 2.96E-01 & 14 & $2.96 \mathrm{E}-01$ & & \\
\hline 14 & 3.24E-01 & 14 & 3.24E-01 & & \\
\hline 20 & 3.52E-01 & 20 & 3.52E-01 & & \\
\hline 20 & $3.80 \mathrm{E}-01$ & 20 & $3.80 \mathrm{E}-01$ & & \\
\hline 21 & 4.07E-01 & 21 & 4.35E-01 & & \\
\hline 22 & 4.63E-01 & 22 & 4.63E-01 & & \\
\hline 24 & 4.91E-01 & 24 & 4.91E-01 & & \\
\hline 30 & 5.19E-01 & 30 & 5.19E-01 & & \\
\hline 32 & 5.46E-01 & 32 & $5.46 \mathrm{E}-01$ & & \\
\hline 40 & 5.74E-01 & 40 & 5.74E-01 & & \\
\hline 40 & $6.02 \mathrm{E}-01$ & 40 & $6.02 \mathrm{E}-01$ & & \\
\hline 40 & $6.30 \mathrm{E}-01$ & 40 & $6.30 \mathrm{E}-01$ & & \\
\hline 46 & 6.57E-01 & 46 & 6.57E-01 & & \\
\hline 50 & $6.85 \mathrm{E}-01$ & 50 & $6.85 \mathrm{E}-01$ & & \\
\hline 50 & 7.13E-01 & 50 & 7.13E-01 & & \\
\hline 53 & 7.41E-01 & 53 & 7.41E-01 & & \\
\hline 60 & 7.69E-01 & 60 & 7.69E-01 & & \\
\hline 60 & 7.96E-01 & 60 & 7.96E-01 & & \\
\hline
\end{tabular}


Table 6-2. Retardation Factor, $R_{c o l}$, Cumulative Probability Distributions for Fractured Volcanics (Continued)

\begin{tabular}{|c|c|c|c|}
\hline \multicolumn{2}{|c|}{ Raw Data CDF } & \multicolumn{2}{c|}{ Truncated CDF } \\
\hline $\begin{array}{c}\text { Retardation } \\
\text { Factor }\end{array}$ & Cumulative Probability & $\begin{array}{c}\text { Retardation } \\
\text { Factor }\end{array}$ & $\begin{array}{c}\text { Cumulative } \\
\text { Probability }\end{array}$ \\
\hline 200 & $8.35 \mathrm{E}-01$ & 200 & $8.35 \mathrm{E}-01$ \\
\hline 280 & $8.91 \mathrm{E}-01$ & 280 & $8.91 \mathrm{E}-01$ \\
\hline 410 & $9.19 \mathrm{E}-01$ & 410 & $9.19 \mathrm{E}-01$ \\
\hline 600 & $9.46 \mathrm{E}-01$ & 600 & $9.46 \mathrm{E}-01$ \\
\hline 800 & $1.00 \mathrm{E}+00$ & 800 & $1.00 \mathrm{E}+00$ \\
\hline
\end{tabular}

Output DTN: LA0303HV831352.002.

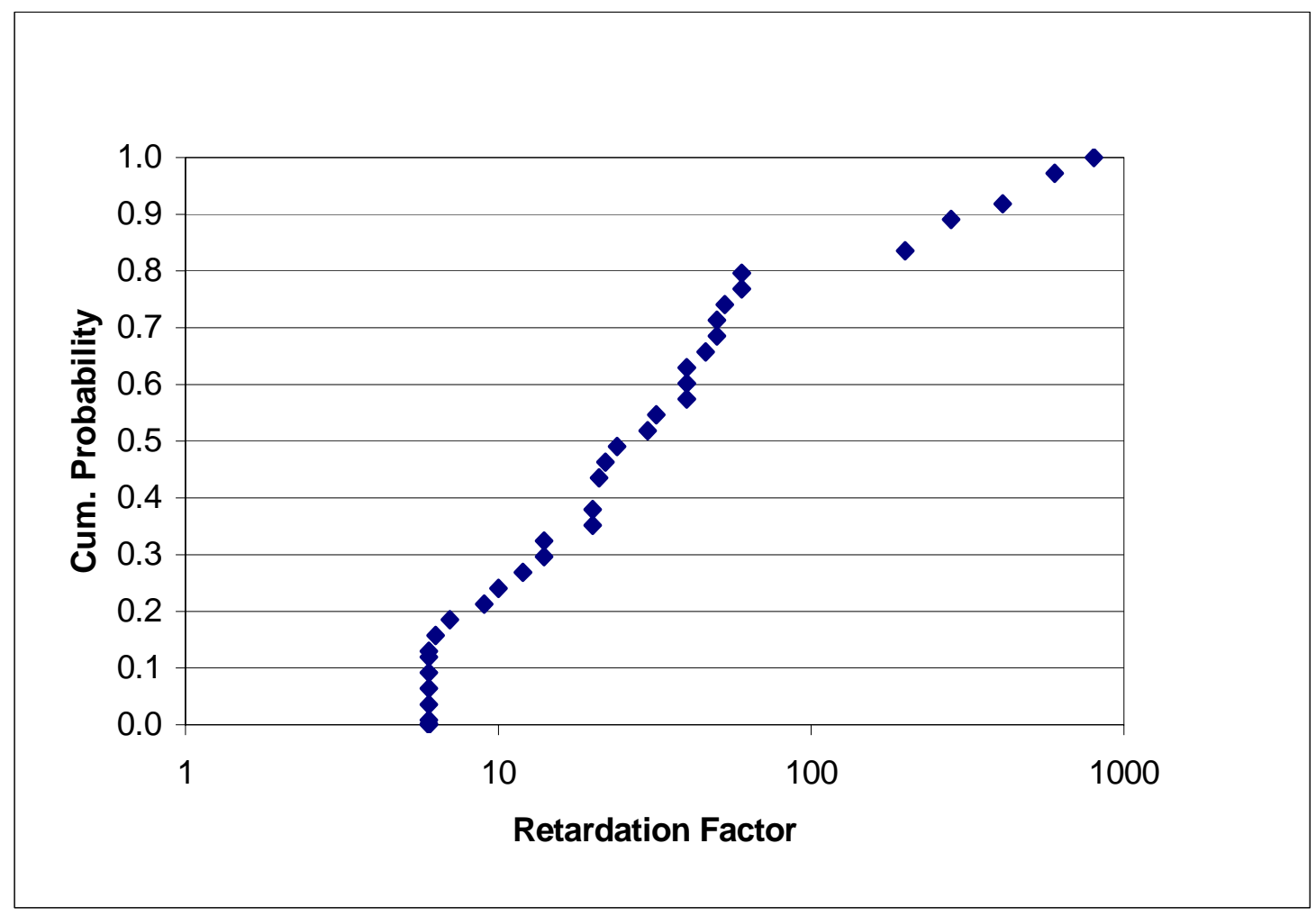

Output DTN: LA0303HV831352.002.

Source: Notebook SN-LANL-SCI-297-V1 (Viswanathan 2003 [DIRS 163757], p. 23).

NOTE: See text for recommendations on how to use the fits to generate stochastic retardation factors.

Figure 6-3. Truncated Cumulative Probability Distribution of Retardation Factors for the Fractured Volcanics 
The ER-20-5 observations were omitted from the $R_{c o l}$ distribution(s) because it was assumed that $k_{d e t}$ was zero when estimating $k_{\text {filt }}$ (i.e., $R_{c o l}=$ infinite). Also, the results from the two microsphere responses in the BULLION forced-gradient experiment production well were omitted because there was a significant increase in microsphere concentrations in the tails of the responses that apparently resulted from a flow transient in the production well. This increase prevented an unbiased estimate of $k_{\text {det }}$. The maximum retardation factor assumed for any of the colloid data sets was 1000 . For any of these data sets, the factor of 1000 could effectively not be distinguished from an infinite retardation factor $\left(R_{c o l}\right.$ values greater than a few hundred in most cases were equivalent to assuming irreversible filtration, or $R_{c o l}=$ infinite). Thus, the distribution of Figure 6-2 is probably conservative at the high end because of this somewhat arbitrary maximum value.

Figure 6-3 shows a fit to the cumulative distribution for retardation factors using the truncated data shown in Table 6-2. Note that the cumulative distribution of retardation factors in the volcanics has a lower limit of $R_{c o l}=6$ (there is zero probability of having a retardation factor less than 6). This is believed to be a reasonable lower bound for retardation factors experienced by colloids that are reversibly filtered in the volcanics. The fact that smaller retardation factors have been observed in tests is attributed to slow filtration rate constants that result in a fraction of the colloids moving conservatively through flow systems. The approach advocated here is to account for this unretarded fraction of colloids using a distribution of observed filtration rate constants, with unretarded colloids having the slowest rates. It is then assumed that all colloids that become filtered experience some minimum delay in the system as a result of filtration and detachment processes. This minimum delay in the fractured volcanics corresponds to a retardation factor of 6 .

\subsection{COLLOID TRANSPORT IN ALLUVIAL MATERIAL}

\subsubsection{Background}

Colloid filtration rate constants and retardation factors for alluvial material have been estimated in a number of laboratory experiments for the YMP. With the absence of YMP field data for colloid filtration in the alluvium, data from Schijven et al. were used to obtain field colloid filtration and detachment rates (Schijven et al. 1999 [DIRS 162423], Table 3, p. 1107).

Laboratory column experiments have been conducted using silica and natural colloids in addition to CML microspheres.

Schijven et al. measured filtration and detachment rates for bacteriophages in alluvial material under natural gradient conditions (Schijven et al. 1999 [DIRS 162423], Table 3, p. 1107). They used bacteriophages denoted as MS-2 and PRD-1 that are in the same size range as colloids. These bacteriophages were chosen because they attach less than most pathogenic viruses and are relatively persistent during transport through the subsurface (Schijven et al. 1999 [DIRS 162423], p. 1101). The groundwater at the site studied by Schijven et al. had somewhat higher divalent cation concentrations than most SZ waters in the vicinity of Yucca Mountain (90 to $100 \mathrm{mg} / \mathrm{L} \mathrm{Ca}^{2+}$ and 10 to $15 \mathrm{mg} / \mathrm{L} \mathrm{Mg}^{2+}$ compared to 2 to $20 \mathrm{mg} / \mathrm{L} \mathrm{Ca}^{2+}$ and 0 to $5 \mathrm{mg} / \mathrm{L} \mathrm{Mg}^{2+}$ at Yucca Mountain) (Schijven et al. 1999 [DIRS 162423], Table 2, p. 1105), 
so colloids would be expected to be less stable at their site. However, the alluvium material at their study site was also coarser, (hydraulic conductivity of $12 \mathrm{~m} /$ day compared to $7.7 \mathrm{~m} /$ day for core permeability estimates at Yucca Mountain) with more sand, less clay, and more organic carbon than the alluvium material south of Yucca Mountain, all of which would tend to result in enhanced colloid transport relative to Yucca Mountain conditions. Thus, the combination of colloid selection, groundwater chemistry, and alluvium characteristics at the site studied by Schijven et al. suggest that their reported colloid filtration and detachment rate constants can be applied to Yucca Mountain alluvium if the uncertainties associated with doing so are recognized.

As with the fractured volcanics, colloid filtration and detachment rate constants have been derived from colloid responses in tracer tests by using the advection-dispersion equation with appropriate terms for a single reversible first-order reaction to account for mass transfer between mobile water and immobile surfaces (filtration and detachment) to fit the data. Equations 6-1, 6-2, and 6-3 also apply to colloid filtration in the alluvium.

As was the case for the fractured volcanics, the values for $V$ and $D$ in Equations 6-1 and 6-2 were always obtained from interpretations of nonsorbing solute tracer responses; therefore, the filtration and detachment rate constants were the only parameters adjusted to match the colloid breakthrough curves.

\subsubsection{Colloid Filtration Rate Constants in Alluvial Material}

Figure 6-4 shows a plot of filtration rate constants obtained from interpretations of several laboratory tracer tests and the Schijven et al. field test conducted in saturated alluvium as a function of the mean solute residence time in the tests (Schijven et al. 1999 [DIRS 162423], Table 3, p. 1107). The filtration rate constants reflect the fraction of colloids that were not filtered during the tests (i.e., the rate constant is constrained primarily by the magnitude of the early arrival of colloids). Figure 6-4 also shows that, even though different sizes and types of colloids were used in the different tests, there is an apparent trend of decreasing filtration rate constant with residence time. This trend is similar to the trend witnessed in the fractured volcanics. However, the experiments involving the two colloids with the largest filtration rate constants, the 330-nm CML microspheres and the 100-nm silica colloids, were conducted in columns in which air bubbles became apparent during the experiments. Later alluvium column experiments that involved the 190-nm and 500-nm CML microspheres, as well as the natural colloids, were conducted much more carefully to avoid air bubbles. It is certainly possible that the air bubbles in the earlier tests could have been at least partly responsible for the greater filtration rate constants in these tests. Figure 6-5 shows the resulting cumulative probability distribution of filtration rate constants in the alluvium. 


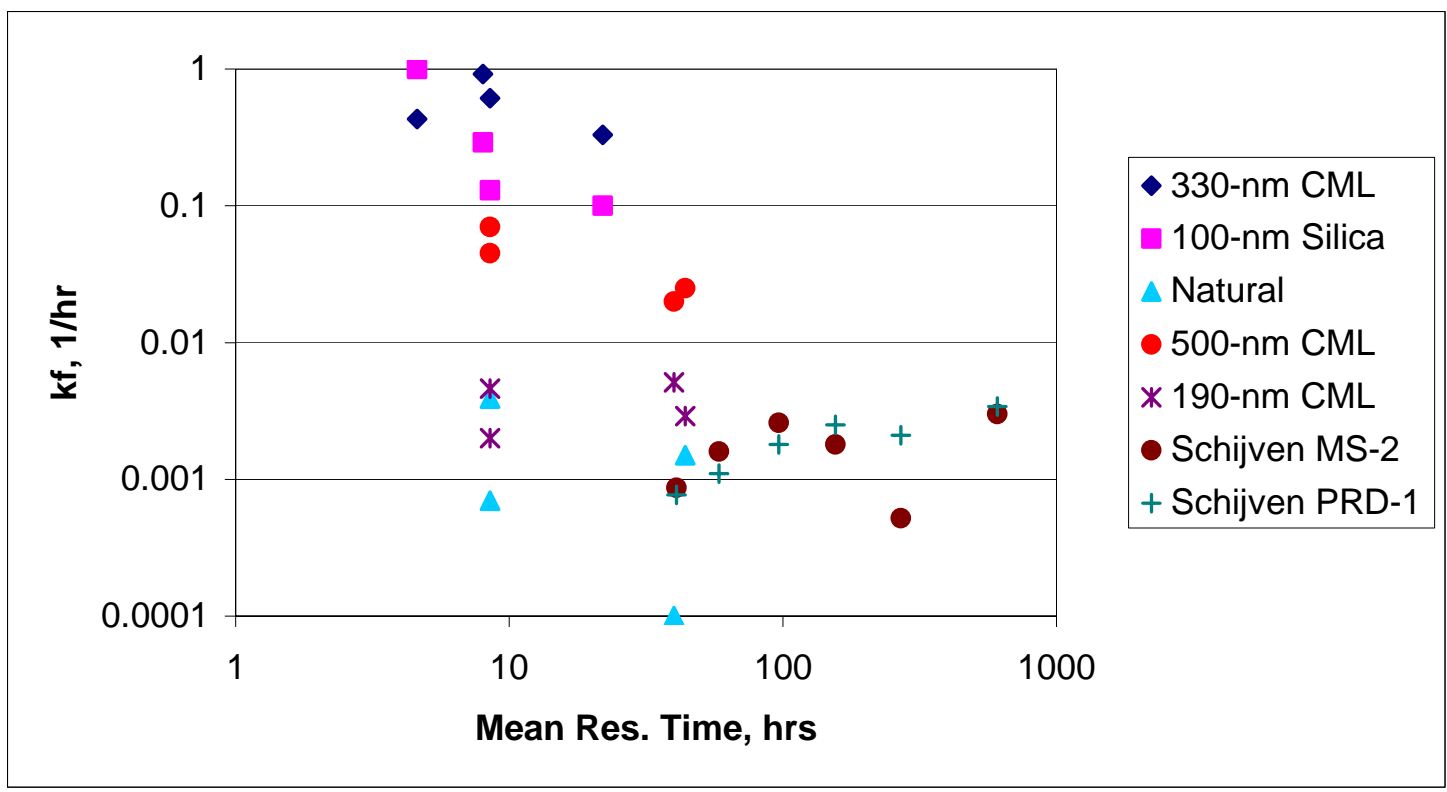

DTNs: LA0206MH831361.001 [DIRS 162426] (330-nm CML and 100-nm silica data); LA0206MH831361.002 [DIRS 162427] (330-nm CML and 100-nm silica data); LA0206MH831361.003 [DIRS 162428] (330-nm CML and 100-nm silica data); LA0206MH831361.004 [DIRS 162430] (330-nm CML and 100-nm silica data); LA0301AA831352.001 [DIRS 162433] (500-nm CML, 190-nm CML and natural colloids data); LA0303PR831361.001 [DIRS 163135] (Analysis of all laboratory rate constants).

Source: Schijven et al. 1999 [DIRS 162423] (MS-2 and PRD-1 rate constants from alluvium field test).

NOTE: CML, silica, and natural colloids are rate constants obtained from alluvium packed columns and Schijven MS-2 and Schijven PRD-1 are rate constants from the alluvium field test.

Figure 6-4. Colloid Filtration Rate Constants, $\mathrm{k}_{\mathrm{f}}$, as a Function of Mean Residence Time in Several Laboratory Experiments and a Field Study in Saturated Alluvium Material

\subsubsection{Colloid Retardation Factors in Alluvial Material}

As with the fractured volcanics, colloid retardation factors, $R_{c o l}$, can be determined from a RELAP fit and the detachment rate is calculated using Equation 6-3. Using the interpretive results from all of the tests represented in Figure 6-4, a cumulative probability distribution for $R_{c o l}$ can be generated. This distribution is shown in Table 6-3 and Figure 6-6 (log scale on $x$ axis). Table 6-3 contains three cumulative probability distributions. The first distribution consists of the best-fitting $R_{c o l}$ values obtained from RELAP (taken from the input DTNs listed in Figure 6-4). These values of retardation factors in the CDF can be applied on a log scale for TSPA purposes. The second distribution is a truncated version of this CDF in which all retardation factors less than eight are set equal to eight. This truncation was implemented for the same reasons that the $R_{c o l}$ distribution for fractured volcanics was truncated (see Section 6.4.3). The final distribution is the CDF for use by TSPA to simulate radionuclide retardation for the radionuclides that sorb irreversibly to colloids, which captures the same trends as the truncated CDF while using fewer points. 


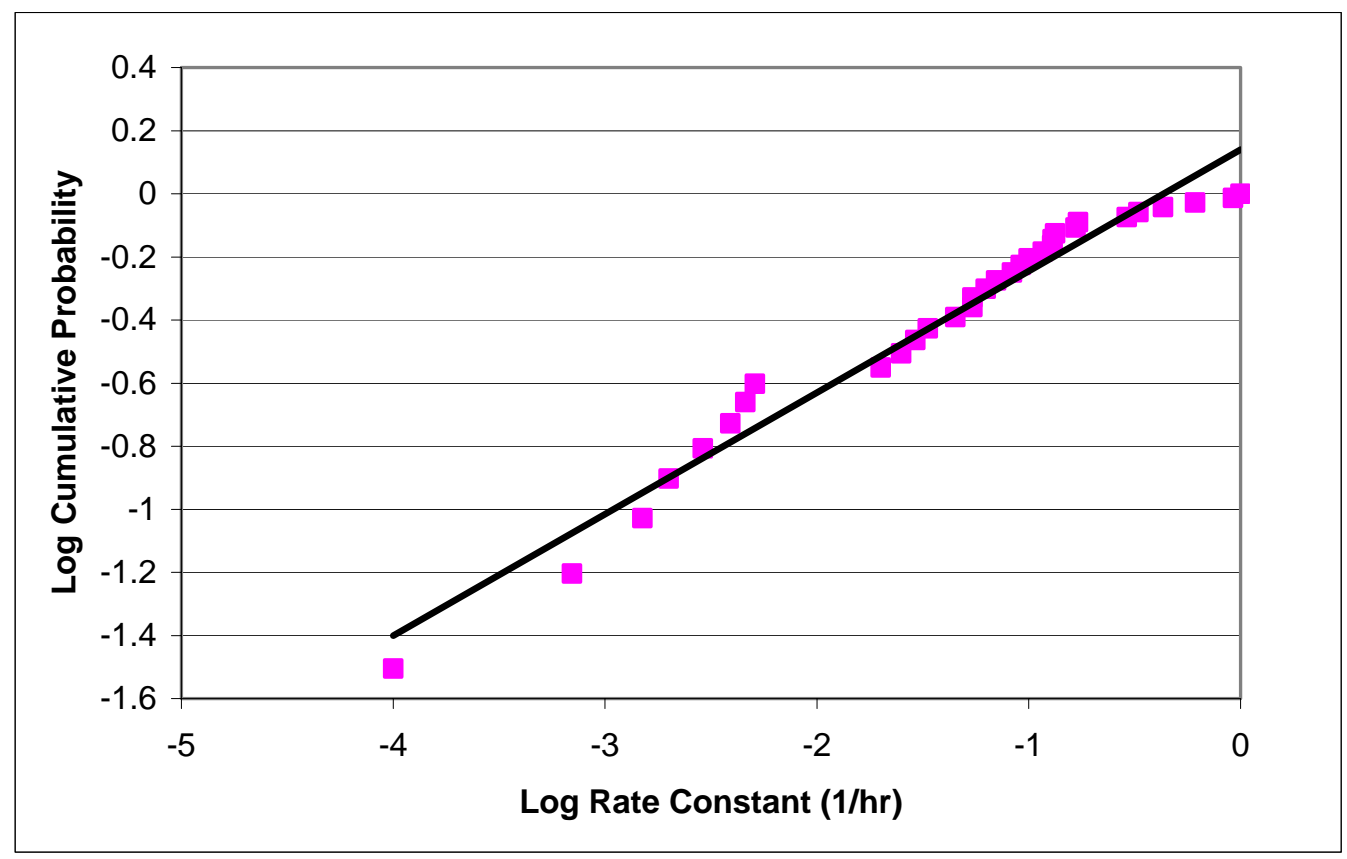

Source: Notebook SN-LANL-SCI-297-V1 (Viswanathan 2003 [DIRS 163757], p. 20).

Figure 6-5. Cumulative Probability Distribution of Log Colloid Filtration Rate Constants in the Alluvium

Note that the filtration rate constants and retardation factors from Schijven et al. (1999 [DIRS 162423], Table 3, p. 1107) are weighted the same as all lab experimental data when generating uncertainty distributions of filtration rate constants and retardation factors in the alluvium. Although the Schijven et al. data were obtained at field scales, the fact that the flow system and aquifer materials are different from Yucca Mountain justifies assigning no greater weight to these data than to data obtained from lab experiments using site-specific materials. Note that, as with the retardation factor distribution for the fractured volcanics, the alluvium retardation factor distribution is truncated at the lower end so that it has an effective minimum greater than one; in this case, the minimum is eight. The rationale for this minimum is the same as for the volcanics: that is, the colloids moving with smaller retardation factors are accounted for using a distribution of filtration rate constants, with unretarded colloids having the slowest rates; all colloids that become filtered experience some degree of retardation in the system as a result of filtration and detachment processes. 
Table 6-3. Retardation Factor, $R_{c o l}$, Cumulative Probability Distributions for Alluvium

\begin{tabular}{|c|c|c|c|c|c|}
\hline \multicolumn{2}{|c|}{ Raw Data CDF } & \multicolumn{2}{|c|}{ Truncated CDF } & \multicolumn{2}{|c|}{ CDF for TSPA } \\
\hline $\begin{array}{c}\text { Retardation } \\
\text { Factor } \\
\end{array}$ & Probability & $\begin{array}{c}\text { Retardation } \\
\text { Factor }\end{array}$ & Probability & $\begin{array}{c}\text { Retardation } \\
\text { Factor }\end{array}$ & Probability \\
\hline 1 & 3.13E-02 & 8 & 3.13E-02 & 8.00 & 0 \\
\hline 1 & $6.25 E-02$ & 8 & $6.25 \mathrm{E}-02$ & 8.02 & 0.331 \\
\hline 1 & 9.38E-02 & 8 & $9.38 \mathrm{E}-02$ & 33.96 & 0.5 \\
\hline 1.5 & $1.25 \mathrm{E}-01$ & 8 & 1.25E-01 & 5188.00 & 1 \\
\hline 1.5 & 1.56E-01 & 8 & 1.56E-01 & & \\
\hline 1.5 & 1.88E-01 & 8 & 1.88E-01 & & \\
\hline 1.5 & 2.19E-01 & 8 & 2.19E-01 & & \\
\hline 1.5 & $2.50 \mathrm{E}-01$ & 8 & 2.50E-01 & & \\
\hline 4.5 & 2.81E-01 & 8 & 2.81E-01 & & \\
\hline 8 & 3.13E-01 & 8 & 3.13E-01 & & \\
\hline 14 & 3.44E-01 & 14 & 3.44E-01 & & \\
\hline 16 & 3.75E-01 & 16 & 3.75E-01 & & \\
\hline 17 & 4.06E-01 & 17 & 4.06E-01 & & \\
\hline 20 & 4.38E-01 & 20 & 4.38E-01 & & \\
\hline 26 & 4.69E-01 & 26 & 4.69E-01 & & \\
\hline 34 & 5.00E-01 & 34 & 5.00E-01 & & \\
\hline 35 & 5.31E-01 & 35 & 5.31E-01 & & \\
\hline 55 & 5.63E-01 & 55 & 5.63E-01 & & \\
\hline 140 & 5.94E-01 & 140 & 5.94E-01 & & \\
\hline 160 & $6.25 \mathrm{E}-01$ & 160 & $6.25 \mathrm{E}-01$ & & \\
\hline 205.8824 & 6.56E-01 & 205.8824 & 6.56E-01 & & \\
\hline 266.6667 & 6.88E-01 & 266.6667 & $6.88 \mathrm{E}-01$ & & \\
\hline 600 & 7.19E-01 & 600 & 7.19E-01 & & \\
\hline 619.0476 & 7.50E-01 & 619.0476 & 7.50E-01 & & \\
\hline 1076.923 & 7.81E-01 & 1076.923 & 7.81E-01 & & \\
\hline 1111.111 & 8.13E-01 & 1111.111 & 8.13E-01 & & \\
\hline 1222.222 & 8.44E-01 & 1222.222 & 8.44E-01 & & \\
\hline 2000 & 8.75E-01 & 2000 & 8.75E-01 & & \\
\hline 2500 & 9.06E-01 & 2500 & 9.06E-01 & & \\
\hline 2818.182 & 9.38E-01 & 2818.182 & 9.38E-01 & & \\
\hline 4712.644 & 9.69E-01 & 4712.644 & 9.69E-01 & & \\
\hline 5194.805 & $1.00 \mathrm{E}+00$ & 5194.805 & $1.00 \mathrm{E}+00$ & & \\
\hline
\end{tabular}

Output DTN: LA0303HV831352.004. 


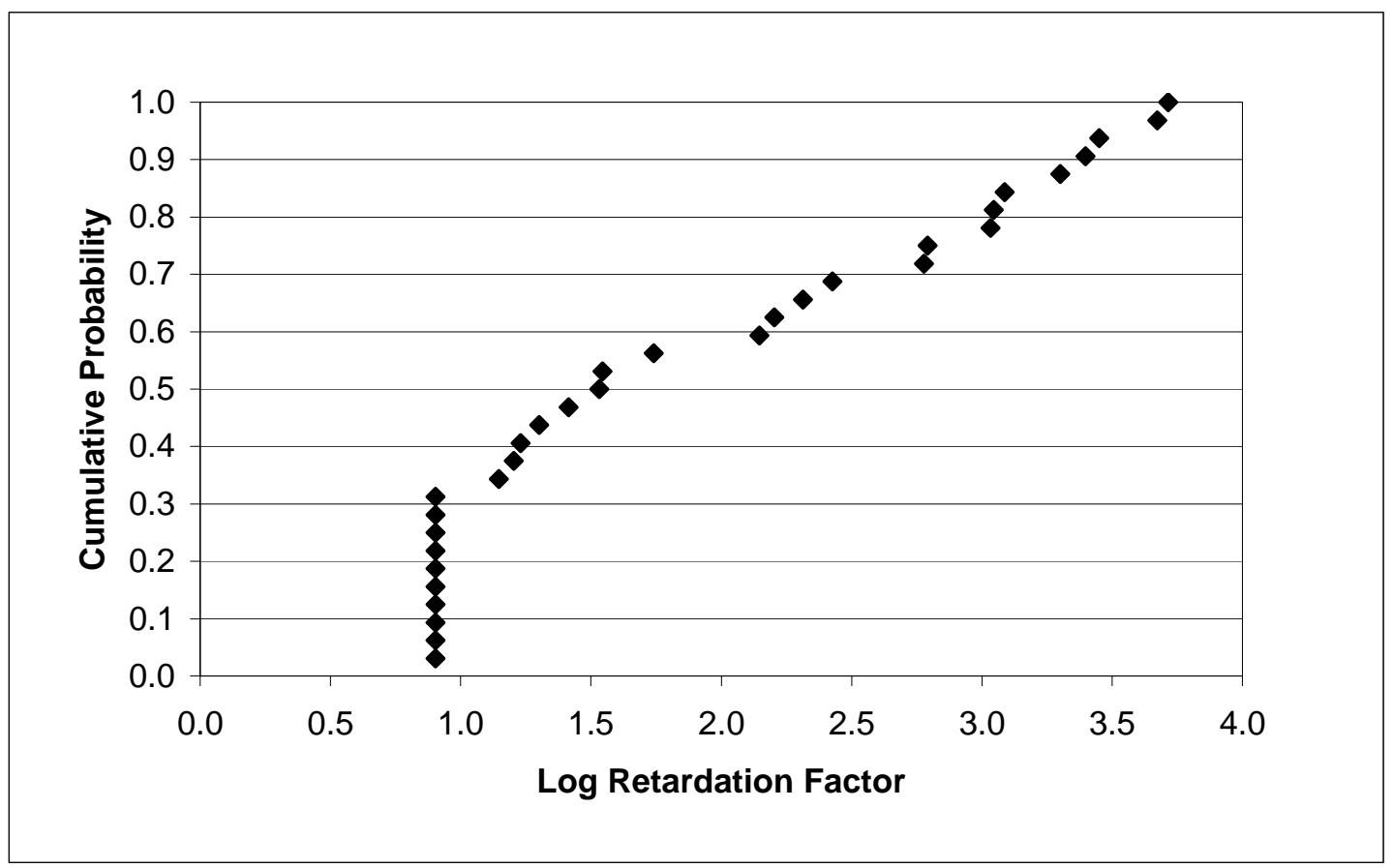

Source: Notebook SN-LANL-SCI-297-V1 (Viswanathan 2003 [DIRS 163757], p. 24).

Figure 6-6. Truncated Cumulative Probability Distribution of Log Retardation Factors in Alluvium

\subsection{FRACTION OF COLLOIDS TRANSPORTING WITH NO RETARDATION}

The majority of the colloids transport assuming reversible filtration given by the $R_{\text {col }}$ distributions developed in Sections 6.4.3 and 6.5.3. However, as mentioned in Section 6.3, several field observations have suggested that a small percentage of colloids transport with essentially no retardation in groundwater, whereas the majority undergo either reversible or irreversible filtration, which can be described by a retardation factor, $R_{c o l}$. In this section, the cumulative probability distribution of colloids that travel with no retardation is developed.

The attachment rate constant can be used to determine the fraction, colfrac, of the colloids that transport with no retardation. Specifically, colloids for which the reciprocal of the attachment rate constant is smaller than the transport time through the system will transport with no retardation. To determine the fraction of colloids that travel with no retardation, the critical rate constant, $k_{\text {filt,crit }}$ is calculated. This critical rate constant is simply one over the transport time through the system. The fraction of colloids that filter with this attachment rate constant is obtained from the cumulative probability distribution of attachment constants (Figure 6-2 for the fractured volcanics and Figure 6-5 for the alluvium). For the distribution of unretarded colloid fractions, water transport times through the UZ (which will include the effects of hydrologic fracture-matrix interactions), the SZ volcanics (in fractures only), and the SZ alluvium are added to obtain a combined transport time from the waste package to the accessible environment. Because the distributions for the fraction unretarded are so close for the volcanics and the alluvium, the volcanic and alluvium data are combined into a single distribution, resulting in 
slightly higher fractions for a given transport time than if the volcanic and alluvium uncertainty distributions had been considered separately.

The TSPA model utilizes the fast fraction model in the following manner. Travel time is uncertain through both the UZ and SZ, and the fast fraction model is also uncertain. Therefore experimental evidence for this model does not warrant the use of a transport time distribution in TSPA. Instead, a conservative model is implemented. Uncertainty in the fraction of colloids that transport with no retardation is accommodated by using a conservative approach that assumes a combined transport time of 100 years in the unsaturated and saturated zone. This approach is conservative because it is expected that the combined transport time in the unsaturated zone and saturated zone will be more than 100 years - the median transit time in the saturated zone alone is expected to be longer than 100 years (BSC 2004 [DIRS 170042] Section 6.7.1). When combined with the unsaturated zone transit time, it is clear that the 100-year transport time is conservative for all but a few realizations. Table 6-4 and Figure 6-7 show the distribution of the fraction of colloids that travel with no retardation. For example, if the transport time is 100 years, the fraction of the total colloid mass transporting with no retardation would be $1.68 \times 10^{-3}$.

Table 6-4. Unretarded Fraction Cumulative Probability Distribution for the Fractured Volcanics and the Alluvium

\begin{tabular}{|c|c|}
\hline Travel Time (Years) & Unretarded Fraction, colfrac \\
\hline 1 & $1.10 \mathrm{E}-02$ \\
\hline 5 & $5.70 \mathrm{E}-03$ \\
\hline 10 & $4.30 \mathrm{E}-03$ \\
\hline 20 & $3.24 \mathrm{E}-03$ \\
\hline 30 & $2.74 \mathrm{E}-03$ \\
\hline 40 & $2.44 \mathrm{E}-03$ \\
\hline 50 & $2.23 \mathrm{E}-03$ \\
\hline 75 & $1.89 \mathrm{E}-03$ \\
\hline 100 & $1.68 \mathrm{E}-03$ \\
\hline 300 & $1.07 \mathrm{E}-03$ \\
\hline 600 & $8.08 \mathrm{E}-04$ \\
\hline 1000 & $6.56 \mathrm{E}-04$ \\
\hline 2000 & $4.94 \mathrm{E}-04$ \\
\hline 5000 & $3.40 \mathrm{E}-04$ \\
\hline 10,000 & $2.56 \mathrm{E}-04$ \\
\hline
\end{tabular}

Output DTN: LA0303HV831352.003. 


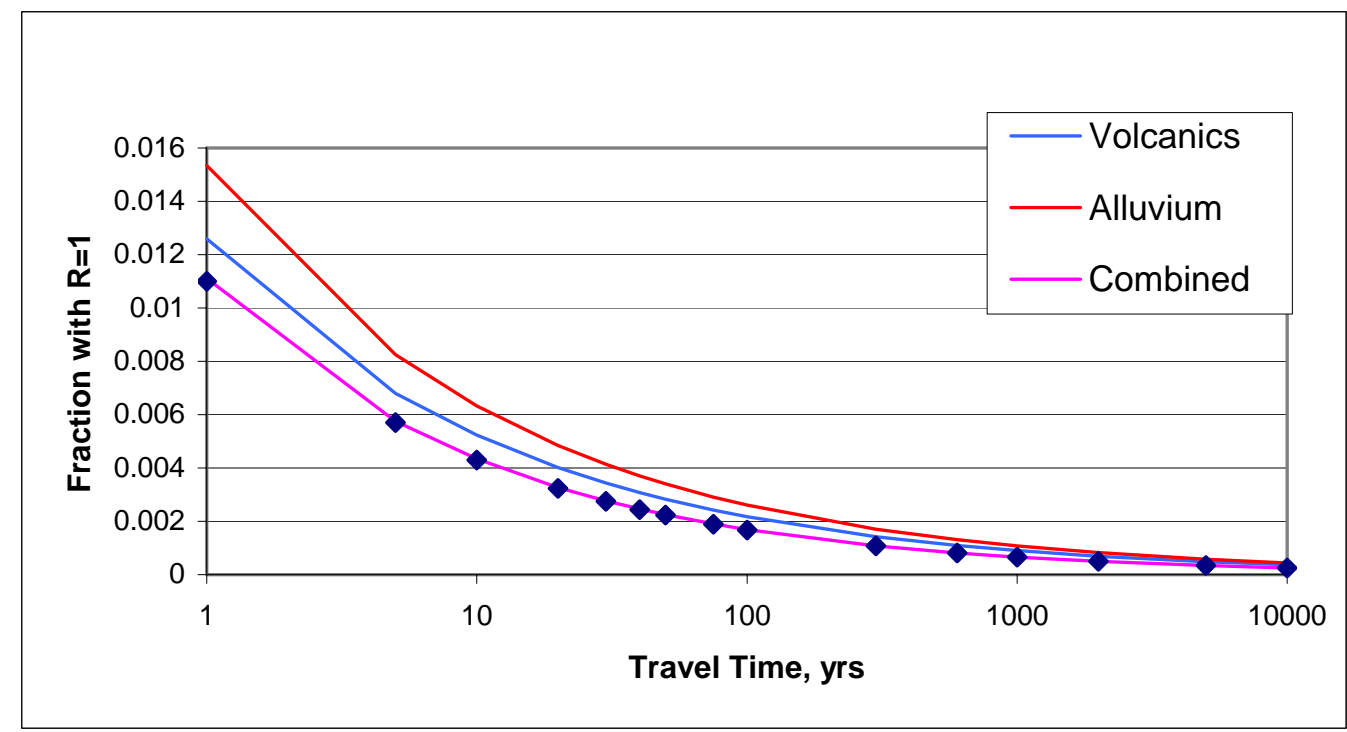

Source: Notebook SN-LANL-SCI-297-V1 (Viswanathan 2003 [DIRS 163757], p. 22).

Figure 6-7. Unretarded Fraction Cumulative Probability Distribution for the Fractured Volcanics, Alluvium, and the Combined Distribution of the Volcanics and Alluvium

\subsection{VALIDITY OF THE LOCAL EQUILIBRIUM ASSUMPTION FOR COLLOIDS THAT ARE RETARDED}

The majority fraction of colloids are retarded by the $R_{c o l}$ uncertainty distributions developed in this analysis. The validity of the local equilibrium assumption must be tested to justify the use of the $R_{c o l}$ distributions. Specifically, for Equation 6-3 to be valid, the local equilibrium assumption must hold. To evaluate the validity of this assumption, a simple analysis can be performed with nondimensional Damköhler numbers. The Damköhler number is simply the rate constant, $k(1 / \mathrm{hr})$, multiplied by a representative residence time, $\tau(\mathrm{hr}), D a=k \tau$. Bahr and Rubin demonstrate that the mass balance equation describing solute transport can be differentiated into an equilibrium and a kinetic component (Bahr and Rubin 1987 [DIRS 144539], p. 440, Equation 12). The smaller the kinetic component, the more accurate are the retardation factors based on the local equilibrium assumption. Note that the techniques utilized by Bahr and Rubin are commonly used in reactive transport systems to determine whether the local equilibrium assumption is valid (Bahr and Rubin 1987 [DIRS 144539]).

For evaluation of colloid behavior, Damköhler numbers, $D a_{\text {att }}$ and $D a_{\text {det }}$, can be computed for attachment and detachment of colloids, respectively, using $k_{\text {filt }}$ and $k_{\text {det }}$. The magnitude of the kinetic component is inversely proportional to $D a_{a t t}+D a_{d e t}$. Thus, the larger the sum of the two Damköhler numbers, the more appropriate the assumption of equilibrium. Bahr and Rubin (1987 [DIRS 144539]) found that equilibrium was well approximated when the sum of the two Damköhler numbers is greater than 100 and reasonably well estimated when the sum is greater than 10 ( Bahr and Rubin 1987 [DIRS 144539], p. 450). Valocchi had a similar result, although he used only the reverse rate (detachment rate for colloids) to compute a Damköhler number (Valocchi 1985 [144579], pp. 812 to 813, Figure 2). Bahr and Rubin point out that the kinetic term can only be completely separated when the sum of the two Damköhler numbers is used (Bahr and Rubin 1987 [DIRS 144539]). 
Bahr and Rubin caution that both Damköhler numbers, $D a_{a t t}+D a_{d e t}$, should be used to assess the kinetic term (Bahr and Rubin 1987 [DIRS 144539]). In this analysis only $D a_{a t t}$ is used, which should, therefore, be conservative. Another conservative aspect of this analysis is that there is no probability of a detachment rate constant of zero. In reality, it is very likely that some colloids will irreversibly attach.

To calculate Damköhler numbers for the fractured volcanics, the rate constants in Figure 6-2 are transformed to a Damköhler number distribution by multiplying the rate constants on the $x$-axis by an assumed transport time. We determine the fraction that has a Damköhler number greater than 100, which according to Valocchi is a good approximation of equilibrium conditions (Valocchi 1985 [DIRS 144579], p. 813, Figure 2). For a 100-year transport time, 96 percent of the colloids will have a Damköhler number greater than 100. For a 1000-year transport time, it will be over 98 percent; and for a 10-year transport time, it will be 94 percent. An analysis of the alluvium rate constants results in very similar results with an even greater percentage with Damköhler numbers greater than 100 . Thus, the vast majority of colloids that are not part of the unretarded fraction will transport in accordance with the local equilibrium assumption.

\subsection{USE OF POLYSTYRENE MICROSPHERES AS TRACER SURROGATES FOR INORGANIC GROUNDWATER COLLOIDS}

Many of the laboratory and field experiments used to develop the $R_{c o l}$ distributions in this analysis use CML microspheres to study colloid transport. This section describes the effectiveness of CML microspheres as analogs to inorganic groundwater colloids. CML microspheres were used as colloid tracers in the multiple-tracer tests in both the Bullfrog Tuff and the Prow Pass Tuff at the C-wells complex (BSC 2004 [DIRS 170010], Section 6). CML microspheres were also used in one of the three single-well tracer tests in the saturated alluvium at NC-EWDP-19D1 (BSC 2004 [DIRS 170025], Section 6.5. CML microspheres were selected as colloid tracers in these field tests because they are very monodisperse (i.e., they have a very narrow range of diameters) and they can be obtained with various fluorescent dyes incorporated into their polymer matrix, which allows them both to be detected at very low concentrations and to be discriminated from natural, nonfluorescing colloids using methods such as epifluorescent microscopy and flow cytometry. Flow cytometry has been used as the microsphere detection and quantification method for all field tracer tests in which microspheres have been used as tracers. This technique allows quantification at microsphere concentrations as low as $100 \mathrm{~mL}^{-1}$ in the presence of natural background colloid concentrations that are 2 to 4 orders of magnitude higher. These levels of detection and discrimination are currently not attainable using any other type of colloid tracer except perhaps viruses/bacteriophages (Bales et al. 1989 [DIRS 104333], pp. 2,063 to 2,064).

CML microspheres were chosen over other types of polystyrene latex microspheres as field colloid tracers for two reasons: 1) they have surface carboxyl groups that give them a negative surface charge at $\mathrm{pH}$ greater than about 5 and 2) they have relatively hydrophilic surfaces compared to other types of polystyrene microspheres (Wan and Wilson 1994 [DIRS 114430], p. 858, Table 1). These properties are consistent with those of natural inorganic groundwater colloids. The hydrophilic surfaces of CML microspheres are the result of their matrix being comprised of a copolymer of styrene and acrylic acid rather than pure styrene. This copolymer gives the CML microspheres a higher surface density of carboxyl groups and also a significantly 
higher degree of surface hydrophilicity than other types of polystyrene microspheres, including "carboxylated" spheres that consist of a pure polystyrene matrix. In addition to providing better consistency with surface characteristics of inorganic colloids, these properties result in greater resistance to flocculation and less attachment to negatively charged, hydrophilic rock surfaces. Fluorescent dyes are generally incorporated into the microspheres by swelling the spheres in an organic solvent containing the dye and then washing the spheres in an aqueous solution to expel the solvent and shrink them back to their original size. Dye molecules tend to remain behind in the spheres because of their affinity for the organic matrix. As discussed above, the dyes in the matrix provide the means for discrimination of tracer colloids from natural colloids and for quantification of tracer colloid concentrations at very low levels.

The CML microspheres used in Yucca Mountain field tracer tests have all been purchased from Interfacial Dynamics Corporation because the company uses a surfactant-free synthesis process that does not require microspheres to be cleaned (by dialysis or centrifugation) to remove trace levels of surfactant before they are used in tests. Small levels of surfactants can greatly affect microsphere surface characteristics, resulting in inconsistency and irreproducibility of their transport behavior.

CML microspheres have properties that make them a suitable choice among synthetic polystyrene microspheres as reasonable surrogates for inorganic colloids. It is clear that although the two types of colloids differ in density, shape, and specific surface chemistry, they both have negative surface charges (at groundwater $\mathrm{pHs}$ ) and hydrophilic surfaces.

To address the suitability of using CML microspheres as surrogates for natural inorganic colloids, a limited number of laboratory experiments were conducted in which the transport behavior of CML microspheres was compared with that of silica microspheres in both saturated volcanic-tuff fractures and saturated alluvium-packed columns. All tests were conducted using the same CML microspheres (330-nm diameter microspheres from Interfacial Dynamics Corporation dyed with a fluorescent yellow-green dye) and silica microspheres (100-nm diameter spheres from Nissan Chemical). Table 6-6 provides further information on the two colloid tracers. Silica microspheres were used for the comparison studies because previous testing had indicated that silica microspheres transport with much less attenuation through vertically oriented fractures than clay (montmorillonite) colloids (Kersting and Reimus 2003 [DIRS 162421], pp. 222 to 223, 226 to 227, 230 to 231, Appendix C, Figures C-1, C-2, C-5, C-6, $\mathrm{C}-9$, and C-10). Thus, if CML microspheres were shown to transport with less attenuation than silica microspheres, they would be expected to transport with far less attenuation than clay colloids.

The 330-nm CML microspheres were selected to be representative of microspheres with diameters ranging from about 250 to $500 \mathrm{~nm}$, which represents a practical size range that can be used in field tests (detection-limited at the small end and cost-limited at the large end). Microspheres at the upper end of this size range will settle about twice as fast and diffuse about one-third slower than 330-nm diameter microspheres, and microspheres at the lower end of this range will settle about half as fast and diffuse about one-fourth faster than 330-nm diameter microspheres. Thus, the CML microspheres ranging in size from 250 to $500 \mathrm{~nm}$ (diameter) will both settle slower and diffuse slower than 100-nm silica microspheres. These characteristics (slower settling and diffusion) are both desirable from the standpoint of reducing the number of 
colloid collisions with aquifer surfaces. Thus, if electrostatic or double-layer interactions between colloids and aquifer surfaces are similar for both types of microspheres (as suggested by their similar zeta potentials, Table 6-5), the CML microspheres would be expected to transport with less attenuation relative to the silica microspheres.

In general, colloid stability may play a role in the behavior of colloid transport in the colloid transport tests presented. However, in all these microsphere tests, there was no evidence that the microspheres aggregated either during or after the tests (while sitting in sample containers, in some cases, for many weeks) (Reimus 2000 [165125]). Even the tracer injection solutions that had high concentrations of both microspheres and solutes, which would tend to destabilize colloids, showed no appreciable aggregation. Aggregation can be readily detected by flow cytometry, the analytical method used to quantify microsphere concentrations. Aggregation cannot be as easily ruled out for inorganic colloids used in lab experiments, but it was clearly not an issue for the natural colloids in the alluvium columns because they had recoveries of nearly 100 percent in all cases.

\subsubsection{Comparison of CML and Silica Microsphere Transport in Fractured Volcanic Rocks}

Testing in fractured volcanic rock was conducted in two different fractured cores from Pahute Mesa at the Nevada Test Site, with the majority of the testing being done in a fractured lava. (At the time of the testing, fractured cores from the SZ near Yucca Mountain were not readily available.) Testing in the lava core was conducted at several different flow rates/residence times.

Details of the test procedures and the test results associated with the fractured volcanic core experiments are contained in Anghel (2001 [DIRS 158639], Chapters 2 and 4) and summarized here. Tables 6-6 through 6-8 provide information on the fractured cores, and Table 6-9 gives the major ion chemistry of the U-20WW water used in the fractured core experiments. Besides their differences in surface characteristics, the silica microspheres should have had greater diffusivity than the CML microspheres by a factor of about 3.3 because of their smaller size, and they also should have settled about 2.75 times faster than the CML microspheres because of their greater density. The two cores differed appreciably in their matrix porosities, with one having a relatively high porosity $(0.369)$ and the other having a very low one $(0.014)$. One experiment was conducted in the higher porosity core (ER-20-6 \#1, $2406 \mathrm{ft}$ below surface). Four experiments were conducted in the lower porosity core (PM-2, $7032 \mathrm{ft}$ below surface). Test details for each experiment are provided in Table 6-10. In addition to the colloid tracers, each experiment also included iodide ion as a conservative (nonsorbing) solute tracer. The responses of the colloid tracers could thus be compared to that of a conservative solute to allow better quantification of any colloid retardation or early arrival. All tracers were injected simultaneously so that they would have exactly the same injection input function. The iodide was analyzed by ion-selective electrode, the silica microspheres by high-sensitivity liquid in situ particle spectrometery (HSLIS-S50, Particle Measuring Systems, Inc.), and the fluorescent microspheres by fluorometry (SPEX Fluorolog-2). 
Table 6-5. Properties of CML and Silica Microspheres Used in Experiments

\begin{tabular}{|l|c|c|}
\hline \multicolumn{1}{|c|}{ Property } & CML Microspheres & Silica Microspheres \\
\hline Particle Diameter $(\mathrm{nm})$ & $330 \pm 11$ & 100 \\
\hline \% Solids $(\mathrm{g} / 100 \mathrm{~g})^{\mathrm{a}}$ & $2 \pm 0.1$ & 40.7 \\
\hline Stock Conc. $(\mathrm{number} / \mathrm{mL})^{\mathrm{a}}$ & $1 \times 10^{12}$ & $3.8 \times 10^{14}$ \\
\hline Density $\left(\mathrm{g} / \mathrm{cm}^{3}\right)$ & 1.055 & 2.65 \\
\hline Dye Excitation/Emission Wavelengths (nm) & $505 / 515$ & No Dye \\
\hline Diffusion Coefficient $\left(\mathrm{cm}^{2} / \mathrm{s}\right)^{\mathrm{b}}$ & $1.34 \times 10^{-8}$ & $4.43 \times 10^{-8}$ \\
\hline Specific Surface Area $\left(\mathrm{cm}^{2} / \mathrm{g}\right)$ & $1.7 \times 10^{5}$ & $2.3 \times 10^{5}$ \\
\hline Surface Charge $(\mathrm{meq} / \mathrm{g})^{\mathrm{c}}$ & 0.08 & $\mathrm{NM}$ \\
\hline Zeta Potential in U-20WW Water $(\mathrm{mV})^{\mathrm{d}}$ & $-42.7 \pm 9.1$ & $-41.2 \pm 4.1$ \\
\hline Zeta Potential in NC-EWDP-19D1 Water (mV) & $\mathrm{NM}$ & $-45.15 \pm 2.9$ \\
\hline
\end{tabular}

Source: All information comes from manufacturers' certificates of analyses or was calculated as described below except for zeta potentials. Zeta potentials are reported by Anghel (2001 [DIRS 158639], Chapter 2).

${ }^{a}$ Manufacturer's stock solution in deionized water; solutions used in experiments were diluted in groundwater to several orders of magnitude below these concentrations.

${ }^{\mathrm{b}}$ Calculated using the Stokes-Einstein equation, $D=k T /(6 \pi \mu R)$, where $k=$ Boltzmann's constant $\left(1.38 \times 10^{-16} \mathrm{ergs} / \mathrm{K}\right)$, $T=$ temperature $\left({ }^{\circ} \mathrm{K}\right), \mu=$ fluid viscosity $(\mathrm{g} / \mathrm{cm}-\mathrm{s})$, and $R=$ colloid radius $(\mathrm{cm})$. Calculations assume water at $25^{\circ} \mathrm{C}$ $\left(298^{\circ} \mathrm{K}\right)$.

${ }^{\mathrm{c}}$ Value reported by the manufacturer (Interfacial Dynamics Corp.).

${ }^{\mathrm{d}}$ The zeta potential is the potential measured at the "surface of shear" near the colloid surface in solution (Hiemenz 1986 [DIRS 117358], p. 745). The surface of shear occurs where ions transition from being immobile to being mobile relative to the colloid surface when the colloid moves relative to the surrounding solution. The zeta potential is generally considered to be the best experimental measure of the strength of electrostatic interactions between colloids or between colloids and surfaces in solution.

$\mathrm{NM}=$ not measured

Table 6-6. Properties of the Fractured Cores Used in the Colloid Transport Experiments: Physical Characteristics

\begin{tabular}{|l|c|c|c|}
\hline $\begin{array}{c}\text { Fracture (Depth below } \\
\text { Land Surface) }\end{array}$ & Fracture Length $\mathbf{( c m )}$ & Fracture Width $(\mathbf{c m})$ & Matrix Porosity \\
\hline PM-2 (7032 ft) & 14 & 9 & 0.014 \\
\hline ER-20-6\#1 (2406 ft) & 23.8 & 12.7 & 0.369 \\
\hline
\end{tabular}

Source: Notebook SN-LANL-SCl-280-V1 (Reimus 2003 [DIRS 163760], Attachment E, accessible in MOL.20030313.0036, Package Number MOY-030228-01-08). 
Table 6-7. Properties of the Fractured Cores Used in the Colloid Transport Experiments: X-Ray Diffraction Results (wt \%)

\begin{tabular}{|l|c|c|c|c|c|c|c|c|c|c|c|c|}
\hline Fracture & $\begin{array}{c}\text { Smec- } \\
\text { tite }\end{array}$ & $\begin{array}{c}\text { Zeo- } \\
\text { lite }\end{array}$ & Opal & Quartz & $\begin{array}{c}\text { K- } \\
\text { Spar }\end{array}$ & $\begin{array}{c}\text { Plagio- } \\
\text { clase }\end{array}$ & $\begin{array}{c}\text { Hema- } \\
\text { tite }\end{array}$ & $\begin{array}{c}\text { Bio- } \\
\text { tite }\end{array}$ & Calcite & Chlorite & $\begin{array}{c}\text { Epidotel } \\
\text { Clinozoisite }\end{array}$ & Total \\
\hline $\begin{array}{l}\text { PM-2 } \\
7032 \mathrm{ft}\end{array}$ & - & - & - & 22.1 & 18.8 & 38.3 & - & 2.0 & 1.2 & 6.7 & 9.6 & 98.7 \\
\hline $\begin{array}{l}\text { ER-20-6\#1 } \\
2406 \mathrm{ft}\end{array}$ & $\mathbf{1 . 7}$ & $\mathbf{8 3 . 4}$ & $\mathbf{2 7 . 3}$ & $\mathbf{0 . 9}$ & 4.8 & 3.3 & - & 1.5 & - & - & - & 102.7 \\
\hline
\end{tabular}

Source: Notebook SN-LANL-SCI-280-V1 (Reimus 2003 [DIRS 163760], Attachment E, accessible in MOL.20030313.0036, Package \# MOY-030228-01-08).

$-=$ not detected

Table 6-8. Properties of the Fractured Cores Used in the Colloid Transport Experiments: Lithologic Descriptions

\begin{tabular}{|c|l|}
\hline Fracture & \multicolumn{1}{c|}{ Description } \\
\hline $\mathrm{PM}-2$ & Devitrified intermediate composition lava from the andesite of Mt. Helen of the volcanics of \\
$7032 \mathrm{ft}$ & Quartz Mountain \\
\hline $\begin{array}{c}\text { ER-20-6\#1 } \\
2406 \mathrm{ft}\end{array}$ & Highly zeolitic, poor to moderately welded vitric, lithic tuff from the Calico Hills Formation \\
\hline
\end{tabular}

Source: Anghel 2001 [DIRS 158639], Chapter 2.

Table 6-9. Chemical Composition of U-20WW Groundwater

\begin{tabular}{|c|c|}
\hline Constituent & Concentration (mg/L) \\
\hline $\mathrm{Ca}^{2+}$ & $7.18 \pm 0.05$ \\
\hline $\mathrm{K}^{+}$ & $1.3 \pm 0.1$ \\
\hline $\mathrm{Na}^{+}$ & $60 \pm 0.3$ \\
\hline $\mathrm{SiO}_{2}$ & 46.9 \\
\hline $\mathrm{Cl}^{-}$ & $11.6 \pm 0$ \\
\hline $\mathrm{F}^{-}$ & $2.6 \pm 0$ \\
\hline $\mathrm{HCO}_{3}{ }^{-}$ & 110 \\
\hline $\mathrm{SO}_{4}{ }^{2-}$ & 32 \\
\hline $\mathrm{PH}^{2}$ & 7.96 \\
\hline Specific Conductance $(\mu \mathrm{S} / \mathrm{cm})$ & 296 \\
\hline TDS $(\mathrm{mg} / \mathrm{L})$ & 273.8 \\
\hline Ionic Strength $(\mathrm{mg} / \mathrm{L})$ & $\sim 0.0035$ \\
\hline
\end{tabular}

Source: Notebook SN-LANL-SCI-280-V1 (Reimus 2003 [DIRS 163760],

Attachment E, accessible in MOL.20030313.0036, Package

Number MOY-030228-01-08).

TDS=total dissolved solids 
Table 6-10. Summary of Experimental Conditions in the Fractured Core Tests

\begin{tabular}{|c|c|c|}
\hline \multicolumn{3}{|l|}{ Core ER-20-6\#1, $2406 \mathrm{ft}$} \\
\hline Measurement & \multicolumn{2}{|l|}{ Test Detail } \\
\hline Flow Rate $(\mathrm{mL} / \mathrm{hr})$ & \multicolumn{2}{|l|}{4.96} \\
\hline Fracture Orientation & \multicolumn{2}{|l|}{ Vertical } \\
\hline Injection Duration (hr) & \multicolumn{2}{|l|}{10.0} \\
\hline Injection Concentration* & \multicolumn{2}{|c|}{$\begin{array}{l}127 \mathrm{mg} / \mathrm{L}\left(\mathrm{I}^{-}\right) \\
4.22 \times 10^{7} \mathrm{~mL}^{-1}(0.33-\mu \mathrm{m} \text { CML microspheres }) \\
5.2 \times 10^{10} \mathrm{~mL}^{-1}(0.1-\mu \mathrm{m} \text { silica microspheres })\end{array}$} \\
\hline $\begin{array}{l}\text { Tracer Recoveries } \\
\text { (Fractional) }\end{array}$ & \multicolumn{2}{|l|}{$\begin{array}{l}0.85\left(\mathrm{I}^{\circ}\right) \\
0.63 \text { (CML microspheres) } \\
0.72 \text { (silica microspheres) }\end{array}$} \\
\hline \multicolumn{3}{|l|}{ Core PM-2, $7032 \mathrm{ft}$} \\
\hline Measurement & Experiment No. 1 Test Detail & Experiment No. 2 Test Detail \\
\hline Flow Rate (mL/hr) & 10.02 & 2.5 \\
\hline Fracture Orientation & Vertical & Vertical \\
\hline Injection Duration (hr) & 3.3 & 13.2 \\
\hline Injection Concentration* & $\begin{array}{l}127 \mathrm{mg} / \mathrm{L}\left(\mathrm{I}^{-}\right) \\
1.6 \times 10^{7} \mathrm{~mL}^{-1} \\
(0.33-\mu \mathrm{m} \mathrm{CML} \text { microspheres }) \\
6.9 \times 10^{10} \mathrm{~mL}^{-1}(0.1-\mu \mathrm{m} \text { silica } \\
\text { microspheres })\end{array}$ & $\begin{array}{l}127 \mathrm{mg} / \mathrm{L}\left(\mathrm{I}^{-}\right) \\
1.9 \times 10^{7} \mathrm{~mL}^{-1} \\
(0.33-\mu \mathrm{m} \mathrm{CML} \text { microspheres }) \\
7.9 \times 10^{10} \mathrm{~mL}^{-1}(0.1-\mu \mathrm{m} \text { silica } \\
\text { microspheres })\end{array}$ \\
\hline $\begin{array}{l}\text { Tracer Recoveries } \\
\text { (Fractional) }\end{array}$ & $\begin{array}{l}1.09\left(\mathrm{I}^{-}\right) \\
1.09 \text { (CML microspheres) } \\
1.06 \text { (silica microspheres) }\end{array}$ & $\begin{array}{l}1.06\left(\mathrm{I}^{\circ}\right) \\
0.89 \text { (CML microspheres) } \\
0.88 \text { (silica microspheres) }\end{array}$ \\
\hline Measurement & Experiment No. 3 Test Detail & Experiment No. 4 Test Detail \\
\hline Flow Rate (mL/hr) & 0.58 & 0.57 \\
\hline Fracture Orientation & Vertical & Horizontal \\
\hline Injection Duration (hr) & 56 & 56 \\
\hline Injection Concentration* & 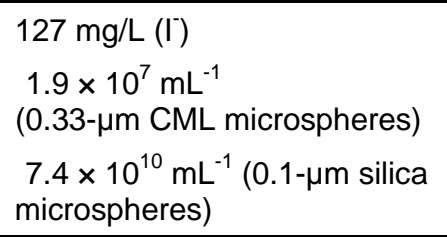 & $\begin{array}{l}127 \mathrm{mg} / \mathrm{L}\left(\mathrm{I}^{-}\right) \\
1.7 \times 10^{7} \mathrm{~mL}^{-1} \\
(0.33-\mu \mathrm{m} \mathrm{CML} \text { microspheres }) \\
7.5 \times 10^{10} \mathrm{~mL}^{-1}(0.1-\mu \mathrm{m} \text { silica } \\
\text { microspheres })\end{array}$ \\
\hline $\begin{array}{l}\text { Tracer Recoveries } \\
\text { (Fractional) }\end{array}$ & $\begin{array}{l}0.96\left(\mathrm{I}^{-}\right) \\
0.77 \text { (CML microspheres) } \\
0.60 \text { (Silica microspheres) }\end{array}$ & $\begin{array}{l}0.93\left(\mathrm{I}^{\prime}\right) \\
0.77 \text { (CML microspheres) } \\
0.24 \text { (Silica microspheres) }\end{array}$ \\
\hline
\end{tabular}

Source: Notebook SN-LANL-SCl-280-V1 (Reimus 2003 [163760], Attachment E, accessible in MOL.20030313.0036, Package Number MOY-030228-01-08).

${ }^{*}$ Calculated concentrations for microspheres are as much as 20-30 percent of error. However, the normalized concentrations should be accurate to within 5 percent. 
Figures 6-8 through 6-12 show the responses of each of the tracers in each of the five fractured core experiments. It is clear that at higher flow rates and shorter residence times, the CML microspheres and the silica microspheres transported almost identically in vertically oriented fractures, with minimal attenuation of either microsphere. However, both microspheres became more attenuated at the lower flow rates (approximately $0.6 \mathrm{~mL} / \mathrm{hr}$ ), with the CML microspheres being consistently less attenuated than the silica microspheres. Figures 6-8 through 6-12 seem to support little retardation for colloids compared to iodide. However, the data collectively suggest that it is small filtration rate constants, not small retardation factors, that are responsible for the unretarded transport behavior of colloids in some of the shorter time-scale experiments. It is our interpretation that the filtration rates are too slow for significant filtration to occur in some of the short time-scale experiments because more colloid filtration is typically observed in tests with longer time scales. The retardation factor, which is more relevant for field-scale transport predictions where time scales are large, is proportional to the filtration rate constant divided by the detachment rate constant, so it can be quite large even when the rate constants are small. It should also be noted that the laboratory experiments were carried out long enough to observe and quantify differences in filtration rate constants, but they were not carried out long enough to obtain well-constrained estimates of detachment rate constants and hence colloid retardation factors. Thus, the comparison of retardation factors of CML and silica microspheres is more uncertain than the comparison of filtration rate constants.

It is also apparent from Figures 6-11 and 6-12 that the silica microspheres were more attenuated in the horizontal orientation of the low-porosity fracture than in the vertical orientation at the same flow rate. The reason for different behavior between the horizontal and vertical cores is that the vertical orientation of the core leads to less resistance to downward water flow through the column. In this case, a horizontal orientation means that the fractured core was oriented such that the fracture surfaces were parallel to the lab bench top, whereas a vertical orientation means that the core was oriented so that the fracture surfaces were perpendicular to the lab bench top.

Quantitative interpretation of the tests in the lower-porosity fracture were carried out by Anghel using the RELAP computer code (Anghel 2001 [DIRS 158639], Chapter 4). The interpretive method is described in detail in Section 6.4.1. The resulting fitted parameter values are listed in Table 6-11. The single test in the higher-porosity fracture was only qualitatively interpreted because a single test at a constant flow rate does not allow unambiguous estimation of solute or colloid transport parameters. However, it is clear from Figure 6-8 that there was no significant difference in the transport of the two colloid tracers in this fracture. Also, the iodide appeared to experience a significant amount of matrix diffusion in this fracture based on its attenuated peak normalized concentration relative to the colloids and its extended tailing behavior. Microsphere recoveries in this fracture suggested a colloid-filtration rate constant of approximately $0.2 \mathrm{hr}^{-1}$. 


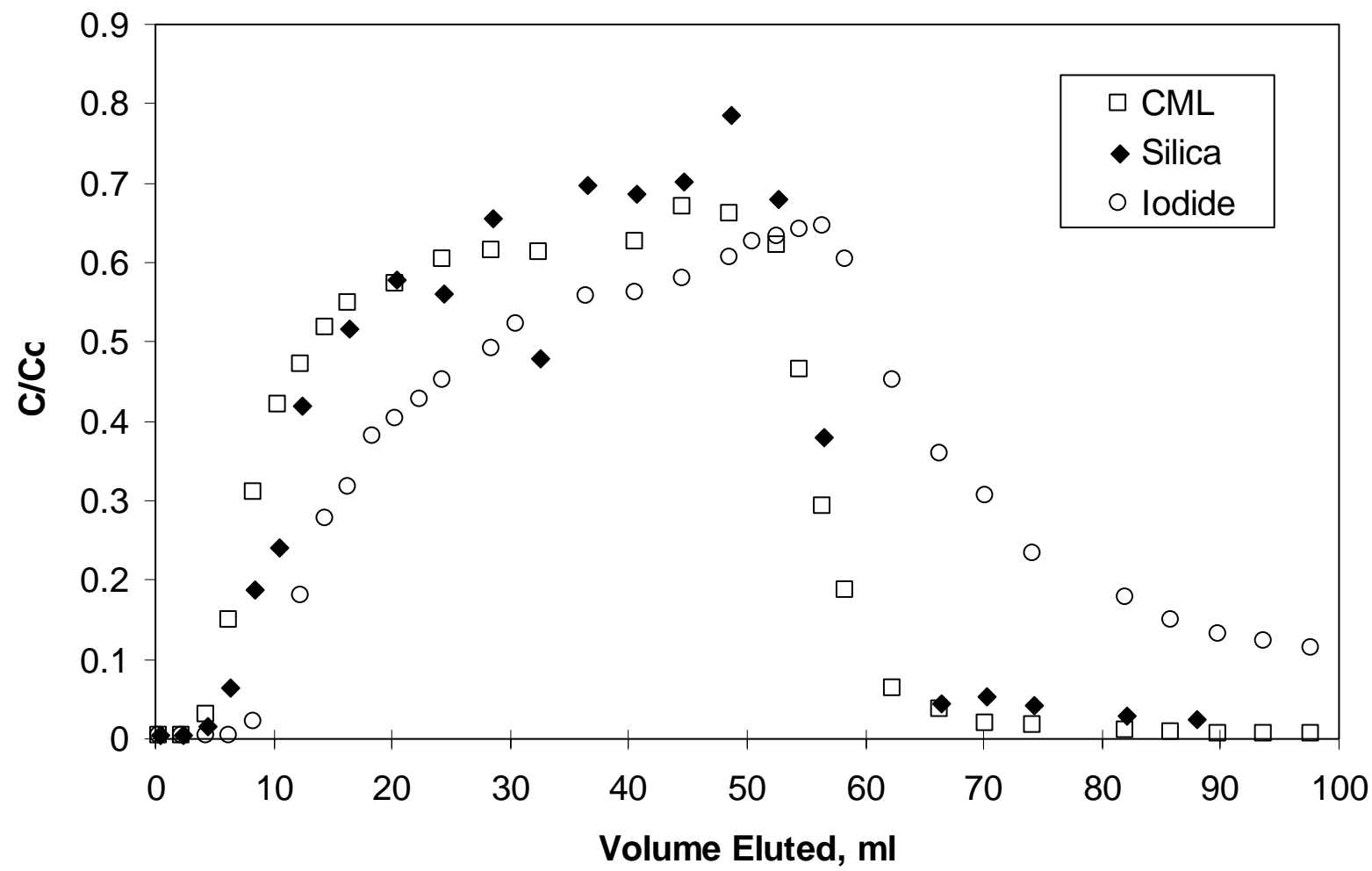

Source: DTN: LA0301PR831352.001 [DIRS 162434].

NOTE: The flow rate was $\sim 5 \mathrm{~mL} / \mathrm{hr}$, and the tracer injection pulse was $\sim 50 \mathrm{~mL}$. Normalized concentrations of silica less than about 0.03 in this figure are subject to error because background colloid concentrations begin to approach silica concentrations at these levels.

Figure 6-8. Normalized Concentrations of 330-nm Diameter CML Microspheres, 100-nm Diameter Silica Microspheres, and lodide in Vertically Oriented Fractured Core from ER-20-6\#1 at $2406 \mathrm{ft}$ 


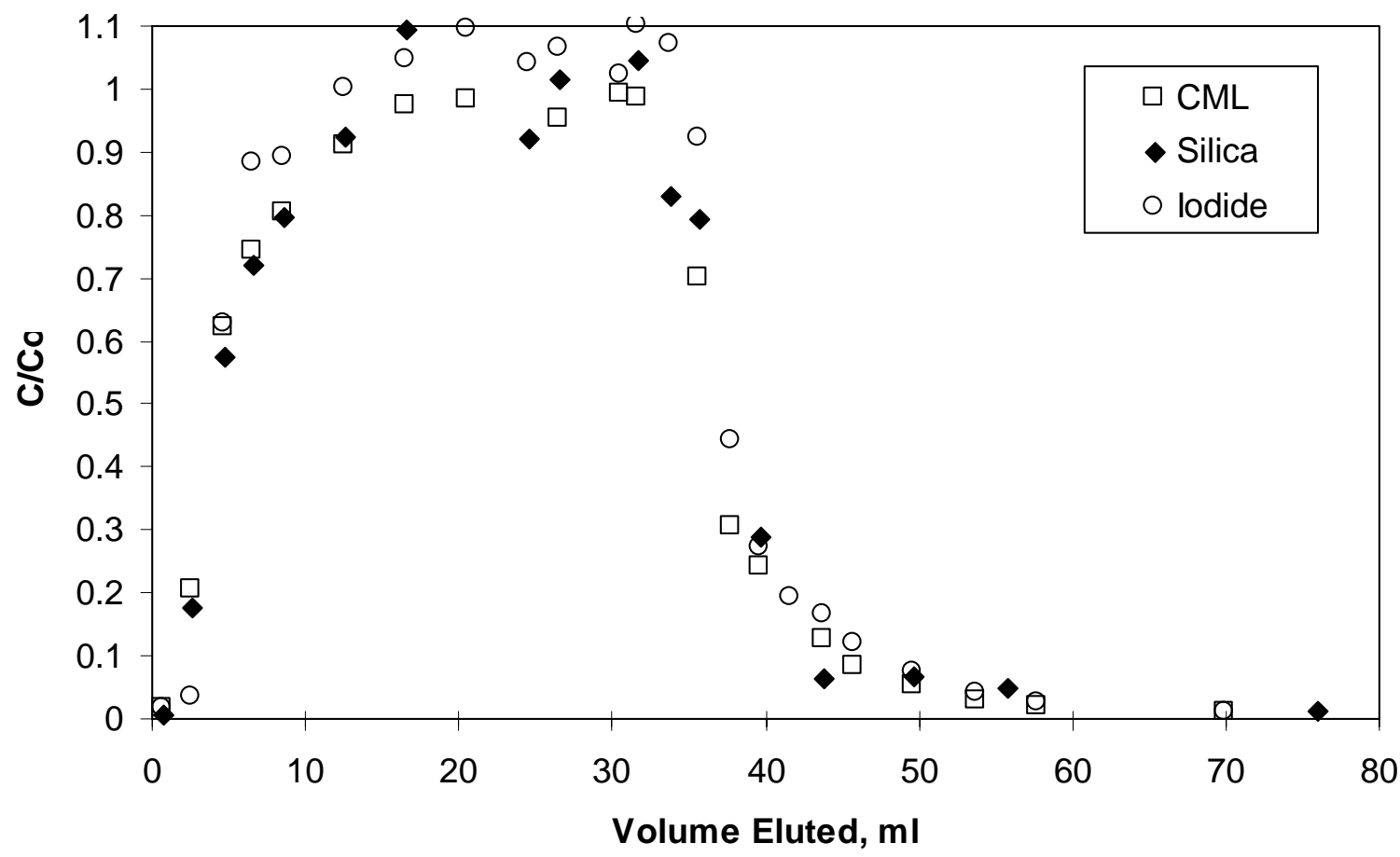

Source: DTN: LA0301PR831352.001 [DIRS 162434].

NOTE: The flow rate was $\sim 10 \mathrm{~mL} / \mathrm{hr}$, with a mean tracer residence time of $\sim 0.6 \mathrm{hr}$. The tracer injection pulse was $\sim 33 \mathrm{~mL}$. Normalized concentrations of silica less than about 0.03 in this figure are subject to error because background colloid concentrations begin to approach silica concentrations at these levels.

Figure 6-9. Normalized Concentrations of 330-nm Diameter CML Microspheres, 100-nm Diameter Silica Microspheres, and lodide in Vertically Oriented Fractured Core from PM-2 at $7032 \mathrm{ft}$ at $10 \mathrm{~mL} / \mathrm{hr}$ 


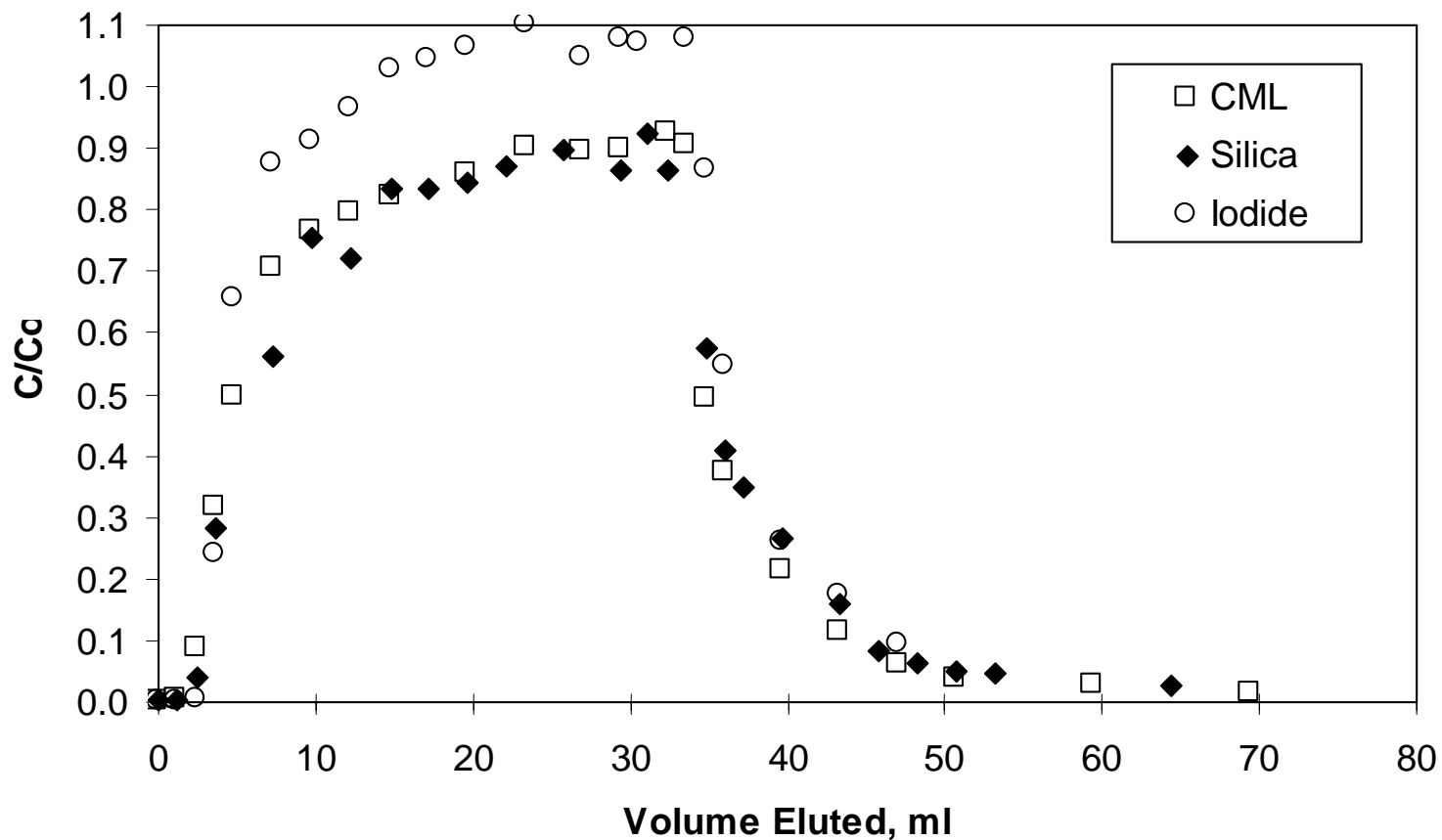

Source: DTN: LA0301PR831352.001 [DIRS 162434].

NOTE: The flow rate was $\sim 2.5 \mathrm{~mL} / \mathrm{hr}$, with a mean tracer residence time of $\sim 2.4 \mathrm{hr}$. The tracer injection pulse was $\sim 33 \mathrm{~mL}$. Normalized concentrations of silica less than about 0.03 in this figure are subject to error because background colloid concentrations begin to approach silica concentrations at these levels.

Figure 6-10. Normalized Concentrations of 330-nm Diameter CML Microspheres, 100-nm Diameter Silica Microspheres, and Iodide in Vertically Oriented Fractured Core from PM-2 at $7032 \mathrm{ft}$ at 2.5 $\mathrm{mL} / \mathrm{hr}$ 


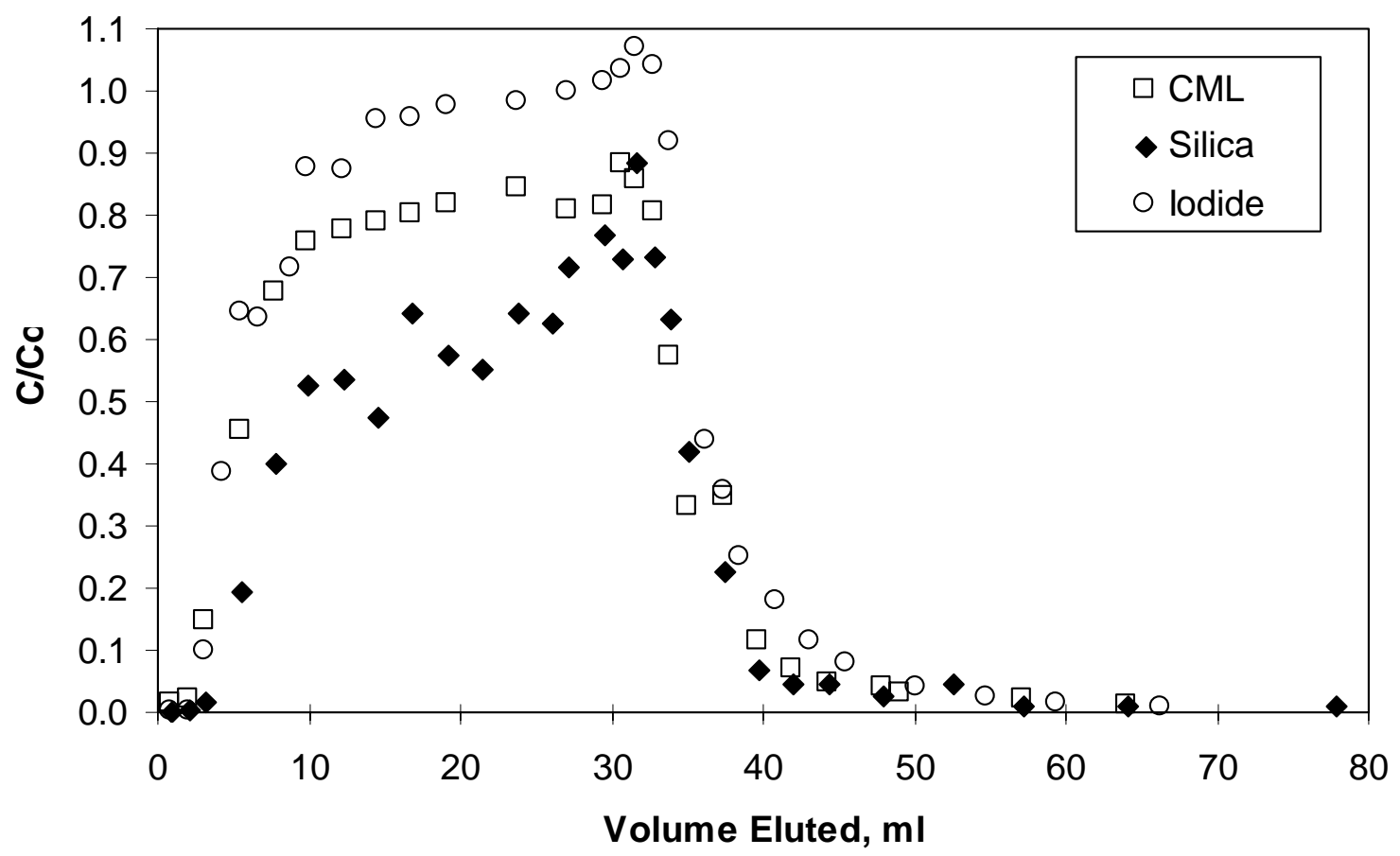

Source: DTN: LA0301PR831352.001 [DIRS 162434].

NOTE: The flow rate was $\sim 0.6 \mathrm{~mL} / \mathrm{hr}$, with a mean tracer residence time of $\sim 10.4 \mathrm{hr}$. The tracer injection pulse was $\sim 33 \mathrm{~mL}$, and the orientation of the core was vertical. Normalized concentrations of silica less than about 0.03 in this figure are subject to error because background colloid concentrations begin to approach silica concentrations at these levels.

Figure 6-11. Normalized Concentrations of 330-nm Diameter CML Microspheres, 100-nm Diameter Silica Microspheres, and lodide in Vertically Oriented Fractured Core from PM-2 at $7032 \mathrm{ft}$ at Approximately $0.6 \mathrm{~mL} / \mathrm{hr}$ 


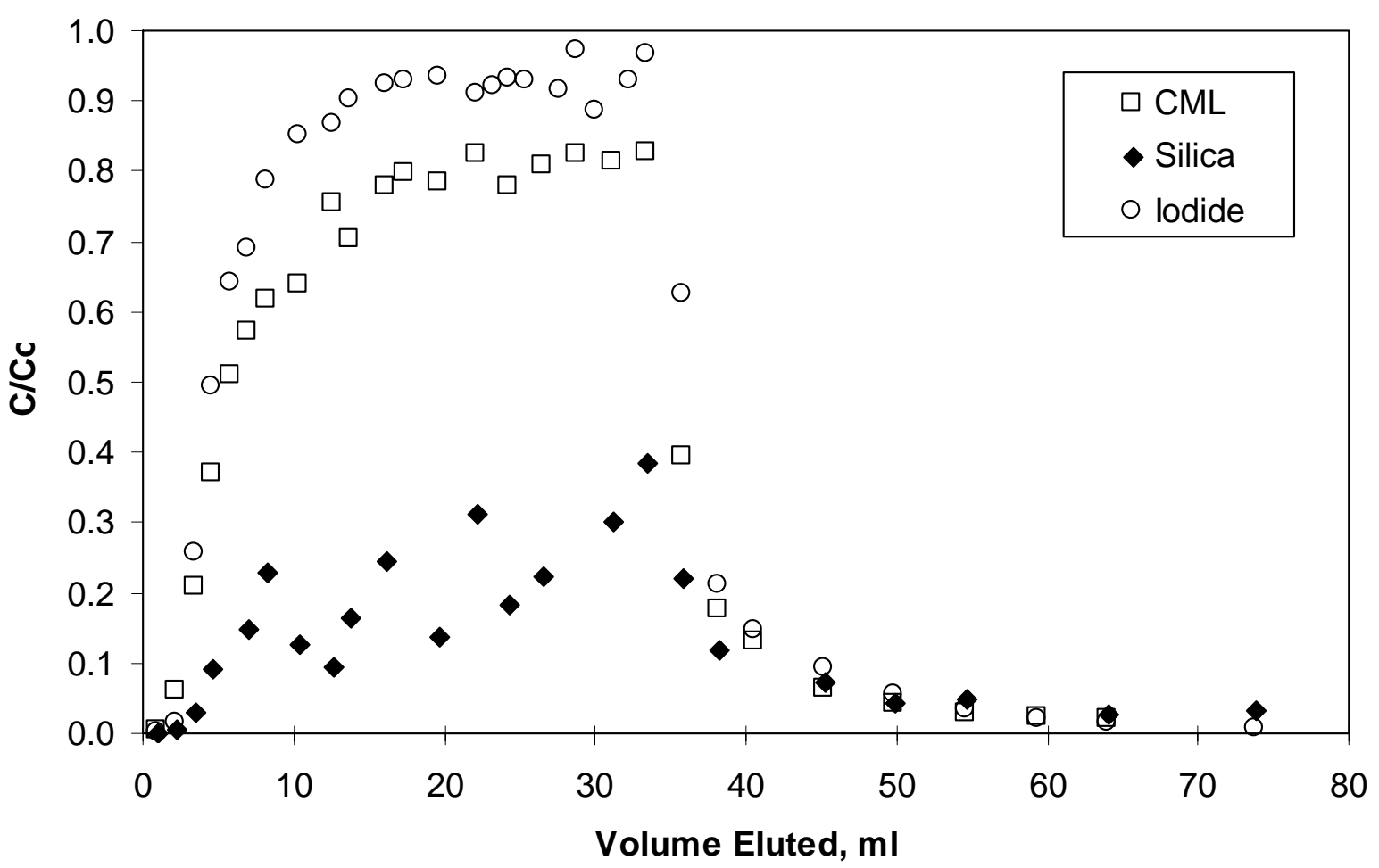

Source: DTN: LA0301PR831352.001 [DIRS 162434].

NOTE: The flow rate was $\sim 0.6 \mathrm{~mL} / \mathrm{hr}$, with a mean tracer residence time of $\sim 10.3 \mathrm{hr}$. The tracer injection pulse was $\sim 33 \mathrm{~mL}$, and the orientation of the core was horizontal. Normalized concentrations of silica less than about 0.03 in this figure are subject to error because background colloid concentrations begin to approach silica concentrations at these levels.

Figure 6-12. Normalized Concentrations of 330-nm Diameter CML Microspheres, 100-nm Diameter Silica Microspheres, and lodide in Horizontally Oriented Fractured Core from PM-2 at 7032 $\mathrm{ft}$ at Approximately $0.6 \mathrm{~mL} / \mathrm{hr}$ 
Table 6-11. Model Parameters from RELAP Fits of Tracer Breakthrough Curves in Experiments in Fractured Core from Borehole PM-2

\begin{tabular}{|l|c|c|c|c|}
\hline \multirow{2}{*}{\multicolumn{1}{c|}{ Model Parameter }} & \multicolumn{4}{c|}{ Flow Rate (mL/hr) } \\
\cline { 2 - 5 } & $\mathbf{1 0 . 0}$ & $\mathbf{2 . 5}$ & $\mathbf{0 . 5 8}(\mathbf{V})$ & $\mathbf{0 . 5 7}(\mathbf{H})$ \\
\hline Mean Fluid Residence Time (hr) & 0.60 & 2.43 & 10.43 & 10.27 \\
\hline Fracture Half Aperture (cm) & 0.024 & 0.024 & 0.024 & 0.024 \\
\hline lodide Peclet Number & 14.0 & 9.5 & 9.5 & 9.5 \\
\hline lodide Dispersivity (cm) & 1.0 & 1.5 & 1.5 & 1.5 \\
\hline Colloid Peclet Number & 2.88 & 2.88 & 2.88 & 2.88 \\
\hline Colloid Dispersivity (cm) & 4.86 & 4.86 & 4.86 & 4.86 \\
\hline lodide Matrix Diffusion Coefficient $\left(\mathrm{cm}^{2} / \mathrm{s} \times 10^{-7}\right)$ & 5.9 & 14.4 & 14.4 & 14.4 \\
\hline CML Microsphere Filtration Rate Constant $\left(\mathrm{hr}^{-1}\right)$ & 0.080 & 0.065 & 0.021 & 0.026 \\
\hline Silica Microsphere Filtration Rate Constant $\left(\mathrm{hr}^{-1}\right)$ & 0.090 & 0.085 & 0.051 & 0.201 \\
\hline
\end{tabular}

DTN: LA0403PR831352.001 [DIRS 171416], Microsoft Excel files used: PM-2 lodide.xls, PM-2 Microspheres.xIs.

NOTE: Fracture half-aperture calculated from $b=\frac{Q \tau}{2 L W}$, where $Q=$ volumetric flow rate, $\mathrm{m} \mathrm{L} / \mathrm{hr}, \tau=$ mean residence time, $\mathrm{hr}, L=$ fracture length, $\mathrm{cm}$, and $W=$ fracture width, $\mathrm{cm}$. Mean fluid residence times were estimated from simultaneous RELAP fits to the iodide breakthrough curves at different flow rates.

$\mathrm{V}=$ vertical orientation; $\mathrm{H}=$ horizontal orientation

Before drawing conclusions from the results of the fracture transport experiments, it is useful to define two characteristic length quantities (Hiemenz 1986, p. 65 [DIRS 117358]):

$$
\begin{gathered}
L_{\mathrm{D}}=\sqrt{2 D \tau} \\
L_{\mathrm{S}}=V_{\mathrm{S}} \tau=\left(\frac{1}{18 \mu}\right)\left(\rho_{\mathrm{P}}-\rho_{\mathrm{f}}\right) g d_{\mathrm{p}}^{2} \tau
\end{gathered}
$$

where

$L_{\mathrm{D}}=$ characteristic diffusion length during time $\tau, \mathrm{cm}$

$L_{\mathrm{S}}=$ characteristic gravitational settling length during time $\tau, \mathrm{cm}$

$D=$ colloid diffusion coefficient (calculated using Stokes-Einstein equation-see Note 2 of Table 6-5), $\mathrm{cm}^{2} / \mathrm{s}$

$\tau=$ fluid residence time in fracture, $\mathrm{s}$

$V_{\mathrm{S}}=$ settling velocity, $\mathrm{cm} / \mathrm{s}$

$\mu=$ fluid viscosity, $\mathrm{g} / \mathrm{cm}-\mathrm{sec}$

$\rho_{\mathrm{p}}=$ particle density, $\mathrm{g} / \mathrm{cm}^{3}$

$\rho_{\mathrm{f}}=$ fluid density, $\mathrm{g} / \mathrm{cm}^{3}$

$g=$ gravitational acceleration, $\mathrm{cm} / \mathrm{s}^{2}$

$d_{\mathrm{p}}=$ colloid diameter, $\mathrm{cm}$. 
The characteristic lengths $L_{\mathrm{D}}$ and $L_{\mathrm{S}}$ differed for the two microsphere tracers in each of the fracture transport tests in the lower-porosity fracture (Table 6-12). $L_{\mathrm{D}}$ represents the length scale at which diffusion is a dominant process and $L_{\mathrm{S}}$ represents the length scale at which gravitational settling is an important process.

Table 6-12. Characteristic Diffusion and Settling Lengths $\left(L_{D}\right.$ and $\left.L_{S}\right)$ for the CML and Silica Microspheres in the Four Experiments in the Fractured Core from Borehole PM-2

\begin{tabular}{|c|c|c|c|c|}
\hline \multirow{2}{*}{ Microsphere Characteristic Lengths } & \multicolumn{5}{|c|}{ Flow Rate (mL/hr) } \\
\cline { 2 - 5 } & $\mathbf{1 0 . 0}$ & $\mathbf{2 . 5}$ & $\mathbf{0 . 5 8}(\mathbf{V})$ & $\mathbf{0 . 5 7}(\mathbf{H})$ \\
\hline CML Diffusion Length, $L_{\mathrm{D}}(\mathrm{cm})$ & 0.008 & 0.015 & 0.032 & 0.032 \\
\hline Silica Diffusion Length, $L_{\mathrm{D}}(\mathrm{cm})$ & 0.014 & 0.028 & 0.058 & 0.057 \\
\hline CML Settling Length, $L_{S}(\mathrm{~cm})$ & 0.0007 & 0.0028 & 0.012 & 0.012 \\
\hline Silica Settling Length, $L_{S}(\mathrm{~cm})$ & 0.0019 & 0.0078 & 0.034 & 0.033 \\
\hline
\end{tabular}

Source: Anghel 2001 [DIRS 158639], Tables 5.2 and 5.5.

NOTE: The average fracture aperture $(2 b)$ was estimated to be $0.048 \mathrm{~cm}$.

$\mathrm{V}=$ vertical orientation; $\mathrm{H}=$ horizontal orientation

With these quantities defined, the following conclusions from the experiments can now be stated.

- When the fractures were in the vertical orientation, similar colloid responses were obtained at the same flow rate/residence time provided that $L_{\mathrm{D}} / 2 b<1$ for both microspheres, where $2 b=$ average fracture aperture ( $b=$ half aperture). At flow rates where $L_{\mathrm{D}} / 2 b$ greater than 1 for the silica and $L_{\mathrm{D}} / 2 b$ less than 1 for the CML microspheres, the latter transported with much less attenuation than the former.

- The fracture orientation influenced only the silica colloid transport, which is consistent with the greater silica settling velocity and the fact that $L_{\mathrm{S}} / 2 b \approx 1$ for the silica microspheres and $L_{\mathrm{S}} / 2 b<1$ for the CML microspheres. A significant fraction of the silica microspheres was apparently able to settle to the lower surface of the horizontally oriented fracture during their residence time in the flow system, whereas most of the CML microspheres did not settle during this time.

- The "sticking efficiencies" (fractions of colloid-wall collisions that resulted in attachment) of the two colloids appeared to be quite similar. This conclusion is based on comparing the experimental results to colloid deposition theory in a parallel-plate channel in the absence of gravitational effects, which predicts that the filtration rate constant, $k_{\mathrm{f}}$, should be proportional to $\left(\tau d_{\mathrm{p}}^{2}\right)^{-1 / 3}$ if all colloid-wall collisions result in irreversible attachment; i.e., a "perfect-sink" boundary condition (Van de Ven 1989 [DIRS 158637], pp. 452 to 453, Equation 6.20 and Table 6.2; definition of Pe for parallel-plate channel on p. 446, Table 6.1, and diffusion coefficient dependence on $d_{\mathrm{p}}$, p. 77, Equation 2.112). This proportionality of $k_{\text {filt }}$ to $\left(\tau d_{\mathrm{p}}^{2}\right)^{-1 / 3}$ in the absence of gravity effects is derived from Van de Ven in the following paragraph. 
Equation 6.20 shows that the deposition flux, $J$, in a parallel-plate channel is given by $J=\frac{S h D n_{\infty}}{r}=k_{f} n_{\infty}$, where $S h=$ Sherwood number (dimensionless), $D=$ colloid diffusion coefficient, $\mathrm{cm}^{2} / \mathrm{s}, n_{\infty}=$ colloid concentration in bulk solution, $\mathrm{mL}^{-1}$, and $r=$ colloid radius (Van de Ven 1989 [DIRS 158637], p. 452). The Sherwood number for a parallel-plate channel is equal to $\frac{0.678 P e^{1 / 3}}{\widetilde{x}^{1 / 3}}$ (Van de Ven 1989 [DIRS 158637], Table 6.2, p. 453), where $P e=\frac{3 v_{m} r^{3}}{2 b^{2} D}$ (Van de Ven, 1989 [DIRS 158637], Table 6.1, p. 446), $\tilde{x}=x / L, v_{m}=$ mean flow velocity in channel, $\mathrm{cm} / \mathrm{s}$, and $b=$ channel halfaperture, $\mathrm{cm}$. Substituting the expression for $P e$ into the expression for $S h$, one obtains $S h=\frac{C v_{m}{ }^{1 / 3} r}{b^{2 / 3} D^{1 / 3} \widetilde{x}^{1 / 3}}$, where $C$ is a proportionality constant. Recognizing that any given distance $x$ down the parallel-plate channel will be equal to $v_{m} \tau$, where $\tau$ is the time required to travel the distance $x$, then $S h=\frac{C^{\prime} r}{b^{2 / 3} D^{1 / 3} \tau^{1 / 3}} \quad$ and $J=k_{f} n_{\infty}=C^{\prime \prime} \frac{D^{2 / 3}}{b^{2 / 3} \tau^{1 / 3}} n_{\infty}$. Now, substituting the Stokes-Einstein equation (see Note 2 of Table 6-5) for $D$ in this expression yields $J=k_{f} n_{\infty}=C^{\prime \prime \prime}\left(\frac{1}{\tau^{1 / 3} r^{2 / 3}}\right) n_{\infty}$, from which it is readily apparent that $k_{f} \propto\left(\tau d_{\mathrm{p}}^{2}\right)^{-1 / 3}$, where $d_{\mathrm{p}}$ is the colloid diameter.

The quantity $d_{\mathrm{p}}^{2}$ for the CML microspheres was 10.9 times greater than that for the silica microspheres, so if the two microspheres had the same "sticking efficiency", they would be predicted to have the same $k_{\text {filt }}$ values when the residence time $\tau$ of the CML microspheres is 10.9 times less than that for the silica. In fact, when the residence time was approximately 9 times less for the CML microspheres, the filtration rates constants were 0.06 and $0.051 \mathrm{hr}^{-1}$ for the CML and silica microspheres, respectively. These rate constants are in relatively good agreement with each other (within experimental error), which suggests that the "sticking efficiencies" of the two microspheres were very similar. Note that the CML rate constant of $0.06 \mathrm{hr}^{-1}$ was obtained in an experiment conducted at a flow rate of approximately $5 \mathrm{~mL} / \mathrm{hr}$ in which only CML microspheres and iodide were used as tracers. This experiment is not presented or discussed elsewhere in this analysis report because it did not involve a direct comparison of CML and silica microspheres (all other experiments involved simultaneous injection of both microsphere tracers). For details of the experiment, see Anghel (2001 [DIRS 158639], Sections 2.10 and 4.6).

The three conclusions above suggest that CML microspheres on the order of 250 to $500 \mathrm{~nm}$ in diameter should transport either similarly to or with less attenuation than natural inorganic groundwater colloids in saturated fractured systems. 


\subsubsection{Comparison of CML Microsphere and Inorganic Colloid Transport in Saturated Alluvium}

Two separate sets of experiments were conducted in which the transport of CML microspheres were compared to that of natural inorganic colloids in saturated alluvium. The natural colloids were collected from water discharged from NC-EWDP-19D1 during the last few weeks of a single-well tracer test, after tracer concentrations had decayed to the point where they contributed insignificantly to the ionic strength of the groundwater. A portion of the discharged water was first directed through a 1-micron cartridge prefilter to remove all larger entrained solids. The prefiltered water was then passed through a high-surface-area membrane filter with a pore size rating of 5 to $10 \mathrm{~nm}$ to trap colloids in the groundwater. The membrane filter was allowed to collect colloids until flow through it became significantly restricted. At this point, the filter was backflushed (flow reversed using prefiltered groundwater) to dislodge the colloids from the filter. The backflushing produced a highly concentrated colloid solution that was collected in a container. The filtration and backflushing process was then repeated until more than 100 liters of concentrated colloid solution had been collected. In the first set of experiments, 330-nm diameter CML microspheres and 100-nm diameter silica microspheres were simultaneously injected into columns packed with alluvium from the uppermost screened interval of NC-EWDP-19D1. Water from the same interval was used in these experiments. The CML and silica microspheres were the same microspheres that were used in the fracture transport experiments discussed in Section 6.8.1 (see Table 6-6). In the second set of experiments, 190-nm and 500-nm diameter CML microspheres were injected simultaneously with natural colloids collected from NC-EWDP-19D1. The alluvium and water in these experiments were taken from the lowest screened interval completed in the alluvium at the ATC (the water came from NC-EWDP-19D1, and the alluvium came from NC-EWDP-19IM1A). In this set of experiments, $\mathrm{Pu}(\mathrm{V})$ was sorbed onto the natural colloids prior to the colloids being injected into the columns. Thus, these experiments also provided a test of colloid-facilitated $\mathrm{Pu}$ transport in saturated alluvium, although the Pu transport results are not discussed in this analysis report. The results from the first set of experiments (involving CML and silica microspheres) are discussed in Section 6.8.2.1, and the results from the second set of experiments involving the Pu-tagged natural colloids and CML microspheres are discussed in Section 6.8.2.2.

\subsubsection{CML and Silica Microsphere Transport in Saturated Alluvium}

Column experiments were conducted in two separate $30 \mathrm{~cm}$ long by $2.5 \mathrm{~cm}$ diameter glass columns equipped with polytetrafluoroethylene end fittings, including a $20 \mu \mathrm{m}$ end frit and polytetrafluoroethylene tubing. The alluvium used in the experiments was obtained from NC-EWDP-19D1 at the depth intervals of 405 to 410 and 420 to $425 \mathrm{ft}$ below ground surface, approximately 50 to $75 \mathrm{ft}$ below the water table. Cuttings samples were wet sieved (using NC-EWDP-19D1 well water) in the laboratory, and the size range between 75 and $2000 \mu \mathrm{m}$ was retained for testing. Material from the two intervals was combined in a 50:50 mass ratio for the column experiments because there was not enough material from the individual intervals to pack the columns. The packed porosities of the two columns were 0.404 and 0.418 . The water used in testing was taken from the uppermost screened interval of well NC-EWDP-19D1, which was the same interval that the alluvium material came from. 
The column experiments involved the simultaneous introduction of a pulse (approximately $60 \mathrm{~mL}$ ) of groundwater containing the same $330 \mathrm{~nm}$ diameter CML microspheres and $100 \mathrm{~nm}$ diameter silica microspheres used in the fracture experiments along with sodium bromide, with bromide ion serving as a nonsorbing solute tracer. Bromide was analyzed by ion chromatography, the CML microspheres were analyzed by fluorometry, and the silica microspheres were analyzed by high-sensitivity liquid in situ spectrometry. The first two experiments were conducted at flow rates of 2 and $6 \mathrm{~mL} / \mathrm{hr}$ in Columns $\mathrm{A}$ and $\mathrm{B}$, respectively. The normalized concentration responses of the colloids and bromide in these two experiments are shown in Figures 6-13 and 6-14. Not surprisingly, the normalized concentrations of both colloid tracers were greater in the column with the higher flow rate (Column B). However, in contrast to the fracture transport experiments, the CML microspheres were more attenuated than the silica microspheres in both columns. The greater attenuation of the CML microspheres relative to the silica microspheres could be the result of enhanced deposition of the larger microspheres by interception (collisions with alluvium grains as a result of flow streamlines bringing the microspheres into contact with the grain surfaces). Interception in a porous medium is predicted to be proportional to $\left(d_{\mathrm{p}} / d\right)^{2}$ (Harvey and Garabedian 1991 [DIRS 109256], Equation 6, p. 180), where $d_{\mathrm{p}}$ is the colloid diameter and $d$ is the grain size of the porous medium. The microsphere recoveries in the experiments were not calculated, but as a first approximation, they are about equal to the peak normalized concentrations of microspheres. Clearly, the recoveries are much lower than in the fracture transport experiments of Section 6.8.1.

For the fracture transport experiments (both horizontal and vertical orientations), colloid interception played an insignificant role in deposition because the average fracture aperture was on the order of $0.5 \mathrm{~mm}$ (i.e., very large compared to the colloid diameters) and the fracture walls were primarily parallel to flow. However, in a porous medium, flow can follow much more tortuous pathways around grains, and pore throats around small grains may be quite narrow. Although sieving of the material used to pack the columns was intended to exclude grain sizes smaller than $75 \mu \mathrm{m}$ in diameter, it is likely that finer material was present in the columns or perhaps generated after the columns were allowed to flow. Also, because of the irregular shapes of the alluvium grains, most pore throats were probably quite a bit narrower than would be predicted assuming spherical grains. These factors may have resulted in a significant number of collisions of the CML microspheres due to interception with the alluvium grains in the columns. The silica microspheres, however, had a value of $\left(d_{\mathrm{p}} / d\right)^{2}$ about a factor of 11 less than that of the CML microspheres, so interception would be expected to play a much less important role in their deposition. 


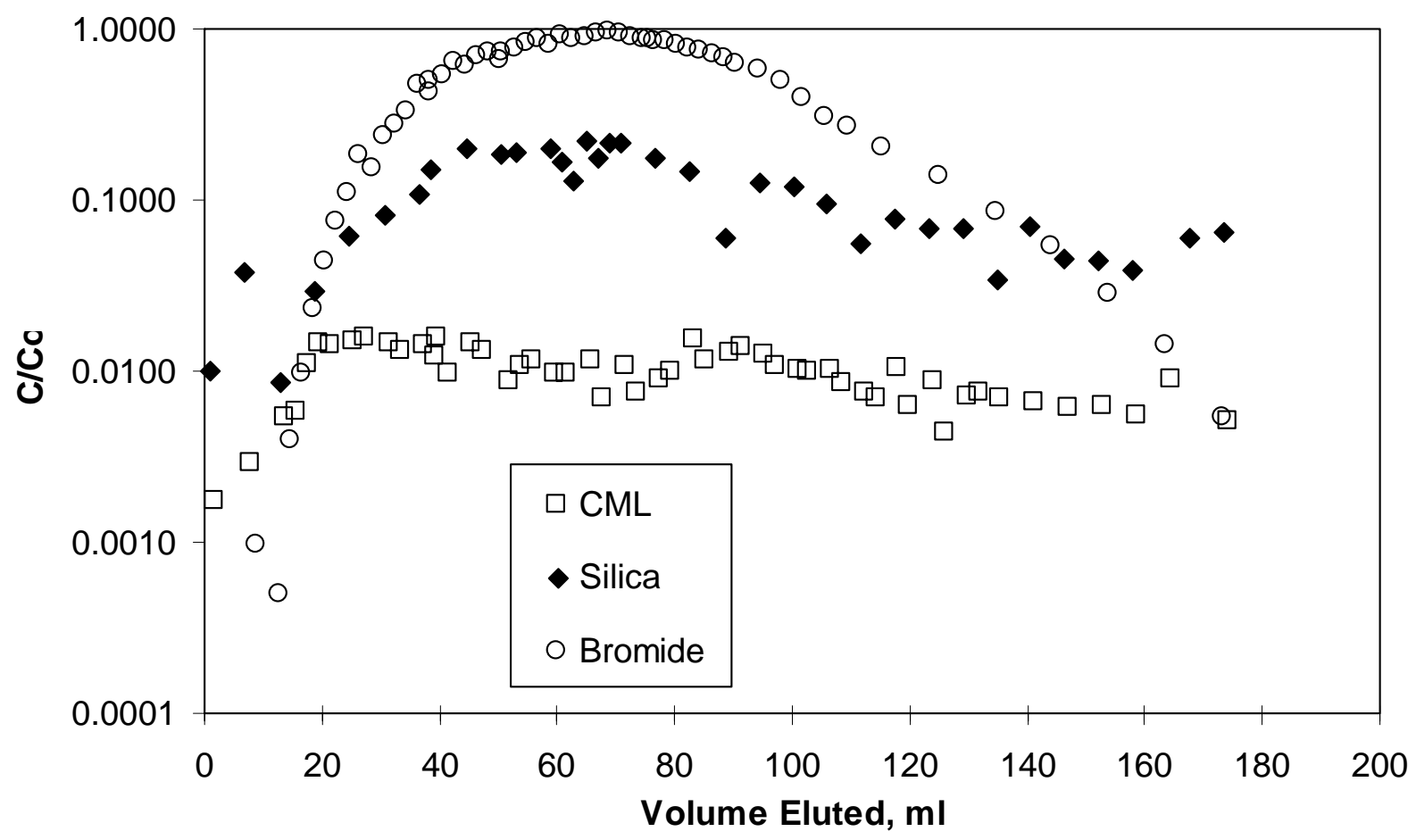

Source: DTN: LA0206MH831361.001 [DIRS 162426].

NOTE: The flow rate was $\sim 2 \mathrm{~mL} / \mathrm{hr}$. Normalized concentrations of silica less than about 0.03 in this figure are subject to error because background colloid concentrations begin to approach silica concentrations at these levels.

Figure 6-13. Log Normalized Concentrations of 330-nm Diameter CML Microspheres, 100-nm Diameter Silica Microspheres, and Bromide in Alluvium-Packed Column A 


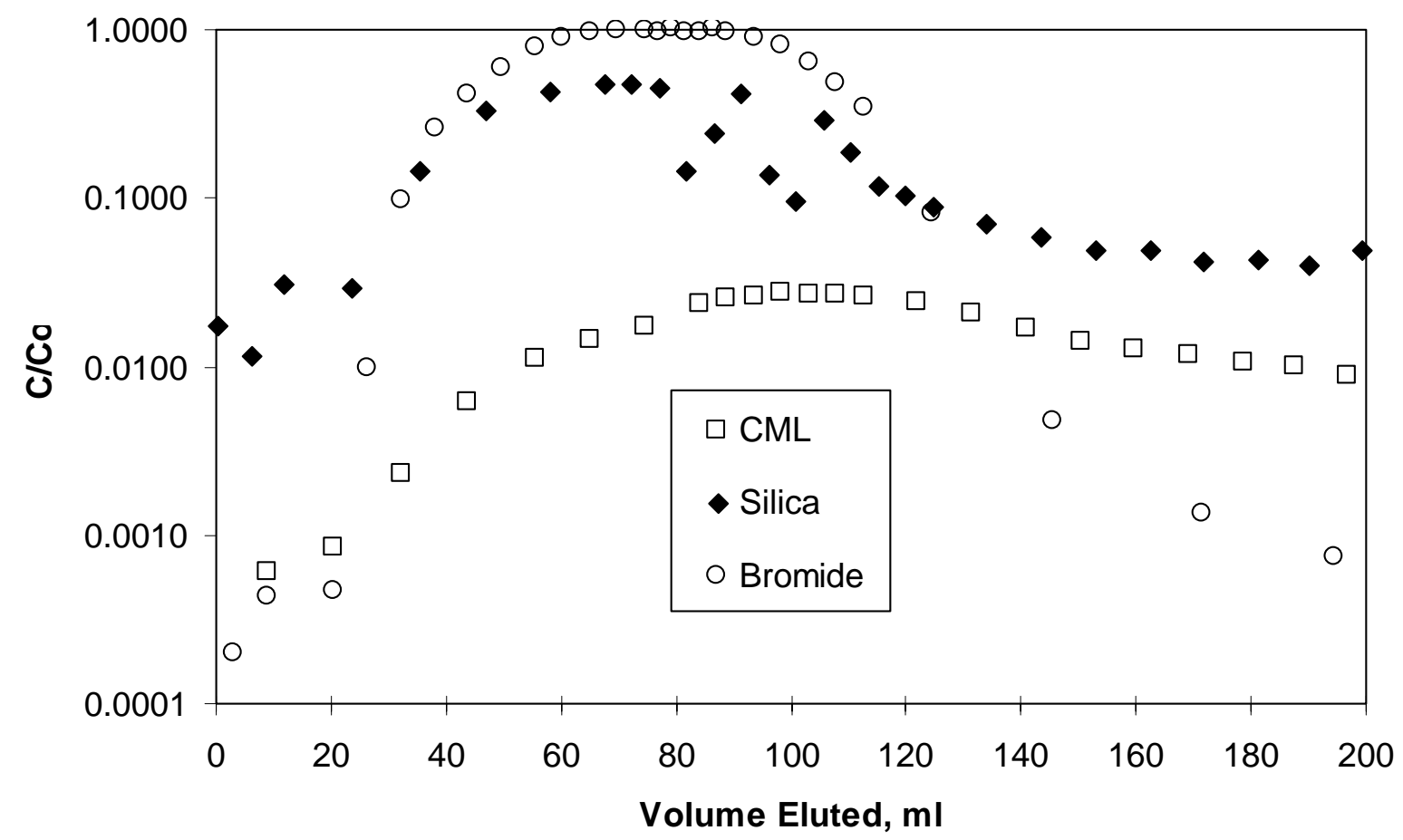

Source: DTN: LA0206MH831361.002 [DIRS 162427].

NOTE: The flow rate was $\sim 6 \mathrm{~mL} / \mathrm{hr}$. Normalized concentrations of silica less than about 0.03 in this figure are subject to error because background colloid concentrations begin to approach silica concentrations at these levels.

Figure 6-14. Log Normalized Concentrations of 330-nm Diameter CML Microspheres, 100-nm Diameter Silica Microspheres, and Bromide in Alluvium-Packed Column B

A second set of CML and silica microsphere transport experiments was conducted in the two alluvium-packed columns. The second experiment in Column B was conducted at the same flow rate as the first experiment in this column (approximately $6 \mathrm{~mL} / \mathrm{hr}$ ), whereas the second experiment in Column A was conducted at a flow rate of approximately $12 \mathrm{~mL} / \mathrm{hr}$, approximately 6 times greater than in the first experiment. The normalized concentration responses of the tracers in these two experiments are shown in Figures 6-15 and 6-16. When comparing the first and second experiments in Column B (Figures 6-14 and 6-16), it is apparent that both colloids were appreciably more attenuated in the second experiment, and the CML microspheres became even more attenuated relative to the silica microspheres. The peak concentration of the silica microspheres in this column decreased by about a factor of 3 in the second experiment, whereas the peak concentration of the CML microspheres decreased by nearly a factor of 10 compared to the first experiment. These decreases might be attributed to a decrease in the hydraulic conductivity of the columns, which often occurs over time due to microbial growth or redistribution of fines, both of which tend to decrease effective pore throat diameters in columns. The hydraulic conductivity of both columns was measured only after the second test, not prior to either test, so it was not possible to unequivocally attribute the decrease in colloid recoveries in Column B to a decrease in hydraulic conductivity. 


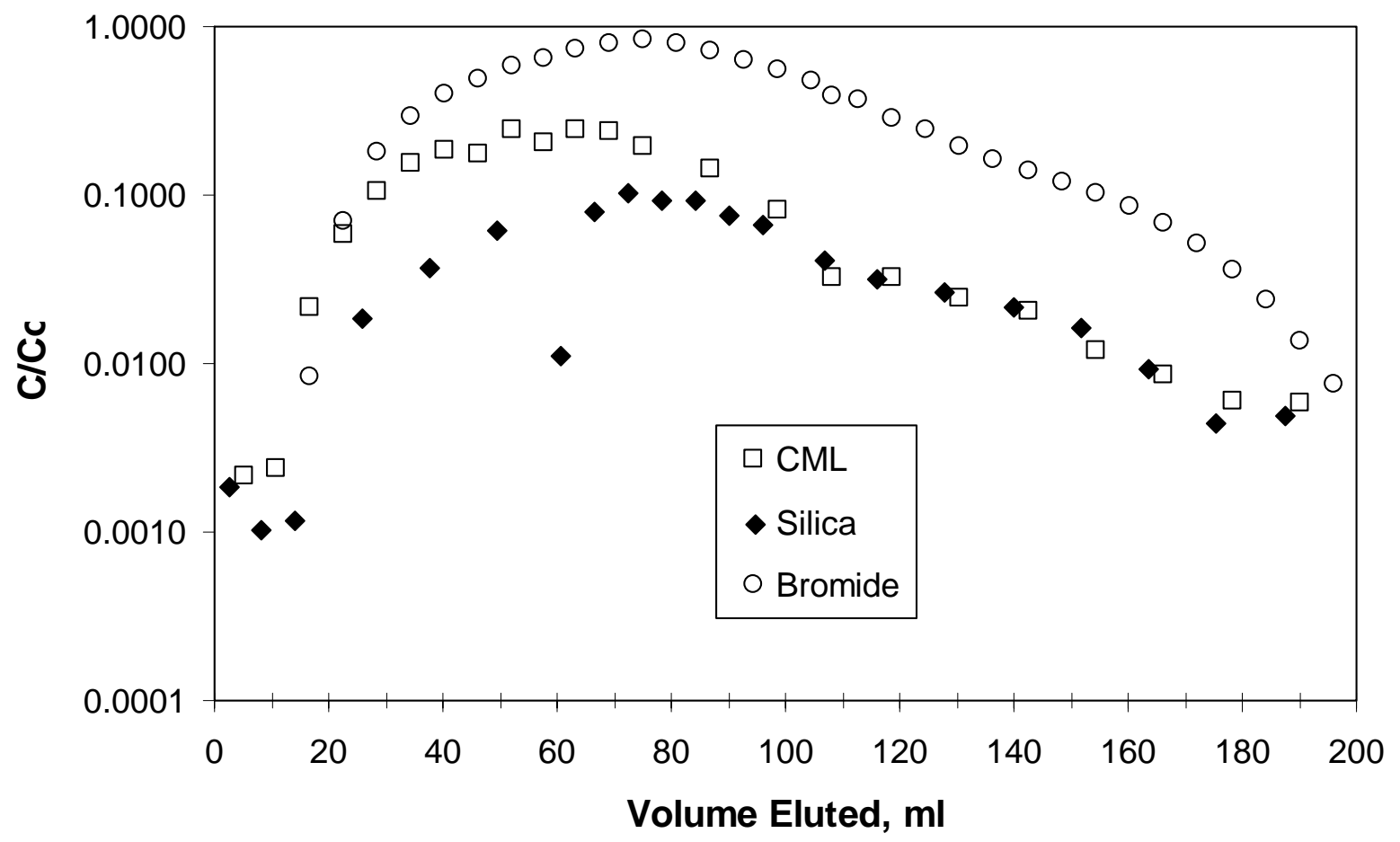

Source: DTN: LA0206MH831361.003 [DIRS 162428].

NOTE: The flow rate was $\sim 12 \mathrm{~m} \mathrm{L/hr}$. Normalized concentrations of silica less than about 0.03 in this figure are subject to error because background colloid concentrations begin to approach silica concentrations at these levels.

Figure 6-15. Log Normalized Concentrations of 330-nm Diameter CML Microspheres, 100-nm Diameter Silica Microspheres, and Bromide in Second Experiment in Alluvium-Packed Column A 


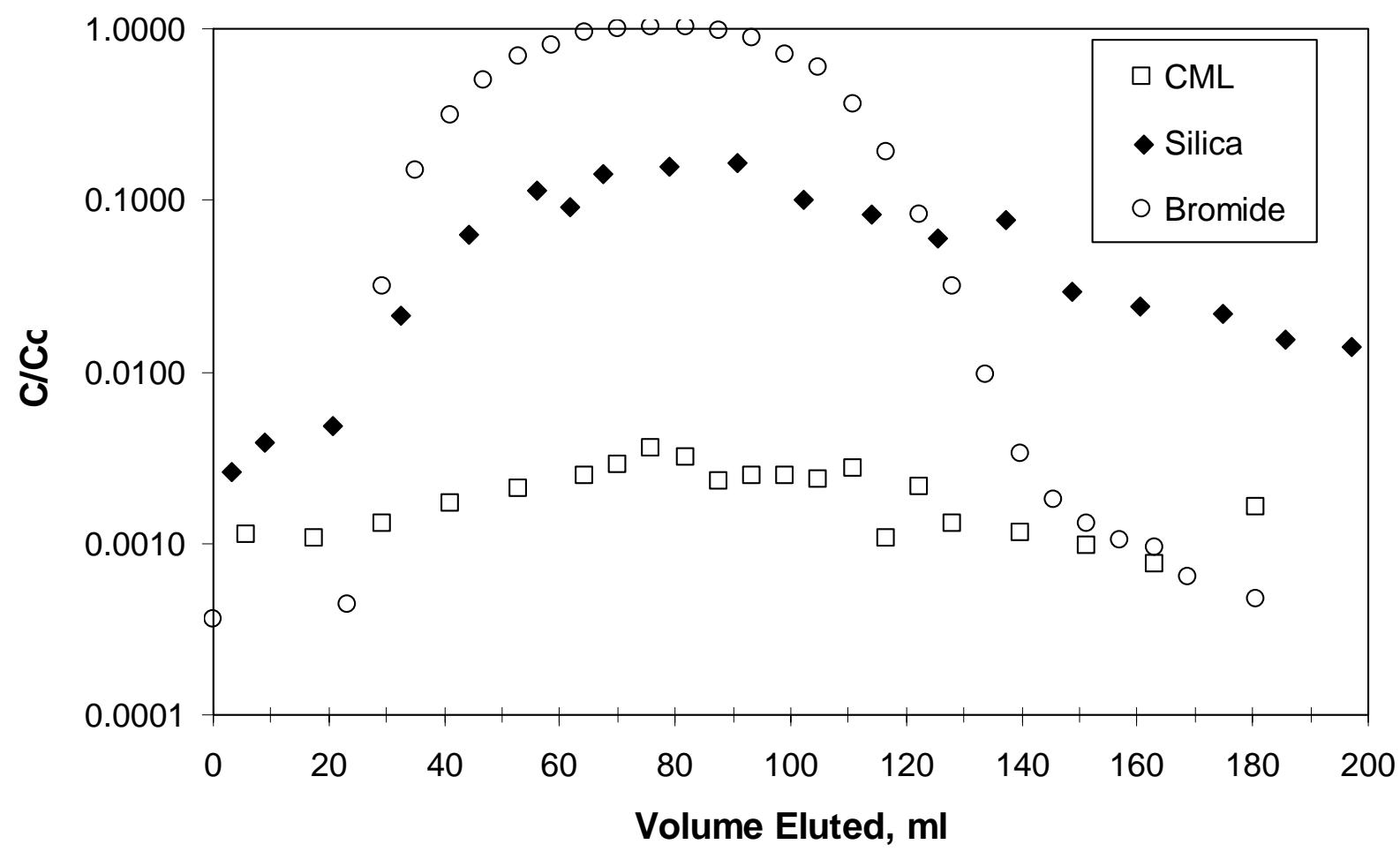

Source: DTN: LA0206MH831361.004 [DIRS 162430].

NOTE: The flow rate was $\sim 6 \mathrm{~mL} / \mathrm{hr}$. Normalized concentrations of silica less than about 0.03 in this figure are subject to error because background colloid concentrations begin to approach silica concentrations at these levels.

Figure 6-16. Log Normalized Concentrations of 330-nm Diameter CML Microspheres, 100-nm Diameter Silica Microspheres, and Bromide in Second Experiment in Alluvium-Packed Column B

Despite the fact that the flow rate in the second experiment in Column A was about six times greater than in the first experiment, the peak concentration of CML microspheres was only marginally higher than in the first test, and the peak concentration of silica microspheres was lower (compare Figures 6-13 and 6-15). Normally, one would expect greater peak concentrations of both microspheres at a higher flow rate in the same column. Also, unlike the other three alluvium column tests, the peak concentration of CML microspheres was higher than the silica peak concentration in the second test in Column A. The microsphere responses in the second test were probably influenced by the presence of air pockets that appeared in both the top and bottom ends of the column some time after the first experiment had been completed. These air pockets were presumably the result of slow leaks that occurred in the top and bottom end fittings of the columns.

The lower-than-expected peak concentrations of both microspheres in the second test in Column A and the fact that the silica microspheres were more attenuated than the CML microspheres in this test are attributed to the attachment of both microspheres to the air-water interfaces present at either end of the column. Colloids that come into contact with air-water interfaces become essentially irreversibly attached to the interface as a result of strong capillary forces 
(Abdel-Fattah and El-Genk 1998 [DIRS 158692], pp. 248 to 250). The silica microspheres would be expected to collide more frequently with these interfaces than the CML microspheres because of their greater diffusivity, thus resulting in greater attenuation relative to the CML microspheres.

Table 6-13 provides estimates of filtration and detachment rate constants for the CML and silica microspheres in each of the alluvium column experiments. These estimates were obtained by fitting the experimental data using the approach described in Section 6.4.1. That is, the RELAP computer code was used to fit the bromide responses to estimate the mean residence times and Peclet numbers in the column tests, and then the colloid filtration rate constants and retardation factors were adjusted to fit the colloid responses. The retardation factors were constrained by fitting the tails of the colloid responses. Detachment rate constants were then obtained by rearrangement of Equation 6-3. It should be recognized that the detachment rate constants for silica are very crude estimates because the silica tails rapidly approached background colloid concentrations. Table 6-13 also provides the effective partition coefficients $\left(K_{\mathrm{d}}\right.$ values) for the colloids in each experiment, given by the filtration rate constant divided by the detachment rate constant. These retardation factors would apply to large time scales if it is assumed that filtration is completely reversible.

Table 6-13. Estimates of Filtration Rate Constants and Detachment Rate Constants for CML Microspheres and Silica Colloids in Columns Packed with Alluvium

\begin{tabular}{|l|c|c|c|c|}
\hline \multirow{2}{*}{\multicolumn{1}{c|}{ Colloid Transport Parameters }} & \multicolumn{4}{c|}{ Column / Flow Rate } \\
\cline { 2 - 5 } & A / 2 $\mathbf{~ L L / h r}$ & B / 6 $\mathbf{~ L / h r}$ & A / 12 $\mathbf{~ m L / h r ~}$ & B / 6 mL/hr \\
\hline CML filtration rate constant $\left(\mathrm{hr}^{-1}\right)$ & 0.68 & 0.6 & 0.38 & 0.91 \\
\hline CML detachment rate constant $\left(\mathrm{hr}^{-1}\right)$ & 0.004 & 0.019 & 0.0027 & 0.0065 \\
\hline CML Retardation Factor & 170 & 33 & 140 & 140 \\
\hline Silica filtration rate constant $\left(\mathrm{hr}^{-1}\right)$ & 0.22 & 0.13 & 0.73 & 0.28 \\
\hline Silica detachment rate constant $\left(\mathrm{hr}^{-1}\right)$ & $0.0022^{*}$ & 0.0081 & 0.0037 & 0.0156 \\
\hline Silica Retardation Factor & 100 & 17 & 200 & 19 \\
\hline
\end{tabular}

Source: DTN: LA0303PR831361.001 [DIRS 163135].

*This value cannot be practically distinguished from zero. The filtration rate and retardation factor are fit using RELAP and the detachment rate constant is calculated using Equation 6-3.

It is apparent from Figures 6-13 through 6-16 and Table 6-13 that the relative transport behavior of the CML microspheres and the silica microspheres was appreciably different in the alluvium columns from that in the fractured cores. These differences are attributed to smaller pore throat sizes in the alluvium columns and, hence, greater interception of the CML microspheres in these columns. The results indicate that CML microspheres with diameters greater than approximately $300 \mathrm{~nm}$ will not necessarily behave as conservative surrogates for natural groundwater colloids in the saturated alluvium south of Yucca Mountain.

\subsubsection{CML Microsphere and Natural Colloid Transport in Saturated Alluvium}

A second set of colloid transport experiments was conducted to further investigate and compare the transport of CML microspheres and inorganic colloids in saturated alluvium. This set of experiments had several objectives. 
- There was concern that air bubbles in the columns in the first set of experiments (Section 6.8.2.1) may have influenced the results. Thus, a second set of experiments in which more emphasis was placed on eliminating air bubbles was desired.

- Natural colloids from NC-EWDP-19D1, which were collected to be used in a cross-hole field tracer test, became available after the first set of tests. These colloids were more representative of natural colloids in the alluvium than the synthetic silica colloids used in the first set of experiments, so it was desirable to conduct a second set of experiments using these colloids.

- It was desirable to use lower concentrations of CML microspheres than in the first set of tests to minimize any interactions between the microspheres and inorganic colloids. This could be accomplished by using flow cytometry to determine microsphere concentrations instead of fluorometry. Flow cytometry offers better precision and much lower detection limits for fluorescent microspheres than fluorometry because individual fluorescent colloids are counted, whereas with fluorometry, only the bulk fluorescence of solutions containing fluorescent colloids is measured.

- It was desirable to use at least two different sizes of CML microspheres in a second set of experiments to determine what size would be the best candidate for use in planned crosshole field tracer tests in the saturated alluvium at the ATC (site of NC-EWDP-19D1).

- The alluvium and water from the first set of experiments came from a zone that had a relatively low hydraulic conductivity and a relatively high divalent cation concentration (8-10 $\left.\mathrm{mg} / \mathrm{L} \mathrm{Ca}^{2+}\right)$, both of which would tend to hinder colloid transport. It was desirable to conduct a second set of experiments using alluvium and water from a highconductivity zone with a lower divalent cation concentration; i.e., the lowest screened interval in the alluvium in NC-EWDP-19D1 (1-2 $\left.\mathrm{mg} / \mathrm{L} \mathrm{Ca}^{2+}\right)$. The lower divalent cation concentrations favor colloid stability and transport, so water from this interval would provide a more stringent test of colloid transport in saturated alluvium.

- Finally, it was desirable to conduct colloid-facilitated $\mathrm{Pu}$ transport experiments using the natural colloids collected from NC-EWDP-19D1. Such experiments would provide valuable estimates of colloid-facilitated $\mathrm{Pu}$ transport parameters for use in transport process models that feed TSPA. (Pu transport results are not discussed in this analysis report, but are discussed in the model report Site-Scale Saturated Zone Transport, (BSC 2004 [DIRS 170036], Appendix B). 
The second set of colloid transport experiments was conducted using alluvium material collected during the drilling of NC-EWDP-19IM1A, at a depth of 785 to $790 \mathrm{ft}$ below land surface. Two $30-\mathrm{cm}$ long and $2.5-\mathrm{cm}$ diameter columns were packed with this material. The material was wet-sieved to a size range of 75 to $2000 \mu \mathrm{m}$ for one of the columns and to a size range of 125 to $2000 \mu \mathrm{m}$ for the second column. The intent of the slightly different particle-size ranges was to achieve different hydraulic conductivities in the two columns. The column with the smaller particle sizes was expected to have smaller pore throat diameters and, hence, a lower hydraulic conductivity (which is predicted to be heavily influenced by the lower end of the particle-size range) than the other column. The water for the experiments was collected from the lowest screened interval completed in the alluvium in NC-EWDP-19D1, which corresponds to a depth range of approximately 715 to $800 \mathrm{ft}$ below land surface at a distance of 25 to $30 \mathrm{~m}$ from NC-EWDP-19IM1A (from which the alluvium material was taken).

The natural colloids were collected from the uppermost screened interval in NC-EWDP-19D1 during the last six weeks of a single-well tracer test conducted in this interval in the spring of 2001. These colloids were analyzed by quantitative x-ray diffraction to be approximately 95 percent (by weight) smectite clay, approximately 4 percent zeolites, and approximately 1 percent other minerals (DTN: LA0306PR831321.001 [DIRS 164492]). Definitive determinations of whether this material differed appreciably in composition and origin from the bentonite drilling mud used during the drilling of NC-EWDP-19D1 were inconclusive. The CML microspheres had diameters of $190 \mathrm{~nm}$ and $500 \mathrm{~nm}$, and they were tagged with yellow and red fluorescent dyes, respectively. The natural colloids were analyzed by high-sensitivity liquid in situ particle spectrometry (HSLIS-S50, Particle Measuring Systems, Inc.), and the fluorescent microspheres were analyzed by flow cytometry (PAS-III, Partec).

The characteristics of the two columns used in the experiments are listed in Table 6-14. The porosity of both columns was around 40 percent, and the hydraulic conductivities, somewhat unexpectedly, were initially identical (within measurement error), and both increased significantly during the course of the experiments. The column with the smaller-sized particles had a significantly higher hydraulic conductivity at the end of the experiments. The increase in conductivity/permeability in both columns is attributed to the washing of fine-grained material from the columns and, possibly, to some redistribution of material in the columns over the course of the experiments. The washing of fine-grained material was evident from the continuous background concentrations of colloids in the column effluents during the experiments.

The three different types of colloids were injected along with tritiated water $\left({ }^{3} \mathrm{HHO}\right)$ in pulses ranging from 56 to $58 \mathrm{~mL}$ in volume. The flow rates in the first set of experiments (one in each column) were approximately $6 \mathrm{~mL} / \mathrm{hr}$, and the flow rates in the second set of experiments were approximately $1.1 \mathrm{~mL} / \mathrm{hr}$. These flow rates resulted in calculated mean residence times of ${ }^{3} \mathrm{HHO}$ in the columns of 8-10 hrs in the first set of experiments and approximately $50 \mathrm{hrs}$ in the second set. Details of the experimental conditions are provided in Table 6-15. 
Table 6-14. Column Parameters in the CML Microsphere and Natural Colloid Experiments

\begin{tabular}{|l|c|c|c|c|c|c|c|}
\hline & $\begin{array}{c}\text { Length } \\
\text { (cm) }\end{array}$ & $\begin{array}{c}\text { Diameter } \\
(\mathbf{c m})\end{array}$ & $\begin{array}{c}\text { Range of } \\
\text { Grain Size } \\
\text { (microns) }\end{array}$ & $\begin{array}{c}\text { Porosity } \\
\text { (\%) }\end{array}$ & $\begin{array}{c}\text { Standard } \\
\text { Conductivity } \\
\text { (cm/s) }\end{array}$ & $\begin{array}{c}\text { Permeability } \\
\text { Deviation in } \\
\text { (millidarcy) }\end{array}$ & $\begin{array}{c}\text { Permeability } \\
\text { (millidarcy) }\end{array}$ \\
\hline \multicolumn{7}{|c|}{ Column C } \\
\hline Pretest $^{\mathrm{a}}$ & 30 & 2.50 & $75-2000$ & 38.2 & $8.81 \times 10^{-3}$ & 9110 & 432 \\
\hline Posttest $^{\mathrm{a}}$ & $\mathrm{NM}$ & $\mathrm{NM}$ & $\mathrm{NM}$ & $\mathrm{NM}$ & $4.21 \times 10^{-2}$ & 43,600 & 597 \\
\hline & & \multicolumn{7}{|c|}{ Column D } \\
\hline Pretest $^{\mathrm{a}}$ & 30 & 2.50 & $125-2000$ & 41.0 & $9.02 \times 10^{-3}$ & 9330 & 386 \\
\hline Posttest $^{\mathrm{a}}$ & $\mathrm{NM}$ & $\mathrm{NM}$ & $\mathrm{NM}$ & $\mathrm{NM}$ & $1.11 \times 10^{-2}$ & 11,500 & 599 \\
\hline
\end{tabular}

Source: DTN: LA0301AA831352.001 [DIRS 162434].

${ }^{\text {a }}$ Prior to both experiments in each column.

${ }^{\mathrm{b}}$ After both experiments in each column.

NOTE: The two columns are designated $C$ and $D$ to distinguish them from Columns $A$ and $B$ discussed in Section 6.8.2.1 for the first set of alluvium column experiments.

$\mathrm{NM}=$ not measured

Table 6-15. Experimental Conditions in the CML Microsphere and Natural Colloid Experiments

\begin{tabular}{|l|l|l|l|l|l|l|}
\hline \multicolumn{1}{|c|}{ Experiment } & $\begin{array}{c}\text { 190-nm CML } \\
\text { Concentration } \\
\left(\mathrm{mL}^{-1}\right)\end{array}$ & $\begin{array}{c}\text { 500-nm CML } \\
\text { Concentration } \\
\left(\mathrm{mL}^{-1}\right)\end{array}$ & $\begin{array}{c}\text { Natural } \\
\text { Colloid } \\
\text { Concentration } \\
\left(\mathrm{mL}^{-1}\right)\end{array}$ & $\begin{array}{c}{ }^{3} \text { HHO } \\
\text { Concentration } \\
(\mathrm{CPM} / \mathrm{mL})\end{array}$ & $\begin{array}{c}\text { Injection } \\
\text { Pulse } \\
\text { Volume } \\
(\mathrm{mL})\end{array}$ & $\begin{array}{c}\text { Flow } \\
\text { Rate } \\
(\mathrm{mL} / \mathrm{hr})\end{array}$ \\
\hline $\begin{array}{l}\text { Test 1, } \\
\text { Column C }\end{array}$ & $3.58 \times 10^{6}$ & $5.82 \times 10^{5}$ & $2.92 \times 10^{10}$ & $1.57 \times 10^{5}$ & 56.70 & 6.01 \\
\hline $\begin{array}{l}\text { Test 1, } \\
\text { Column D }\end{array}$ & $3.55 \times 10^{6}$ & $5.78 \times 10^{5}$ & $2.93 \times 10^{10}$ & $1.57 \times 10^{5}$ & 56.02 & 5.93 \\
\hline $\begin{array}{l}\text { Test 2, } \\
\text { Column C }\end{array}$ & $3.15 \times 10^{6}$ & $4.97 \times 10^{5}$ & $2.98 \times 10^{10}$ & $4.54 \times 10^{5}$ & 58.25 & 1.19 \\
\hline $\begin{array}{l}\text { Test 2, } \\
\text { Column D }\end{array}$ & $3.14 \times 10^{6}$ & $5.13 \times 10^{5}$ & $2.98 \times 10^{10}$ & $4.54 \times 10^{5}$ & 56.94 & 1.19 \\
\hline
\end{tabular}

Source: DTN: LA0301AA831352.001 [DIRS 162433].

$\mathrm{CPM}=$ counts per minute

The experiments were interpreted in the same way as the first set of colloid transport experiments in alluvium-packed columns (i.e., first, the mean residence time and Peclet number of ${ }^{3} \mathrm{HHO}$ in each experiment was determined using the RELAP computer code, and then colloid filtration rate constants and retardation factors were determined for the colloids assuming that the ${ }^{3} \mathrm{HHO}$ Peclet numbers applied to the colloids). The mean residence times of the colloids were allowed to be adjusted because the colloids broke through the columns significantly earlier than the ${ }^{3} \mathrm{HHO}$ in three of the four experiments. The breakthrough curves of the ${ }^{3} \mathrm{HHO}$ and colloids in each experiment are shown in Figures 6-17 through 6-20. Also shown in these figures are the RELAP fits to each data set. The ${ }^{3} \mathrm{HHO}$ and colloid transport parameters obtained from the fits are listed in Table 6-16. 


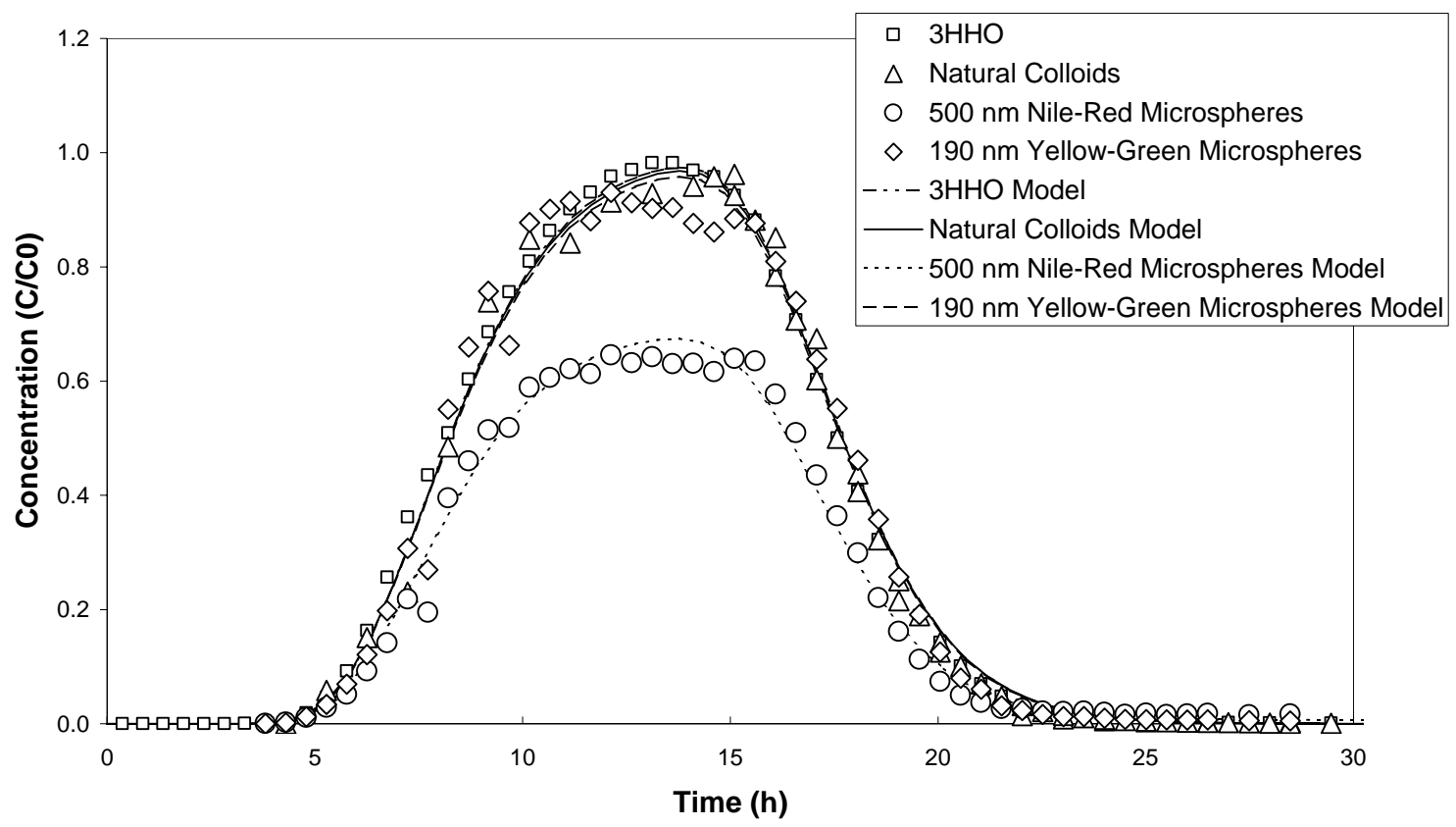

Source: DTNs: LA0301AA831352.001 [DIRS 162433]; LA0303PR831361.001 [DIRS 163135].

Figure 6-17. ${ }^{3} \mathrm{HHO}$ and Colloid Breakthrough Curves and RELAP Fits in Test 1, Column C (6.01 mL/hr Flow Rate)

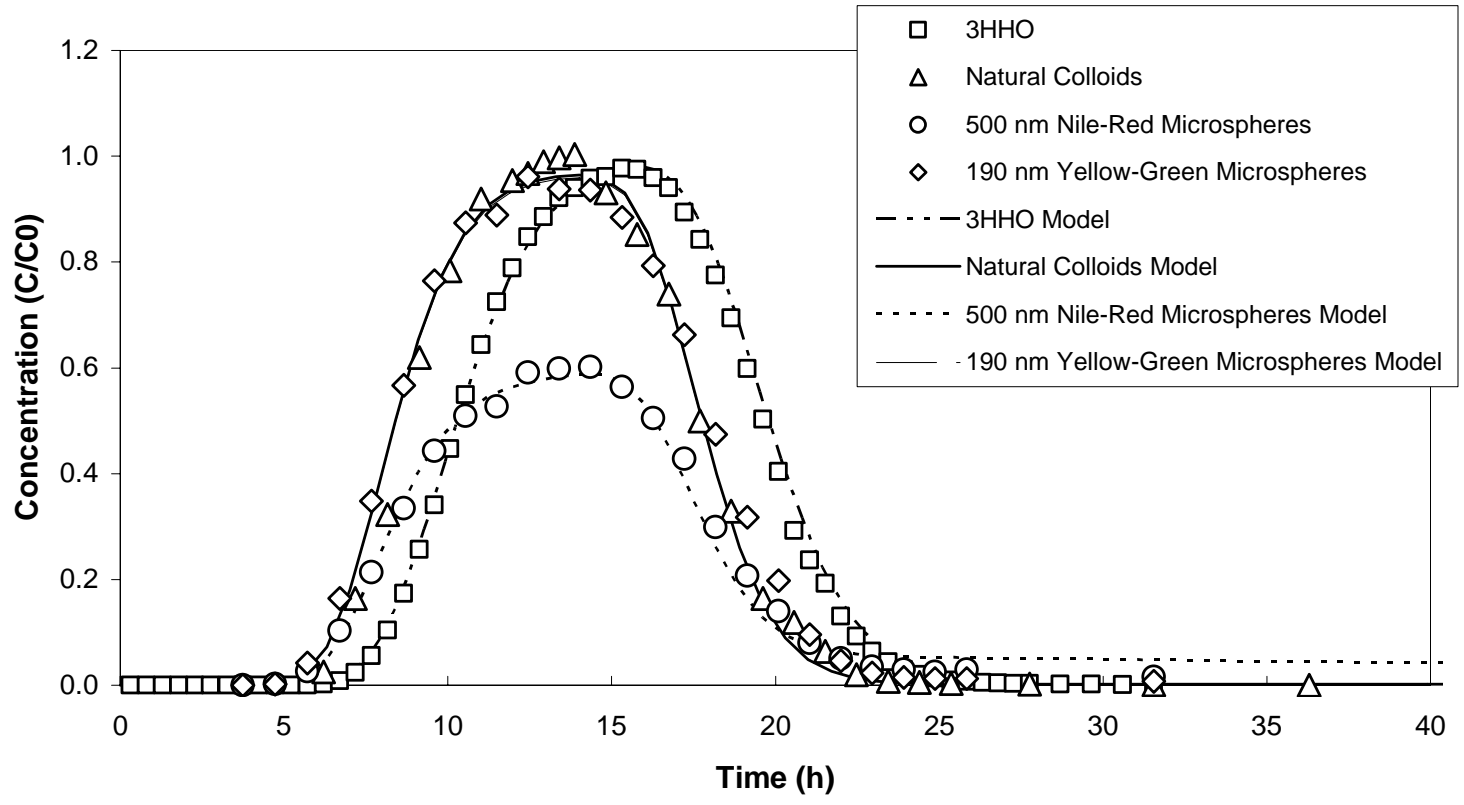

Source : DTNs: LA0301AA831352.001 [DIRS 162433]; LA0303PR831361.001 [DIRS 163135].

Figure 6-18. ${ }^{3} \mathrm{HHO}$ and Colloid Breakthrough Curves and RELAP Fits in Test 1, Column D (5.93 mL/hr Flow Rate) 


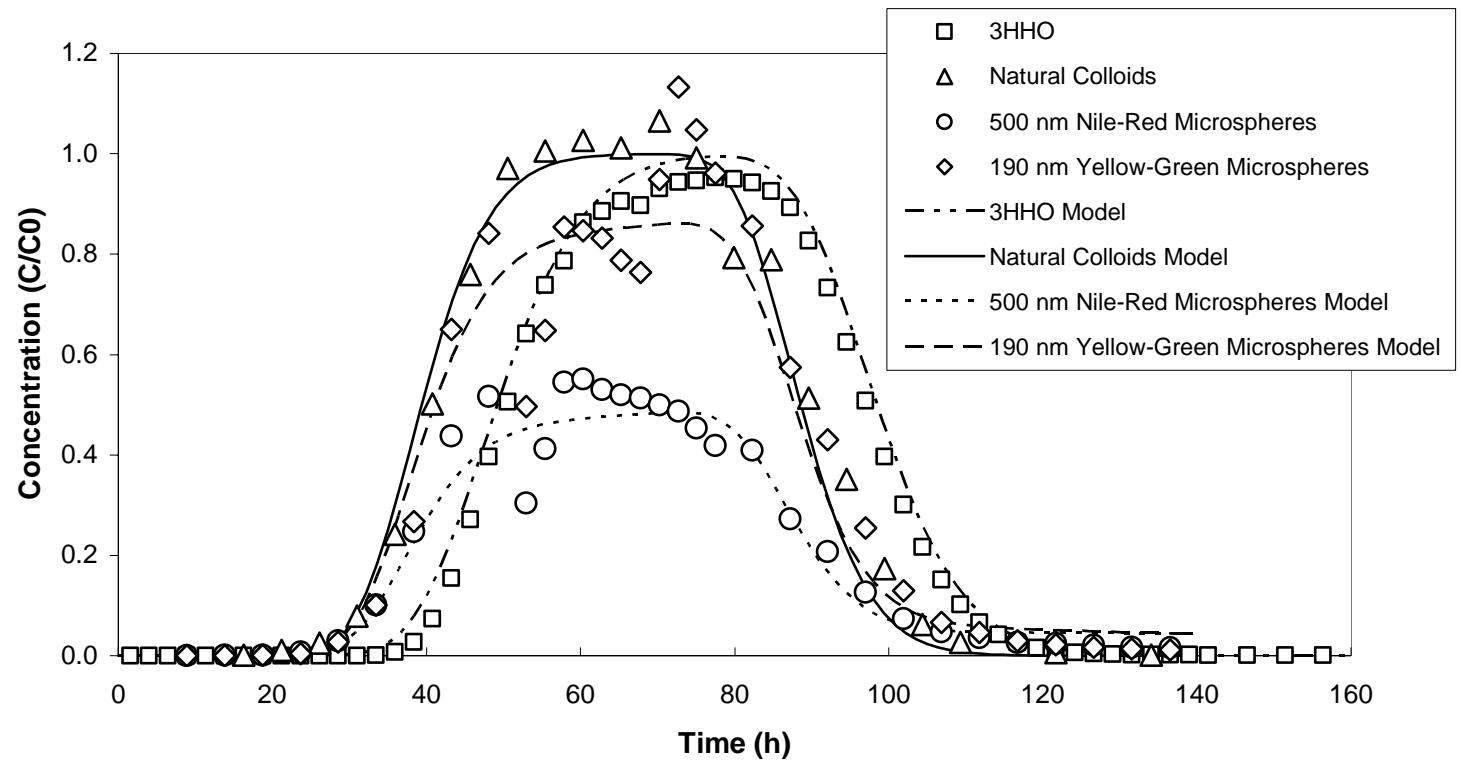

Source: DTNs: LA0301AA831352.001 (data) [DIRS 162433]; LA0303PR831361.001 (model) [DIRS 163135].

Figure 6-19. ${ }^{3} \mathrm{HHO}$ and Colloid Breakthrough Curves and RELAP Fits in Test 2, Column C (1.19 mL/hr Flow Rate)

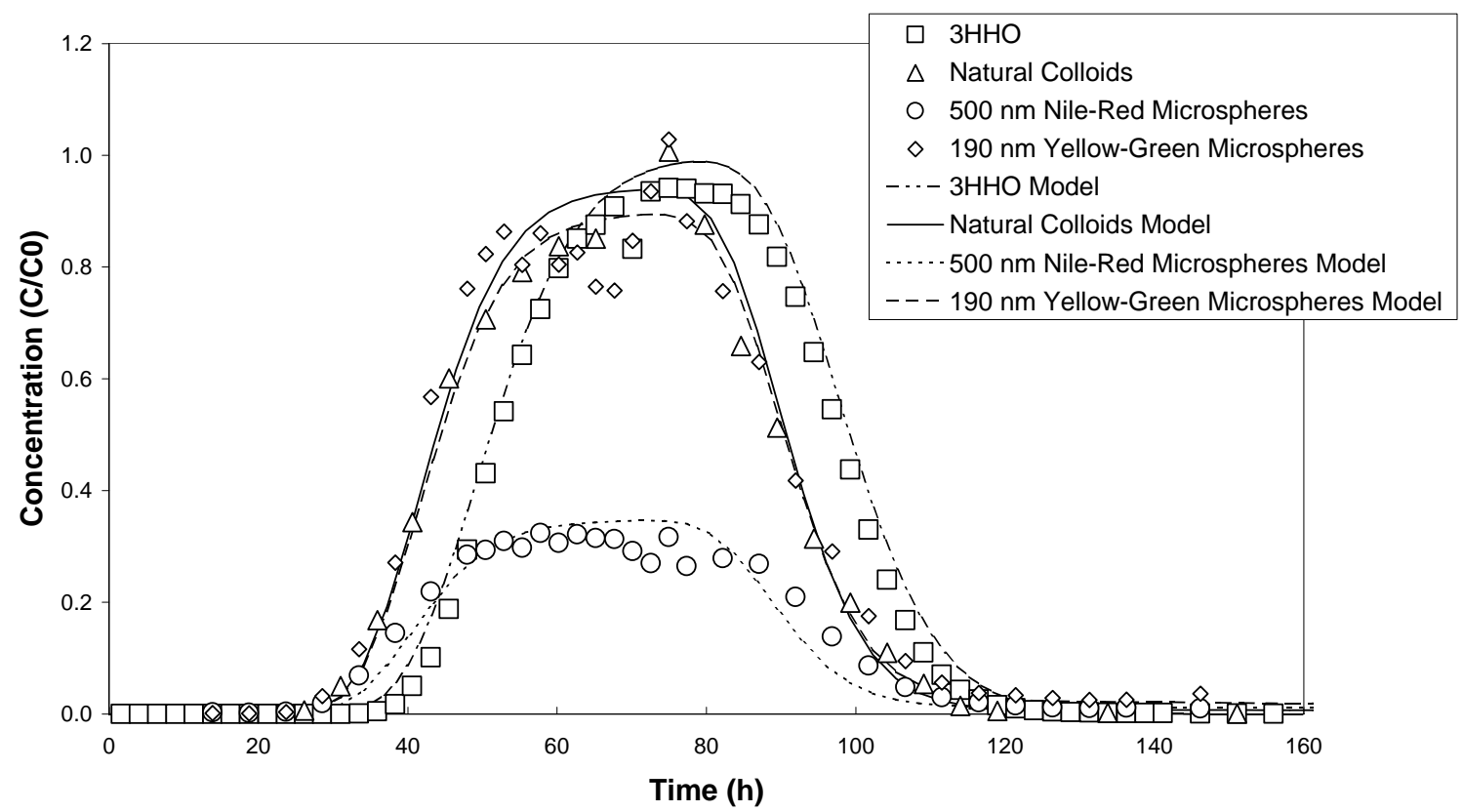

Source: DTNs: LA0301AA831352.001 (data) [DIRS 162433]; LA0303PR831361.001 (model) [DIRS 163135].

Figure 6-20. ${ }^{3} \mathrm{HHO}$ and Colloid Breakthrough Curves and RELAP Fits in Test 2, Column D (1.19 mL/hr Flow Rate) 
Table 6-16. Model Parameters from RELAP Fits of Tracer Breakthrough Curves in CML Microsphere and Natural Colloid Experiments in Saturated Alluvium

\begin{tabular}{|c|c|c|c|c|}
\hline \multirow[b]{2}{*}{ Model Parameter } & \multicolumn{4}{|c|}{ Flow Rate (mL/hr), Column } \\
\hline & 6.01, Col. C & 5.93, Col. D & 1.19, Col. C & 1.19, Col. D \\
\hline${ }^{3} \mathrm{HHO}$ Mean Residence Time (hr) & 8.5 & 10.5 & 50 & 52 \\
\hline${ }^{3} \mathrm{HHO}$ (and Colloid) Peclet Number & 30 & 52 & 64 & 60 \\
\hline Colloid Mean Residence Time (hr) & 8.5 & 8.5 & 40 & 44 \\
\hline 190-nm CML Filtration Rate Constant $\left(\mathrm{hr}^{-1}\right)$ & 0.002 & 0.0046 & 0.0051 & 0.0029 \\
\hline 190-nm CML Retardation Factor & $1 *$ & $1.5^{*}$ & 1.5 & $1.5^{*}$ \\
\hline 500-nm CML Filtration Rate Constant $\left(\mathrm{hr}^{-1}\right)$ & 0.045 & 0.07 & 0.02 & 0.025 \\
\hline 500-nm CML Retardation Factor & 17 & 4.5 & 8 & 35 \\
\hline Natural Colloid Filtration Rate Constant $\left(\mathrm{hr}^{-1}\right)$ & 0.0007 & 0.0039 & 0 & 0.0015 \\
\hline Natural Colloid Retardation Factor & $1^{*}$ & $1.5^{*}$ & $1^{*}$ & $1.5^{*}$ \\
\hline
\end{tabular}

DTN: LA0303PR831361.001 [DIRS 163135].

*The RELAP fits for these cases are extremely insensitive to the retardation factor. Any value between 1 and 1000 offers a good fit to the data provided the filtration rate constants are the values listed.

It is apparent from Figures 6-17 to 6-20 and Table 6-16 that both of the CML microspheres transported through the saturated alluvium columns with much less filtration than in the earlier experiments conducted using 330-nm diameter CML and 100-nm diameter silica microspheres (Section 6.8.2.1). The natural colloids also transported with much less filtration than the silica colloids in these experiments. There are two plausible explanations for the significant differences in colloid transport behavior in the two sets of experiments: 1) air bubbles in the columns in the first set of experiments may have significantly attenuated the colloids by providing air-water interfaces that irreversibly trapped the colloids, and 2) the higher divalent cation concentrations in the water used in the earlier experiments may have destabilized the colloids or at least made them more susceptible to attachment to alluvium surfaces. Although the amount of colloid filtration was significantly different in the two sets of alluvium colloid-transport experiments, the results were consistent in that the inorganic colloids transported with similar or less filtration than the CML microspheres in both sets of tests. However, it was also apparent in the second set of experiments that smaller CML microspheres tend to approximate more closely the transport behavior of natural inorganic colloids than larger microspheres in saturated alluvium. This result supports the hypothesis put forth at the end of Section 6.8.2.1 that interception may be a dominant mechanism of colloid filtration in alluvium because of the small pore throat sizes that are present. It also suggests that the smallest detectable CML microspheres should be used in field tracer tests in saturated alluvium to obtain field-scale colloid-transport parameters that are most representative of natural colloids. The uncertainty in colloid transport in alluvium is preserved by including both sets of experimental results in the overall data set used to develop the cumulative probability distributions for colloid filtration rate constants and for colloid retardation factors, as shown in Figures 6-5 and 6-6. 


\subsubsection{Conclusions from CML and Silica Microsphere and Inorganic Colloid Transport Comparisons}

Laboratory studies comparing CML and silica-microsphere transport in fractured volcanic rocks indicated that CML microspheres of approximately $300-\mathrm{nm}$ diameter behaved as conservative surrogates for $100-\mathrm{nm}$ diameter silica microspheres in fractured rock. That is, the CML microspheres transported with less attenuation than the silica microspheres in the fractures. Similar tests in columns packed with saturated alluvium indicated that CML microspheres may not necessarily transport with less attenuation than either silica microspheres or natural inorganic colloids in saturated alluvium. Smaller CML microspheres (190-nm diameter) approximated the transport behavior of inorganic colloids better than larger microspheres (330- and 500-nm diameter). The fact that the CML microspheres tended to transport with more attenuation than silica microspheres and natural colloids (primarily smectite clay) in the alluvium column experiments does not negate their usefulness as colloid tracers in field tests. The results of the column experiments involving CML microspheres and natural colloids indicate that microspheres with diameters less than $200 \mathrm{~nm}$ should serve as better surrogates for natural colloids than larger microspheres in field tracer tests in alluvium. Even if small CML microspheres transport with somewhat greater attenuation than natural colloids, comparisons of microsphere transport behavior in laboratory and field tracer tests will provide very valuable information on the scale dependence of colloid transport parameters. This information will support further refinement of colloid transport parameter uncertainty distributions in saturated alluvium. 


\section{CONCLUSIONS}

\subsection{SUMMARY OF SCIENTIFIC ANALYSIS}

This analysis report provides CDFs for the uncertainty in the colloid retardation factors in both the saturated volcanics (Output DTN: LA0303HV831352.002) and saturated alluvium (Output DTN: LA0303HV831352.004) for use in TSPA simulations to account for the transport of radionuclides that are irreversibly sorbed to colloids. These retardation factors, $R_{c o l}$ represent the reversible chemical and physical filtration of colloids in the SZ. Interpretation of laboratory and field filtration rate constants (attachment and detachment rate constants) are used to determine the retardation factor distribution. The value of $R_{c o l}$ is dependent on several factors such as colloid size, colloid type, and geochemical conditions (e.g., $\mathrm{pH}$, Eh, and ionic strength). These factors are folded into the distribution of $R_{c o l}$ that has been developed from field and experimental data collected under varying geochemical conditions with different colloid types and sizes. Attachment rate constants, $k_{\text {att }}$, and detachment rate constants, $k_{d e t}$, of colloids to the rock matrix have been determined from laboratory and field experiments, and separate $R_{c o l}$ uncertainty distributions have been developed for the fractured volcanics and the alluvium. This report also describes a method for calculating a small fraction of colloids (and radionuclides that are irreversibly sorbed to colloids) that transport unretarded through the SZ as a function of groundwater transport time (Output DTN: LA0303HV831352.003). It is recommended that the combined groundwater transport time through the $\mathrm{UZ}$ and $\mathrm{SZ}$ (volcanics plus alluvium) be used to obtain an overall fraction of colloids that travels unretarded through the entire natural barrier system.

The transport of colloids is one of the processes that controls the transport of radionuclides through the natural barrier system. Therefore, the process of colloid transport is included in the transport model and is important in evaluating the contribution of the SZ to the natural barrier system. The specific acceptance criteria that relate to this report are discussed in Section 4.2.

The use of a retardation factor to describe colloid transport through the SZ implicitly assumes that colloid filtration and detachment rates are fast relative to groundwater transport times through the system. This assumption is shown to be valid for 94 percent of the colloid mass based on distributions of filtration rate constants from laboratory and field colloid transport experiments.

This analysis report also serves to document laboratory experiments conducted to evaluate the applicability of CML microspheres as field-test surrogates for inorganic colloids in both saturated fractured media and saturated alluvium. In fracture experiments, 330-nm diameter CML microspheres consistently experienced less filtration/attenuation than $100-\mathrm{nm}$ silica colloids. In alluvium-packed column experiments, natural colloids (wide range of diameters, most less than $100 \mathrm{~nm}$ ) transported with slightly less filtration than 190-nm diameter CML microspheres and with considerably less filtration than 500-nm microspheres. These results suggest that 1) small (less than 200-nm diameter) CML microspheres may serve as reasonable surrogates for inorganic colloids in saturated alluvium, and 2) CML microspheres may actually serve as conservative colloid tracers in saturated fractured media (yielding transport parameter estimates that result in overprediction of inorganic colloid transport). 


\subsection{HOW THE APPLICABLE ACCEPTANCE CRITERIA ARE ADDRESSED}

The following information describes how this analysis addresses the acceptance criteria in the Yucca Mountain Review Plan, Final Report (NRC 2003 [DIRS 163274], Section 2.2.1.3.9.3). Only those acceptance criteria that are applicable to this report (see Section 4.2) are discussed.

\section{Acceptance Criteria from Section 2.2.1.3.9.3, Radionuclide Transport in the Saturated Zone}

\section{Acceptance Criterion 1 System Description and Model Integration are Adequate.}

Subcriterion (1): The physical phenomenon of colloid sorption is described in the entire document. The assumptions and approaches applied to this phenomena are consistent and appropriate for describing colloid transport in both fractures and porous media. The key assumption is that the sampling covers a broad enough spectrum of geochemical conditions, colloid types, and sizes for generating a representative distribution of retardation factors. This approach allows the incorporation of diverse experimental and field results under varying geochemical conditions into a retardation factor distribution that closely represents the physical and chemical filtration of colloids in the saturated zone

Subcriterion (2): The description of the physical phenomena (physical filtration and chemical filtration of colloids) is presented in Section 6. Reversible and irreversible sorbing of colloids is reviewed in Section 6.3. Colloid filtration and retardation in fractured tuff is described in detail in Sections 6.4.2 and 6.4.3, respectively. Colloid filtration and retardation in alluvial material is discussed in detail in Sections 6.5.2 and 6.5.3. The fraction of colloids that travels with no apparent retardation (fast fraction) is developed in Section 6.6. The substantial variability in geochemistry, which results in heterogeneous geochemical conditions, is accounted for in the distributions developed for the retardation factors in Sections 6.4-6.6. The assumption of local equilibrium is justified and discussed in detail in Section 6.7. The correlation of microsphere transport data to natural colloid transport data is presented in Section 6.8.

Subcriterion (6): This document has been developed under the YMP Quality Assurance and Requirements Description (QARD) (DOE 2004 [DIRS 171539]). The QARD commits to NUREGS 1297 and 1298 and procedures have been adopted to implement that commitment. Adherence to these procedures is determined by quality assurance audits and other oversight activities.

\section{Acceptance Criterion 2 Data are sufficient for Model Justification.}

Subcriterion (1): Data inputs for this investigation are described in Section 4.1 (see Table 4-1, Direct Inputs). Data included in this table have been subjected to the quality assurance requirements in the YMP QARD. Sections 6.4 and 6.5 provide detailed descriptions of how the data were used, interpreted, and synthesized into the CDFs for the uncertainties in the colloid retardation factors in tuff and alluvium, respectively. Section 6.6 provides detailed descriptions of how the data were used, interpreted, and synthesized to determine the fraction of the colloids that transport with no retardation. 
Subcriterion (3): Data collected and applied to the investigations discussed in this report are based on appropriate techniques. The documents cited in Table 4-1 (Section 4.1) describe the details of data collection and development and the appropriateness of the techniques employed. These techniques include laboratory experiments, site-specific field measurements, and process-level modeling studies that are incorporated into the retardation factor distributions for the saturated zone developed in this report. Specific techniques include epifluorescent microscopy and flow cytometry, which were used to reduce measurement uncertainty. Laboratory experiments utilizing epifluorescent microscopy and flow cytometry are discussed in Section 6.8. The resulting retardation factor distribution is considered to be adequate because the distribution does not contain abnormal fluctuations. In addition, data is sufficient for meaningful statistical analysis because it is based on site-specific laboratory and field experiments.

Acceptance Criterion 3 Data Uncertainty Is Characterized and Propagated Through the Model Abstraction.

Subcriterion (1): Technically defensible distributions derived from experiments under a wide variety of conditions reasonably account for uncertainty and variabilities in the retardation factor and fast fraction distributions developed in Sections 6.4 through 6.6. Section 6.4 discusses uncertainties in colloid filtration and retardation in fractured tuff. Section 6.5 discusses uncertainties in colloid filtration and retardation in alluvial material. Section 6.6 discusses uncertainties in development of the fraction of colloids that travels with no apparent retardation. The detailed descriptions of uncertainty of the retardation factors and fast fraction are provided in Section 7.3.

\subsection{UNCERTAINTIES}

The three outputs from this analysis report are the distribution of retardation factors for the volcanics, the distribution of retardation factors in the alluvium, and the fraction of colloid mass that transports unretrarded in the natural system. The following section describes the uncertainty in these outputs.

The parameters developed in this report are dependent on several factors such as colloid size, colloid type, and geochemical conditions (e.g., $\mathrm{pH}, \mathrm{Eh}$, and ionic strength) resulting in the possibility of very complex behavior when trying to predict the transport of colloids. Isolating the effect of each individual factor on colloid transport is not possible with the data that are available. Therefore, combined parameters (net retardation) were measured and the uncertainties and natural variabilities in these factors. The resulting distributions have been developed from field and experimental data collected under varying geochemical conditions with different colloid types and sizes.

Although results from field colloid transport tests and observations at several contaminated field sites suggest it is reasonable to expect a small fraction of colloid mass to move unretarded through natural systems (Kersting et al. 1999 [DIRS 103282], p. 56; Penrose et al. 1990 [DIRS 100811], p. 228), there are uncertainties associated with the assumed partitioning of colloid mass in the SZ into fractions that travel unretarded and retarded. This partitioning is 
based largely on the assumption that the population of colloids having irreversibly sorbed radionuclides entering the $\mathrm{SZ}$ has a cumulative distribution of filtration rate constants approximately equal to the cumulative distribution of filtration rate constants observed in laboratory and field SZ colloid-transport experiments. Additional uncertainty is introduced as a result of extrapolating the cumulative distribution of observed filtration rate constants to very low probabilities for the purposes of estimating colloid mass fractions that move unretarded. In part to address these large and unquantifiable uncertainties, the distributions of filtration rate constants in the volcanics and alluvium are combined to obtain a single filtration-rate-constant distribution to estimate colloid mass fractions that move unretarded through the entire SZ. The use of a combined distribution for the SZ implicitly assumes a high correlation of filtration rate constants between the volcanics and alluvium, resulting in much higher mass fractions transporting unretarded through the SZ than would be estimated assuming little or no correlation.

Uncertainties are also associated with the retardation factors obtained for both the volcanics and alluvium. Since these retardation factors are used to simulate the transport of radionuclides irreversibly sorbed to colloids, these uncertainties directly relate to the uncertainty of the SZ and are important in evaluating the contribution of the SZ to the natural barrier. First, all the laboratory and field transport data used to derive the uncertainty distributions were obtained at scales much smaller than the scales of interest for TSPA modeling. Second, the retardation factors derived from many of the transport tests were based on fitting the low colloid concentrations in the tails of breakthrough curves. These tails were sometimes barely above detection or quantification limits, so the fitted retardation factors have considerable uncertainty. However, long tails are virtually always observed whenever analytical methods are sensitive enough to capture them, so they appear to be ubiquitous. Third, there is an implicit assumption that the limited number of combinations of water chemistry, rock mineralogy, and flow conditions tested in the laboratory and field experiments described in this analysis report effectively represents the range of conditions present in the $\mathrm{SZ}$ as well as the range of conditions that may occur over the 10,000-year performance period. This assumption introduces uncertainty into the distributions obtained for retardation factors. These uncertainties are addressed by 1) assigning lower bounds for retardation factors to cumulative distributions in the volcanics and alluvium such that significant retardation of colloids (seen as long tails in transport tests) always occurs, and 2) assuming that a small fraction of colloid mass moves unretarded through the transport system (as described above) to account for the fact that some finite fraction of colloids always seems to move unretarded in transport tests and is also often observed at contaminated field sites, regardless of scale.

The two sets of laboratory alluvium colloid-transport experiments indicate that a large range of colloid transport behaviors is possible in the alluvium, which should be reflected by large uncertainties in colloid transport parameters in the alluvium. By including both sets of experimental results in the overall data set used to develop the cumulative distributions for colloid-filtration-rate constants and retardation factors in alluvium, the large uncertainties suggested by the experiments are effectively captured. 
The impact of the uncertainty of the distributions developed in this analysis on performance assessment is addressed in SZ Flow and Transport Model Abstraction; specifically, uncertainty in radionuclide transport is embodied in the breakthrough curves developed in Section 6.6. (BSC 2004 [DIRS 170042]).

\subsection{OUTPUTS}

Table 7-1 lists the output data for this scientific analysis report.

Table 7-1. Output Data

\begin{tabular}{|l|c|c|}
\hline \multicolumn{1}{|c|}{ Data Description } & Data Tracking Number & Location in Text \\
\hline $\begin{array}{l}\text { Colloid retardation factors for the saturated zone fractured } \\
\text { volcanics }\end{array}$ & LA0303HV831352.002 & Table 6.2 \\
\hline Colloid retardation factors for the saturated zone alluvium & LA0303HV831352.004 & Table 6.3 \\
\hline Fraction of colloids that travel unretarded & LA0303HV831352.003 & Table 6.4 \\
\hline
\end{tabular}




\section{INTENTIONALLY LEFT BLANK}




\section{INPUTS AND REFERENCES}

The following is a list of the references cited in this document. Column 2 represents the unique six-digit numerical identifier (the DIRS number), which is placed in the text following the reference callout (e.g., BSC 2002 [155950]). The purpose of these numbers is to assist in locating a specific reference in the DIRS database. Within the reference list, multiple sources by the same author and date (e.g., BSC 2002) are sorted alphabetically by title.

\subsection{DOCUMENTS CITED}

Abdel-Fattah, A.I. and El-Genk, M.S. 1998. "On Colloidal Particle Sorption onto a 158692 Stagnant Air-Water Interface." Advances in Colloid and Interface Science, 78, (3), 237 to 266. New York, New York: Elsevier. TIC: 253147.

Anghel, I. 2001. Comparison of Polystyrene and Silica Colloids Transport in 158639

Saturated Rock Fractures. Master's thesis. Albuquerque, New Mexico: University of New Mexico. TIC: 253148.

Bahr, J.M. and Rubin, J. 1987. "Direct Comparison of Kinetic and Local 144539 Equilibrium Formulations for Solute Transport Affected by Surface Reactions." Water Resources Research, 23, (3), 438 to 452. Washington, D.C.: American Geophysical Union. TIC: 246894.

Bales, R.C.; Gerba, C.P.; Grondin, G.H.; and Jensen, S.L. 1989. "Bacteriophage Transport in Sandy Soil and Fractured Tuff." Applied and Environmental Microbiology, 55, (8), 2061-2067. Washington, D.C.: American Society for Microbiology. TIC: 224864.

BSC (Bechtel SAIC Company) 2003. Total System Performance AssessmentLicense Application Methods and Approach. TDR-WIS-PA-000006 REV 00 ICN 01. Las Vegas, Nevada: Bechtel SAIC Company. ACC: DOC.20031215.0001.

BSC 2004. EBS Radionuclide Transport Abstraction. ANL-WIS-PA-000001, 169868 Rev. 01. Las Vegas, Nevada: Bechtel SAIC Company.

BSC 2004. Features, Events, and Processes in SZ Flow and Transport. 170013 ANL-NBS-MD-000002, Rev. 03. Las Vegas, Nevada: Bechtel SAIC Company.

BSC 2004. Q-List. 000-30R-MGR0-00500-000-000 REV 00. Las Vegas, Nevada: Bechtel SAIC Company. ACC: ENG.20040721.0007.

BSC 2004. Saturated Zone Flow and Transport Model Abstraction. 104333 MDL-NBS-HS-000021, Rev. 02. Las Vegas, Nevada: Bechtel SAIC Company.

BSC 2004. Saturated Zone In-Situ Testing. ANL-NBS-HS-000039, Rev. 01. 166296 Las Vegas, Nevada: Bechtel SAIC Company. 
BSC 2004. Site-Scale Saturated Zone Transport. MDL-NBS-HS-000010, Rev. 02.170036 Las Vegas, Nevada: Bechtel SAIC Company.

BSC (Bechtel SAIC Company) 2004. Technical Work Plan for: Natural System

- Saturated Zone Analysis and Model Report Integration. TWP-NBS-MD-000002 REV 02 ICN 01. Las Vegas, Nevada: Bechtel SAIC Company.

ACC: DOC.20040818.0004.

BSC 2004. Waste Form and In-Drift Colloids-Associated Radionuclide Concentrations: Abstraction and Summary. MDL-EBS-PA-000004, Rev. 01. Las Vegas, Nevada: Bechtel SAIC Company.

Canori, G.F. and Leitner, M.M. 2003. Project Requirements Document. 166275 TER-MGRMD-000001 REV 02. Las Vegas, Nevada: Bechtel SAIC Company. ACC: DOC.20031222.0006.

DOE (U.S. Department of Energy) 2004. Quality Assurance Requirements and Description. DOE/RW-0333P, Rev. 16. Washington, D.C.: U.S. Department of Energy, Office of Civilian Radioactive Waste Management.

ACC: DOC.20040907.0002.

Freeze, R.A. and Cherry, J.A. 1979. Groundwater. Englewood Cliffs, New Jersey: Prentice-Hall. TIC: 217571.

Harvey, R.W. and Garabedian, S.P. 1991. "Use of Colloid Filtration Theory in Modeling Movement of Bacteria Through a Contaminated Sandy Aquifer." Environmental Science \& Technology, 25, (1), 178 to 185. Washington, D.C.: American Chemical Society. TIC: 245733.

Hiemenz, P.C. 1986. Principles of Colloid and Surface Chemistry. 2nd Edition, Revised and Expanded. Undergraduate Chemistry Volume 9. Lagowski, J.J., ed. New York, New York: Marcel Dekker. TIC: 246392.

Kersting, A.B.; Efurd, D.W.; Finnegan, D.L.; Rokop, D.J.; Smith, D.K.; and Thompson, J.L. 1999. "Migration of Plutonium in Ground Water at the Nevada Test Site." Nature, 397, (6714), 56 to 59. London, England: Macmillan Journals. TIC: 243597.

Kersting, A.P. and Reimus, P.W., eds. 2003. Colloid-Facilitated Transport of 162421 Low-Solubility Radionuclides: A Field, Experimental, and Modeling Investigation. UCRL-ID-149688. Livermore, California: Lawrence Livermore National Laboratory. TIC: 254176.

NRC (U.S. Nuclear Regulatory Commission) 2003. Yucca Mountain Review Plan, Final Report. NUREG-1804, Rev. 2. Washington, D.C.: U.S. Nuclear Regulatory Commission, Office of Nuclear Material Safety and Safeguards. TIC: 254568. 
Penrose, W.R.; Polzer, W.L.; Essington, E.H.; Nelson, D.M.; and Orlandini, K.A.

100811 1990. "Mobility of Plutonium and Americium Through a Shallow Aquifer in a Semiarid Region." Environmental Science \& Technology, 24, 228 to 234.

Washington, D.C.: American Chemical Society. TIC: 224113.

Reimus, P. 2003. Laboratory Testing in Support of Saturated Zone Investigations.

Scientific Notebook SN-LANL-SCI-280-V1. ACC：MOL.20030227.0286.

Reimus, P.W. and Haga, M.J. 1999. Analysis of Tracer Responses in the BULLION Forced-Gradient Experiment at Pahute Mesa, Nevada. LA-13615-MS. Los Alamos, New Mexico: Los Alamos National Laboratory. TIC: 249826.

Schijven, J.F.; Hoogenboezem, W.; Hassanizadeh, S.M.; and Peters, J.H. 1999. 162423 "Modeling Removal of Bacteriophages MS2 and PRD1 by Dune Recharge at Castricum, Netherlands." Water Resources Research, 35, (4), 1101-1111. Washington, D.C.: American Geophysical Union. TIC: 252295.

Valocchi, A.J. 1985. "Validity of the Local Equilibrium Assumption for Modeling 144579 Sorbing Solute Transport Through Homogeneous Soils." Water Resources Research, 21, (6), 808-820. Washington, D.C.: American Geophysical Union. TIC: 223203.

Van de Ven, T.G.M. 1989. "Brownian Motion of Emulsion Droplets." Section 2.1.6 of Colloidal Hydrodynamics. Pages 77 to 78. New York, New York: Academic Press. TIC: 254717.

Viswanathan, H. 2003. Contaminant Transport Modeling of the Saturated Zone at Yucca Mountain, NV. Scientific Notebook SN-LANL-SCI-297-V1.

ACC: MOL.20030609.0493; MOL.20030821.0052.

Wan, J. and Wilson, J.L. 1994. "Colloid Transport in Unsaturated Porous Media." Water Resources Research, 30, (4), 857 to 864. Washington, D.C.: American Geophysical Union. TIC: 222359.

\subsection{CODES, STANDARDS, REGULATIONS, AND PROCEDURES}

10 CFR 63. Energy: Disposal of High-Level Radioactive Wastes in a Geologic Repository at Yucca Mountain, Nevada. Readily available.

AP-2.22Q, Rev. 1, ICN 1. Classification Analyses and Maintenance of the Q-List. Washington, D.C.: U.S. Department of Energy, Office of Civilian Radioactive Waste Management. ACC: DOC.20040714.0002.

AP-2.27Q, Rev. 1, ICN 4. Planning for Science Activities. Washington, D.C.: U.S. Department of Energy, Office of Civilian Radioactive Waste Management. ACC: DOC.20040610.0006. 
AP-SIII.9Q, Rev. 1, ICN 7. Scientific Analyses. Washington, D.C.: U.S. Department of Energy, Office of Civilian Radioactive Waste Management. ACC: DOC.20040920.0001.

LP-SI.11Q-BSC, Rev. 0, ICN 1. Software Management. Washington, D.C.: U.S. Department of Energy, Office of Civilian Radioactive Waste Management. ACC: DOC.20041005.0008.

\subsection{SOURCE DATA, LISTED BY DATA TRACKING NUMBER}

LA0007PR831231.001. Bullfrog Reactive Tracer Test Data. Submittal 156043 date: $07 / 21 / 2000$.

LA0206MH831361.001. Nye County Alluvial Testing Complex Column 162426 Experiment ATC COL A NCEWDP 19D1 25, 8/20/2001. Submittal date: $07 / 01 / 2002$.

LA0206MH831361.002. Nye County Alluvial Testing Complex Column 162427 Experiment ATC COL B NCEWDP 19D1 25, 8/8/2001. Submittal date: $07 / 01 / 2002$.

LA0206MH831361.003. Nye County Alluvial Testing Complex Column 162428 Experiment ATC COL A NCEWDP 19D1 25, 11/15/2001. Submittal date: $07 / 01 / 2002$.

LA0206MH831361.004. Nye County Alluvial Testing Complex Column 162430 Experiment ATC COL B NCEWDP 19D1 25, 11/15/2001. Submittal date: $07 / 01 / 2002$.

LA0301AA831352.001. Experiments on Pu (V)-Colloid Transport in Columns 162433 Packed with Material from Nye County Borehole 19D, Zone 4. Submittal date: $01 / 23 / 2003$.

LA0301PR831352.001. Breakthrough Curves of Iodide, CML Microspheres, and 162434 Silica Colloids in Saturated Fractured Cores from the Nevada Test Site. Submittal date: $01 / 23 / 2003$.

LA0301PR831361.003. Breakthrough Curves of Tritium, Plutonium, and Various Colloids in Saturated UE20C Fractured Cores from the Nevada Test Site.

Submittal date: 01/22/2003.

LA0301PR831361.004. Breakthrough Curves of Tritium, Plutonium, and Various 162436 Colloids in Saturated PM-1 and PM-2 Fractured Cores from the Nevada Test Site. Submittal date: 01/22/2003. 
LA0302PR831231.002. Solute Data from ER-20-6\#2 in the BULLION

Forced-Gradient Field Tracer Test at the ER-20-6 Wells at NTS. Submittal date: $02 / 03 / 2003$.

LA0302PR831231.003. Solute Data from ER-20-6\#3 in the BULLION Forced-

162438

Gradient Field Tracer Test at the ER-20-6 Wells at NTS. Submittal date: $02 / 03 / 2003$.

LA0302PR831352.001. Transport of CML Microspheres in Field Tracer Test at 162439 ER-20-6\#2 Site at the Nevada Test Site (NTS). Submittal date: 03/06/2003.

LA0302PR831352.002. Transport of CML Microspheres in Field Tracer Test at ER-20-6\#3 Site at the Nevada Test Site (NTS). Submittal date: 03/06/2003.

LA0303PR831231.003. Model Interpretations of C-Wells Field Tracer Transport Experiments. Submittal date: 03/31/2003.

LA0303PR831352.001. Calculations to Determine Detachment Rate Constant of Microspheres in a Single-Well Tracer Test in Saturated Alluvium. Submittal date: $03 / 31 / 2003$.

LA0303PR831352.002. Model Interpretations of ER-20-6 Field Tracer Transport Experiment. Submittal date: 03/31/2003.

LA0303PR831361.001. RELAP V2.0 Model Interpretations of Solute and Colloid Transport in Alluvium-Packed Column Transport Experiments. Submittal date: $03 / 31 / 2003$.

LA0306PR831321.001. Mineralogy of ATC Colloids and Bentonite Drilling 164492 Muds. Submittal date: 06/03/2003.

LA0403PR831352.001. Model Interpretations of NTS Fractured Core Colloid and Colloid-Facilitated Transport Experiments. Submittal date: 03/18/2004.

171416

LAPR831231AQ99.001. Prow Pass Reactive Tracer Test Field Data. Submittal 140134 date: $02 / 10 / 1999$.

MO0407SEPFEPLA.000. LA FEP List. Submittal date: 07/20/2004.

\subsection{OUTPUT DATA, LISTED BY DATA TRACKING NUMBER}

DTN: LA0303HV831352.002. Colloid Retardation Factors for the Saturated Zone Fractured Volcanics.

DTN: LA0303HV831352.004. Colloid Retardation Factors for the Saturated Zone Alluvium.

DTN: LA0303HV831352.003. Fraction of Colloids that Travel Unretarded. 


\subsection{SOFTWARE CODES}

RELAP. V2.0. PC, Windows 2000/NT. 10551-2.0-00.

159065 